QL

403

E69

1891

T. 1-2

Mo11.

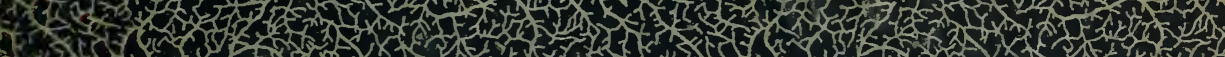

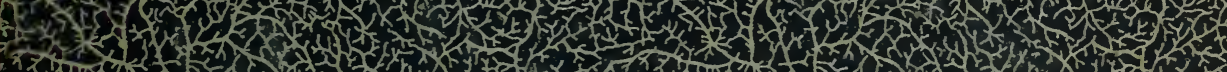

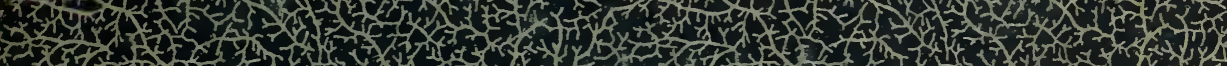

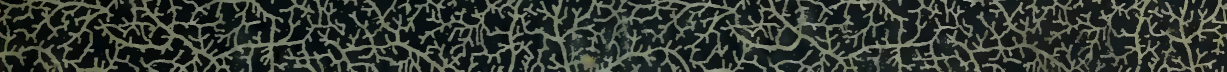
T) $+2,2$. 15. 2. 3. 3 . B.

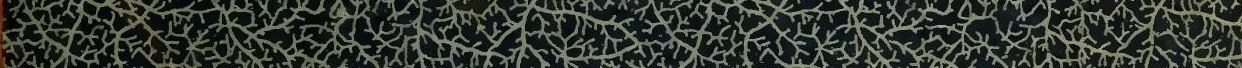

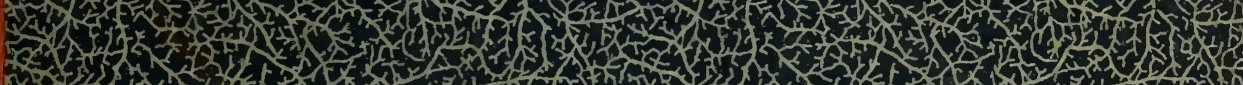

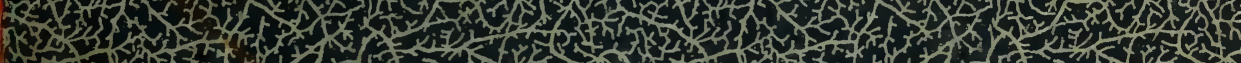
1.

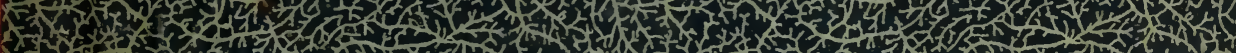
3)

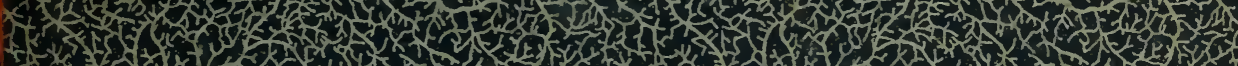

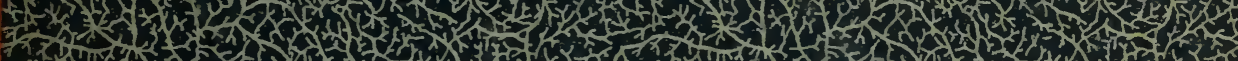
ant

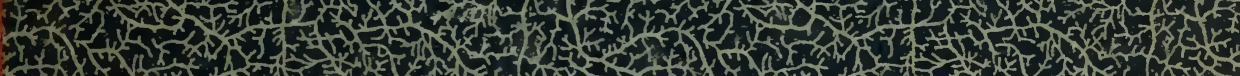

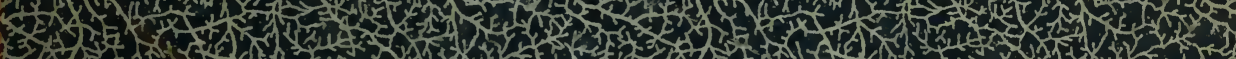

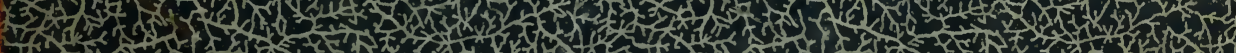

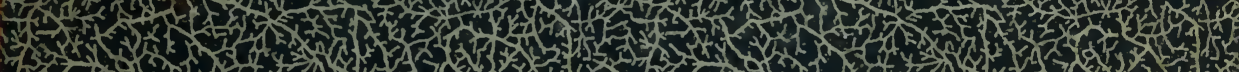

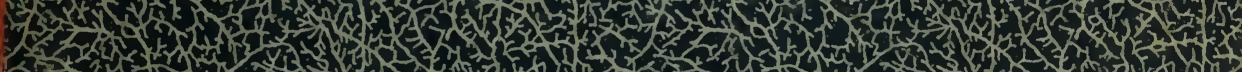

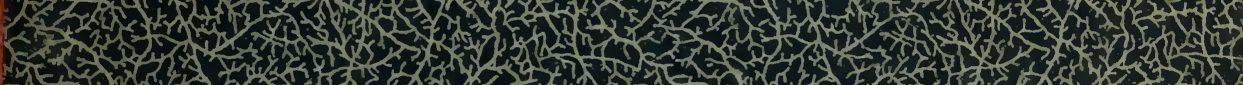

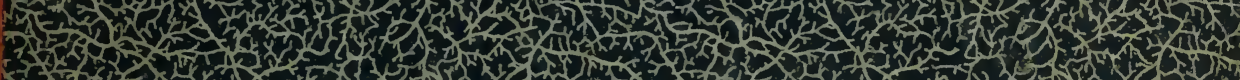

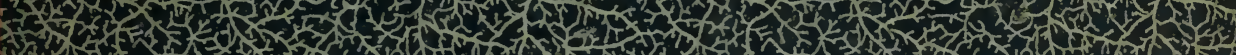
Q4. 2 -

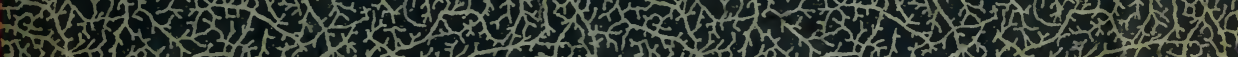

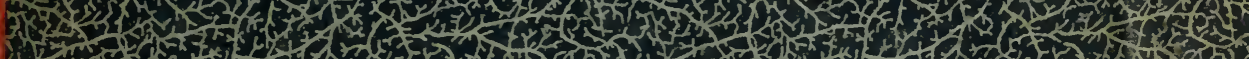

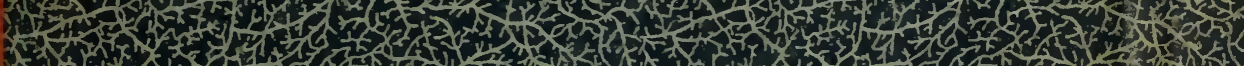
2. 30 .

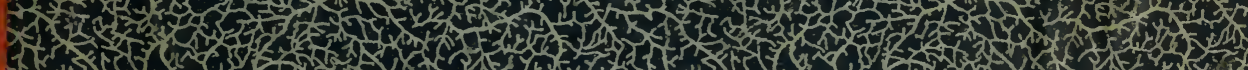
1.50 .

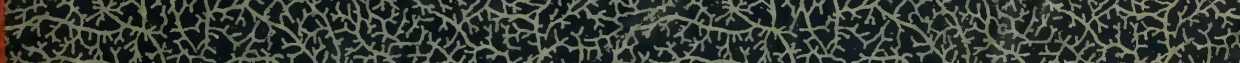

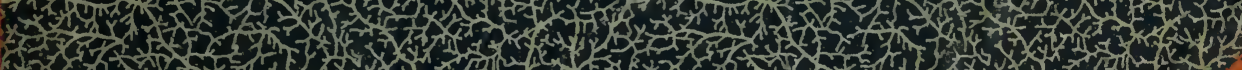

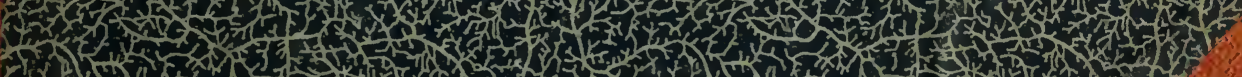

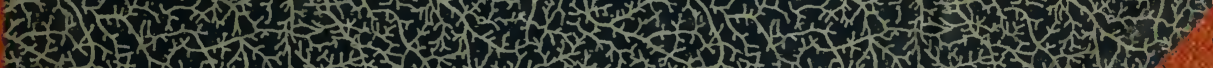

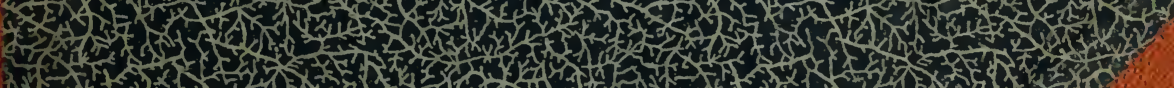

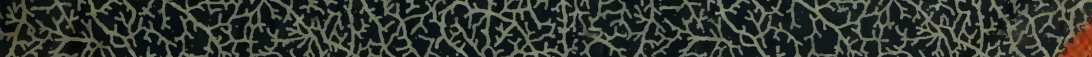

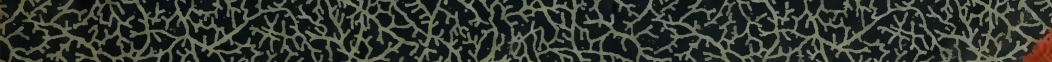

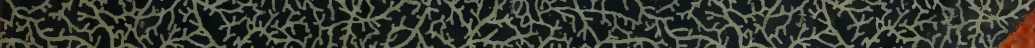
$\rightarrow 120$. 


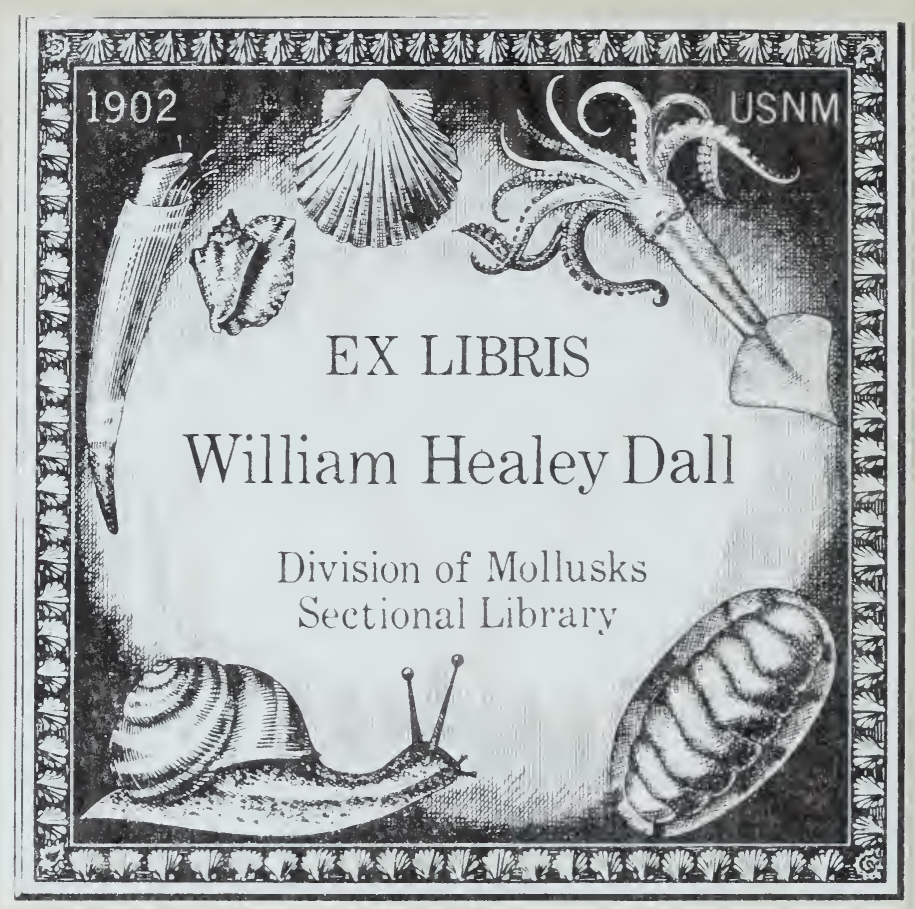


$I E R L A N G$

190

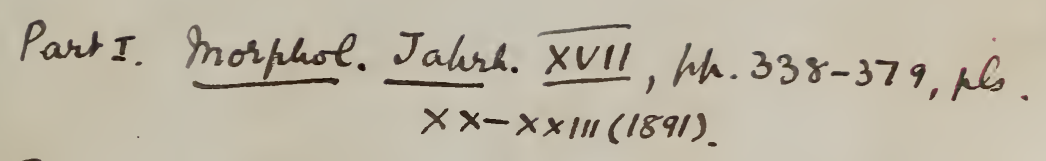

PartI ih. id. Mh. 636-680, hls. $x \times x i i, x \times x i i i(1891)$. 

Separat-Abdruck aus: Morpholog. Jahrbuch. XVII. Heft 3. 


\section{Theil.}

Wie ich schon in einer vorläufigen Mittheilung erwähnte ${ }^{1}$, hatte ich mir bei dieser Untersuchung vorgenommen, speciell die Entwicklung des Herzbeutels, des Herzens und der bleibenden Niere zu studiren. Da nun das Perikard und der secernirende Theil der Niere aus dem Mesoderm entstehen, wurde ich veranlasst, auch dem Ursprung des mittleren Keimblattes nachzuforschen, sowie der Bildung der Urniere, welche sich ebenfalls aus dem Mesoderm entwickelt, einige Aufmerksamkeit zu widmen. Weiter musste ich die Entstehung des Ausfithrganges der Niere, obgleich dieser ans dem Ektoderm hervorgeht, wegen des Zusammenhanges mit der Niere beriicksichtigen. Ich hoffe in einer späteren Arbeit, die Entwicklung des Nervensystems, von der ich bereits einen kurzen Überblick gegeben habe, so wie die der Sinnesorgane und des Geschlechtsapparates behandeln zu können.

Das Material zu dieser Untersuchung wurde aus verschiedenen Quellen bezogen; den größten Theil davon verdanke ich der Freundlichkeit des Herrn Lehramtspraktikanten Förs'ser in Mannheim, dem ich an dieser Stelle meinen Dank aussprechen möchte.

1 Zur Entwicklung von Paludina vivipara. Vorläufige Nittheilung. Zool. Anzeiger. $\mathrm{Nr}$. 357. 1891. 
Die von ihrer Eiweißhülle mit Hilfe von Präparirnadeln befreiten Embryonen wurden zum Theil lebend in einer zu diesem Zweck bereiteten Eiweißlösung (20 cem Eiweiß, $1 \mathrm{~g}$ Kochsalz und $200 \mathrm{ccm}$ Wasser) untersucht, zum Theil behufs weiterer Präparation mit verschiedenen Konservirungsfliissigkeiten behandelt. Vor der Fixirung ist es jedoch nothwendig den Embryo durch Abspiilen mit 0,6\% iger Kochsalzlösung vom anhaftenden Eiweiß zu befreien, da dieses sonst gerinnt. Von Konservirungsfluissigkeiten wurde die Flemmingsche Chromosmiumessigsäure, Pikrinschwefelsäure und Pikrinessigsäure verwendet. Am günstigsten erwies sich Pikrinschwefelsäure (nach Kleinenberg), zu welcher einige Tropfen einer $0,5 \%$ igen Osmiumsäure zugesetzt wurden. Die verschiedenen Gewebe werden darin ausgegezeichnet fixirt und die Embryonen erleiden keine nennenswerthe Schrumpfung. So sind auf meinen Präparaten die feinsten Wimpern noch ganz gut auf Schnitten zu erkennen und die verästelten Zellen des Mesoderm wie im lebenden Zustand erhalten. Die Embryonen wurden je nach der Größe 5-20 Minuten in der Fixirungsfluissigkeit gelassen und nachher mit $75 \%$ igem Alkohol sorgfältig ausgewaschen.

Als Färbemittel wurden vorzugsweise Alaunkarmin und Alaunkochenille gebraucht, da Hämatoxylin schlecht durchdringt und Boraxkarmin, wegen des nachträglichen Ausziehens mit angesäuertem Alkohol einen nachtheiligen Einfluss auf die sehr empfindlichen Embryonen ausiibt.

Die gefärbten Präparate wurden, nach vorausgegangener Entwässerung und Aufhellung, in Dammarlack eingeschlossen. Legt man feine Glasfäden unter das Deckglas, an welchem Wachsfiißchen angebracht wurden, so lassen sich die Embryonen nach Wunsch drehen, so dass man sie in jeder beliebigen Lage untersuchen kann, was fuir das Verständnis von großer Wichtigkeit ist. Ganz junge Stadien lassen sich nur auf diese Weise in toto genïgend untersuchen, da der Dotter sie undurchsichtig macht; ältere Embryonen können auch lebend untersucht werden, jedoch lassen sie sich nicht gut drehen; daher ist es besser sie zu färben und in Dammarlack zu untersuchen. Entfernt man die vordere Hälfte durch einen Schnitt, so lässt sich das beschalte Hinterende nach der eben beschriebenen Methode bequem drehen.

Wenn man auch die topographischen Verhältnisse am ganzen Embryo übersehen kann, so ist es zur Erforschung des Zusammenhangs der Organe und ihrer histologischen Beschaffenheit unerlässlich Schnittserien anzufertigen. Daher machte ich Schnittserien durch 
alle Stadien und zwar in transversaler, horizontaler und sagittaler Richtung. In Bezug auf die Orientirung bemerke ich, dass ich mir den Embryo stets in der Lage denke. welche die erwachsene Schnecke beim Kriechen einnimmt. Die Seite, auf welcher der Fuß sich befindet, wird daher als die ventrale bezeichnet. Aus den Serien wurde mehrfach das Hinterende des betreffenden Stadiums rekonstruirt, indem die Schnitte zuerst einzeln auf Pauspapier und dann itber einander gezeichnet wurden. Dies Verfahren war namentlich zur Ermittlung des Zusammenhanges der Niere mit dem Herzbentel einerseits und ihrem Ausfïhrgang andererseits von großem Nutzen.

Die Orientirung der ersten Stadien, zum Anfertigen von Schnitten, stößt, wegen der außerordentlichen Kleinheit der Embryonen, auf beträchtliche Schwierigkeiten. Ich bediente mich folgender Methode, welche eine annähernde Orientirung der Anfangsstadien gestattet.

Die Embryonen wurden in kleinen Uhrgläsern, in wenig Paraffin eingebettet, so dass man ihre Lage im erstarrten Paraffin unter einem starken Trockensystem feststellen konnte, dann herausgeschnitten und in der gewïnschten Lage auf einen größeren Paraffinblock aufgeschmolzen.

Bei jungen noch symmetrischen Embryonen fällt die Längsachse annähernd mit der Verbindungslinie der zwei von einander am weitesten entfernten Punkte zusammen und diese habe ich daher für die Schnittrichtung als maßgebend beibehalten, da sie die einzige ist, welche leicht festgestellt werden kann. Sobald der Embryo die äußere Gestalt des ausgewachsenen Thieres angenommen hat, wird die Orientirung ohne Weiteres verständlich.

Die Querschnitte sind senkrecht zu dieser Längsachse geführt und zerlegen den Embryo von vorn nach hinten in Scheiben. Horizontale Schnitte sind parallel zu dieser Achse und senkrecht zur Medianebene gefuihrt und zerlegen den Embryo vom Rücken nach dem Bauch zu fortschreitend.

Sagittale Schnitte sind ebenfalls parallel zur Längsachse geführt, schreiten aber von einer Seite zur anderen.

Die morphologische Längsachse fällt mit der von mir angenommenen nicht zusammen, konnte aber aus praktischen Riicksichten nicht zur Orientirung fur die Schnitte verwendet werden.

Da ich die Embryonen von mehr als Tausend Paludinen konservirt und mehrere Hunderte von Präparaten und Schnittserien untersucht habe, glaube ich, dass ich kein wichtiges Stadium iibersehen habe und dass meine Beobachtungen eben so liickenlos sind, als ob 
ich die Entwicklung einer eierlegenden Form studirt hätte. Ich erwähne dies hier, weil SARASIN (18) Paludina als vivipar für ein ungeeignetes Objekt erklärt hat.

Zur Zeit, wo ich anfing, die Entwicklung des Mesoderms zu untersuchen, waren die Furchungsstadien sehr selten. Ich verzichtete daher auf das Studium der Furchung, wozu ich mich um so mehr berechtigt glanbte, als schon von mehreren Forschern keine Spuren ron Mesoderm ror dem Gastrulastadium gefunden werden konnten.

Geht man ron einer ausgebildeten Gastrula aus (Taf. XX Fig. 1), an welcher der Urmund $(B)$ länglich oval ist, so sieht man an derselben nur Ektoderm und durch Invagination entstandenes Entoderm $\left(L^{r} r^{\prime}\right.$, welche von einander durch eine nicht sehr weite Furchungshöhle $(F)$ getrennt werden. Zwei Richtungskörper $(r)$ bezeichnen den animalen, dem Urmund $(B)$ gegeniiberliegenden Pol. Die bilaterale Symmetrie ist schon in verschiedenen Merkmalen ausgeprägt. Der Urmund ist länglichoval und seine Längsachse dorsoventral geelagert (was sich aus dem Vergleich mit älteren Stadien ergiebt). Die Gestalt des Urdarmes ist verschieden, je nachdem man das Ei von der Riicken- resp. der Bauchfläche oder von der Seite betrachtet, da derselbe seitlich zusammengedriickt ist. Die Zellen sind auf diesem Stadium alle unter einander gleich und es ließen sich an keiner der zahlreichen Gastrulae, welche ich untersuchen konnte, Urmesodermzellen konstatiren, auch an ganz jungen, an welchen der Einstülpúngsvorgang noch deutlich zu erkennen ist, war nichts ron solchen zu bemerken. Solche Zellen sind auch, wie ich schon erwähnt habe, ron keinem der Beobachter, welche früher die Entwicklung ron Paludina studirten, gesehen worden. Alle Zellen sind cylindrische bis kegelförmige Epithelzellen, mit deutlichem Kern und zeigen in ihrem Protoplasma eingelagerte Dotterkörnchen, welche das Ei im Leben ziemlich undurchsichtig machen.

Ein folgendes Stadium (Taf. XX Fig. 2) unterscheidet sich rom vorhergehendeu etwas in Größe und Gestalt. Unter den Ektodermzellen zeichnen sich auf dem optischen Längsschnitt jederseits zwei $(V V)$ durch besondere Größe und hellere Färbung aus und gehören zur Anlage des Velums. Das Velarfeld umgreift etwa die animale oder vordere Hälfte des Embryo: da deren Zellen sich weniger intensir färben als die iibrigen Ektodermzellen, so erscheint die hintere Hälfte des Embryo viel dunkler. Der Urmund $(\boldsymbol{B})$ ist sehr stark verengt und oft nur mit Mühe zu erkennen, und erscheint in der Flächenansicht als ein schmaler Spalt, ron dem eine Rinne ausgeht und 
sich ziemlich weit dorsalwärts erstreckt. Auf diesem Stadium sieht man, dass der Urdarm sich seitlich und ventralwärts ausbuchtet. Die seitlichen Ausbuchtungen $(c c)$ lassen sich schon ganz gut in ventraler oder dorsaler Ansicht (wie sie die Figur zeigt) beobachten.

Betrachtet man das Ei von dem animalen oder vegetativen Pol, so erkennt man, dass die Ausbuchtung eine einheitliche ist und dass sie, wie es aus dem Vergleich mit späteren Stadien hervorgeht, welche die Anlage der Schalendriise als Verdickung des Ektoderms der Dorsalseite zeigen, nur ventral und lateralwärts hervortritt. Die Zellen der Ausstülpung hängen unter einander lockerer zusammen als die übrigen Entodermzellen, welche alle an Höhe abgenommen haben. Diese Ausstiulpung des Urdarmes ist die Anlage des Mesoderms.

Auf einem etwas älteren Stadium hat sich die Mesodermanlage schon deutlicher vom Darm abgegliedert (Taf. XX Fig. 3).

In seitlicher Ansicht (Fig. 3) sieht man, dass der Urdarm sich in zwei Schläuche gesondert hat, welche beide an ihrem Hinterende zusammenhängen und durch den Blastoporus ausmünden. Der ventral gelegene kürzere Schlauch $C$ ist die Anlage des Mesoderms und sein Lumen das Cölom; der dorsale längere Schlauch $D$ die Anlage des Darmes. Der Urmund, welchen man schon als den After bezeichnen darf, da der Darm als solcher bereits deutlich zu erkennen ist, hat sich im Vergleich zum vorhergehenden Stadium, wo er iiberhaupt am engsten ist, wieder etwas erweitert. Durch Verschiebung des Tubus kann man erkennen, dass die Anlage des Cöloms eine einheitliche und unpaare ist, noch besser tritt dies bei Betrachtung von der Ventralseite hervor (Taf. XX Fig. 4). Hier sieht man das Cölom $(C$, als einen weiten Sack ventral von dem engeren Darm $(D)$ liegen und erkennt, dass der Mesodermsack nach vorn in zwei kurze Zipfel ausläuft. Die Zellen des Mesoderms hängen ziemlich locker zusammen und beginnen schon auf diesem Stadium aus einander zu weichen, was die Beobachtung erschwert; sie sind daher auch, der größeren Deutlichkeit wegen, näher an einander und regelmäßiger gezeichnet, als sie in Wirklichkeit erscheinen.

Die Auflösung des Mesoderms elfolgt hauptsächlich in der ventralen Mittellinie, wie es auf einem Querschnitt durch ein solches Stadium (Taf. XX Fig. 15) ersichtlich wird. Dieser Schnitt geht etwa in der Mitte des Embryo, dicht hinter dem Velum, und schneidet den Mesodermsack $(c)$ da, wo dieser seine größte Ausdehnung hat. Mfan sieht den Darm $(D)$ deutlich mit dem Cölom kommuniciren. Der 
Mesodermsack hat etwa die Gestalt eines Halbmondes und sein Lumen ist bedeutend weiter als das des Darmes. Fig. 14 stellt einen Schnitt durch dasselbe Ei, der dicht vor dem Blastoporus gefiihrt wurde, vor, und erläutert die Bildung von Darm und Cölom. Es ist daraus ersichtlich, dass der Darm dorsalwärts, das Cölom ventralwärts und seitlich durch Abfaltung entsteht. Auf dem Schnitt Fig. 14 ist der Zusammenhang der Zellen ein viel innigerer als auf dem weiter nach vorn gelegenen Schnitt Fig. 15.

Auf demselben Stadium kann man ferner bei seitlicher Ansicht (Fig. 3) erkennen, dass das Ektoderm der Dorsalseite (Sch) dicker geworden ist als das der ventralen Seite; damit ist die Stelle, an welcher später die Schalendrüse sich einstiulpt, bezeichnet. Etwa bis zu dieser Stelle erstreckt sich die schon erwähnte Rinne, welche vom Blastoporus ausgeht und wohl der Verwachsungsstrecke des Urmundes entsprechen diurfte.

Bald schniirt sich der Cölomsack ganz vom Darm ab und liegt bei seitlicher Ansicht ventralwärts von demselben (Taf. XX Fig. 6). Dasselbe zeigt ein Querschnitt durch ein entsprechendes Stadium (Fig. 13).

Man sieht hier, dass das Cölom den Darm in Gestalt eines Halbmondes umgiebt, d. h. dass der Darm in die Konkavität des Mesodermsackes eingebettet ist. Der Vergleich mit Fig. 15 ergiebt, dass das Cölom, dorsalwärts wachsend, den Darm mehr und mehr umgreift. Hier fällt schon (Fig. 13) ein scharfer Unterschied zwischen der Beschaffenheit der Zellen des Darmes einerseits und der des Mesoderms andererseits auf. Letztere haben bereits Spindelform ang'enommen, während die Darmzellen in Gestalt von hohen Cylinderzellen das runde Darmlumen umgeben. Betrachtet man nun ein solches Stadium von der dorsalen Fläche (Fig. 5), so rufen die Theile des Cölomsackes, welche seitlich vom Darm liegen, den Eindruck von paarigen Cölomsäcken hervor $(c c)$. Beobachtet man nun einen solchen Embryo vom After oder vom entgegengesetzten Pol, so fällt die bilateral-symmetrische Anlage des Mesoderms auf, welche schon die Aufmerksamkeit von friheren Beobachtern auf sich gelenkt hat, es ist jedoch sehr schwer, ohne Schnitte die gegenseitigen Beziehungen zwischen Darm und Cölom festzustellen.

Ferner erkennt man auch, dass der Darm im Vergleich zum vorhergehenden Stadium einen viel größeren Raum einnimmt, obgleich die Furchungshöhle noch deutlich erhalten ist. Letztere wird nun bald (Fig. 7 und 10) vollständig verdrängt, indem das viscerale und das parietale Blatt des Mesoderms mehr und mehr aus einander 
weichen und die Zellen des einen sich an die Wand des Darmes, die des anderen an das Ektoderm dicht anschließen. Fig. 7 stellt einen optischen horizontalen Durchschnitt, Fig. 10 einen wirklichen Horizontalschnitt durch ein solches Stadium dar. Der Embryo hat nun etwa den doppelten Durchmesser des Stadiums, auf welchem die erste Mesodermanlage zu sehen war, erreicht, jedoch zeigt ein Vergleich zwischen Fig. 7 und Fig. 10, welche bei derselben Vergrößerung gezeichnet sind, einen beträchtlichen Unterschied in der Größe zwischen Embryonen nämlicher Entwicklungsstufe, eine Erscheinung, welche mir im ganzen Lauf der Entwicklung wiederholt begegnete.

Dic Beschaffenheit der Zellen der verschiedenen Keimblätter hat sich wenig verändert, aber man sieht schon (Fig. 7) die Wimpern des Velums ganz deutlich, und beim lebenden Embryo kann man auch in der Nähe des Afters eine Bewimperung beobachten. In den Velarzellen treten jetzt große Vacuolen auf, wodurch die hellere Färbung des Velums noch vermehrt wird.

Die Lagerung der Mesodermzellen wird bald (Fig. 11) eine ganz unregelmäßige und das mittlere Keimblatt wächst von beiden Seiten mehr und mehr gegen die dorsale Mittellinie zusammen. Ferner fällt ein bedeutender Dickenunterschied zwischen dem ventralen und dem dorsalen Ektoderm auf. Die dorsale Verdickung ist, wie erwähnt wurde, die Anlage der Schalendriise.

Auch differenzirt sich jetzt die dorsale Darmwand von der ventralen in ihrer histologischen Beschaffenheit. Die Zellen der Dorsalwand behalten die hohe cylindrische Gestalt, diejenigen der ventralen vergrößern sich nach allen drei Richtungen des Raumes und zeigen in ihrem Inneren Vacuolen, Fetttropfen und Ansammlungen von sogenanntem Deutolecith. Sie stellen die Anlage der Leber vor, während aus der dorsalen Darmwand Magen und Enddarm entstehen.

Auf dem in Fig. 8 abgebildeten Embryo hat sich die Schalendriise eingestiilpt, sie besteht aus sehr hohen cylindrischen Epithelzellen, fängt dicht hinter dem Velum an, und erstreckt sich nach hinten bis zum After. Von der Fläche gesehen, erscheint sie als eine nahezu runde Zellplatte. Das Velum selbst steht auf der Längsachse des Embryo nicht mehr senkrecht, sondern schräg, und zwar riickt das Velarfeld mehr und mehr dorsal, wenn man als Längsachse die durch die zwei am weitesten von einander entfernten Punkte geführte Linie annimmt.

Endlich löst sich das Mesoderm (Fig. 9) ganz in die bekannten 
Spindelzellen auf, welche die Leibeshöhle vollkommen regellos durchsetzen. Sie hängen unter einander durch feine Fortsätze zusammen, kleiden einerseits die Innenseite des Ektoderms, andererseits die äußere Darmwand aus und lassen unter einander zahlreiche Liickenräume in der Leibeshöhle frei.

Damit wäle die Entwicklung des Mesoderms bis zu dem Punkte geschildert, wo die Anlagen der verschiedenen Organe, die aus ihm hervorgehen, auftreten. In Anbetracht, dass die geschilderte Bildungsweise des Mesoderms bei Gasteropoden und den Mollusken iiberhaupt meines Wissens noch nicht beobachtet worden ist, erscheint es angezeigt, einen kurzen Überblick dessen, was iiber diesen Punkt bei den Gasteropoden bis jetzt beschrieben wurde, folgen zu lassen.

Was Paludina anbelangt, so hat schon BütschuI (Nr. 10 des Litteraturverzeichnisses) die Vermuthung geäußert, dass die Anlage des Mesoderms eine bilateralsymmetrische sei und fiigt hinzu, dass sie auf dem optischen Querschnitt seitlich dick, dorsal und ventral dagegen dünn erscheine. Er beschreibt ferner die Entstehung der Leibeshöhle durch Sonderung des Mesoderms in Darm und Hautfaserblatt, zwischen welchen sich Spindelzellen ausspannen. Was den Ursprung des Mesoderms iiberhaupt betrifft, so vermuthet er, wegen der Ähnlichkeit in der Färbung, dass es vom Entoderm stammen muss. Im Laufe meiner Untersuchungen hatte Professor BüTschli die Freundlichkeit mir einige Skizzen, welche er im Jahre 1888 entworfen hatte, anzuvertrauen. Unter diesen befanden sich Abbildungen ron Stadien, welche meiner Fig. 6 auf Taf. XX entsprechen und deutlich die bilateralsymmetrische Anlage des Mesoderms zeigen, jedoch konnte er den Zusammenhang zwischen Mesoderm und Urdarm nicht ermitteln.

Blochmand (24) macht in einer Untersuchung, welche den Zweck hatte die Angabe von Ray Lankester ${ }^{1}$ und Bütschli iiber den direkten Übergang des Blastoporus in den After zu prüfen, im Gegensatz zu RABL (23), welcher einen Verschluss des Urmundes und eine Umbildung des Afters behauptete, ebenfalls einige Angaben über die Anlage des Mesoderms.

$\mathrm{Er}$ findet dieselbe, wie schon BüTSCHLI angegeben hatte, zwischen Ektoderm und Entoderm, konnte aber den Ursprung nicht näher bestimmen.

1 E. Ray Lankester, On the coincidence of the Blastopore and Anus in Paludina vivipara. Quart. Journal Micr. Science. No. 64. 1876. 
Was nun die anderen bis jetzt untersuchten Gasteropoden anbelangt, so gehen die Angaben über die Bildungsweise des Mesoderms sehr aus einander. Einige Beobachter lassen das mittlere Keimblatt aus dem Ektoderm, andere aus dem Entoderm entstehen.

Salensky (2) vermuthet, dass bei Calyptraea sinensis, der Ursprung des Mesoderms, welchen er nicht mit Sicherheit verfolgen konnte, ektodermal ist.

Bobretzky (11) sah bei Nassa mutabilis einige große, langsam sich theilende Zellen, neben dem Rande der Keimscheibe, von den benachbarten Zellen bedeckt und in die Furchungshöhle hinein gedrängt werden und betrachtet sie als die Anlage des Mesoblasts. Die Zellen selbst leitet er rom Entoderm ab. Bei $\mathrm{F} u s u s$ lässt er das Mesoderm aus einer Umbiegung des Blastoderms am Urmund hervorgehen.

Fol (7) äußert bei den Pteropoden die Vermuthung, dass die wenigen Mesodermzellen, welche sich gegen das Ende des embryonalen Lebens, theils in der Kopfgegend iiber dem Munde, theils in der Gegend des After's zeigen, dem Ektoderm entstammen, glaubt dies aber nicht mit Bestimmtheit behaupten zu können. Die Leibeshöhle gehe direkt aus der Furchungshöhle hervor. Bei den Pulmonaten (13) dagegen hat er zwei Urmesodermzellen, ventral am Ektoderm gelegen, beobachtet, deren Ursprung er nicht ermittelte.

Bestimmter lauten die Angaben von P. Sarasin (1S), welcher in seiner Entwicklungsgeschichte von Bythynia das Vorkommen eines selbständigen, rom Ektoderm wohl geschiedenen Mesoderm überhaupt in Abrede stellt. Die Mesodermelemente entstehen nach ihm überall durch Auswanderung von Ektodermzellen. In einem gewissen Widerspruch mit dieser Behauptung steht die in derselben Arbeit an einer fritheren Stelle befindliche Angabe, dass an der Übergangs-stelle des Ektoderms in das Entoderm einige ron der äußeren Lage abgeschnürte Zellen liegen, welche die ersten Mesodermzellen sein mögen. Ich glaube, dass bei By thynia, wo anch keine Urzellen des Mesoderm gesehen worden sind, der Ursprung des Mesoderms ein ähnlicher wie bei Paludina sein wird.

Manfredi (22) lässt bei Aplysia das Mesoderm durch Delamination vom Ektoderm abstammen, ohne dafür andere Beweise g'eltend zu machen, als dass er keine Urzellen des Mesoderms finden konnte. 
Salensky 26$\rangle$ leitet bei Vermetus das Mesoderm vom Ektoderm her, betont aber, dass es ihm viel Müuhe gekostet hat dies festzustellen. Das mittlere Keimblatt soll nach ihm zuerst aus wenigen zerstreuten Zellen bestehen und durch Delamination aus dem Ektoderm entstehen. Er hebt besonders hervor, dass dieser Vorgang durch direkte Kerntheilung erfolgt. Er unterscheidet ferner zwei getrennte Anlag'en des Mesoderms, von denen die eine paarig. und bilateral symmetrisch ist und in der Nähe des Blastoporus entsteht, die andere, welche er perikardiales Mesoderm nennt, soll aus dem Ektoderm der Schalendriise hervorgehen. Die Leibeshöhle bildet sich erst sehr spät im Fuß, durch Auseinanderweichen des Mesoderms in ein parietales und ein viscerales Blatt. Urmesodermzellen ließen sich bei Vermetus nicht nachweisen.

Wolfsohn's Arbeit iiber Lymnaeus stagnalis (14) ist mir nicht zugänglich gewesen, so dass ich nur über einen yon ihm selbst verfassten Auszug berichten kann. In demselben theilt er mit, dass das Mesoderm im Inneren der Morula aus Blastodermzellen des vierten Stadiums (acht Zellen) entsteht, dass aber bald die Unterschiede zwischen den Zellen der drei Keimblätter schwinden. Die Mesodermzellen werden dann bei der Gastrulation in das Innere der Gastrula in der Nähe des Mundes hineingedrängt. WoLfsons bemerkt, dass er keine Gastrula ohne Mesoderm angetroffen hat, obgleich er sehr viele auf Schnitten untersucht hat. Der abgebildete Schnitt durch ein solches Stadium hat eine große Ähnlichkeit mit meiner Fig. 5 auf Taf. XX, und führt mich zu dem Schluss, dass auch bei Lymnaeus der Cölomsack sich vom Urdarm abschnüren düirfte.

RABL, welcher in seiner Ontogenieder Sü $\beta$ wasserpulmonaten (5) dem Mesoderm einen ektodermalen Ursprung zuschrieb, fand bei Planorbis (12) zwei Urmesodermzellen, welche er aus dem Entoderm ableitet, und behauptet in seiner "Theorie des Mesoderms": dass das mittlere Keimblatt aller Wahrscheinlichkeit nach stets vom inneren Keimblatt, theils als Ausstiilpung des Urdarmes, theils als Urmesodermzellen abzuleiten sei.

Blochnand (17) findet bei Neritina eine entodermale Zelle, welche sich in zwei theilt, aus denen je ein Mesodermstreifen entsteht, und hebt hervor, dass die Mesodermanlage eine bilateral-symmetrische sei. Dagegen konnte er bei Aplysia (17) den Ursprung. des mittleren Keimblattes nicht feststellen.

HADDON 19 lässt bei Janthina fragilis das Mesoderm 
durch Segmentation von Dotterzellen in der Nähe des Blastoporus entstehen.

Patten (27) beschreibt bei Patella ein Entomesoderm, da hier das mittlere Keimblatt durch Delamination vom Entoderm entsteht, und zwar so, dass zwei Entodermzellen sich in je zwei Zellen theilen, von denen die eine eine Urmesodermzelle giebt, die andere eine Zelle der Urdarmwand. Von diesen zwei Urmesodermzellen wächst dann je ein Mesodermstreifen aus.

MacMurrich (29) giebt einen doppelten Ursprung des Mesoderms für Fulgur an. Der eine Theil entsteht aus einer Entodermzelle am vegetativen $\mathrm{Pol}$ in der Nähe des Urmundes, dazu kommen noch Zellen, welche sich unregelmäßig ron den Makromeren ablösen.

Kowalevsky (20) sieht bei Chiton Polii die ersten Spuren des Mesoderms im Umkreis des Blastoporus, in Gestalt von wenigen Zellen, welche symmetrisch und ventral zu beiden Seiten des Entoderms gelegen sind und von diesem sich abgelöst haben. Ich möchte hier hervorheben, dass die äußere Gestalt und der innere Bau des Chitonembryo auf dem Stadium, wo das Mesoderm sich anlegt, eine große Ähnlichkeit mit dem entsprechenden Stadium bei Paludina zeigt.

Joyeux Laffure (21) ist, wahrscheinlich weil er keine Schnitte gemacht hat, bei $\mathrm{Onchidium}$ zu keiner Klarheit iiber den Ursprung des Mesoblast gekommen.

F. RHo (32) hat zwar bei der Chromodoris elegans den Ursprung der je zu vier rechts und links rom Urdarm gelegenen Mesodermzellen nicht ermitteln können, hebt jedoch hervor, dass sie dieselbe Färbung wie die Entodermzellen zeigen. Er bleibt dariiber im Zweifel, ob das Mesoderm zwei laterale Streifen oder eine kontinuirliche Schicht bildet. Vom Urdarm sagt er, dass er die Form einer Amphora besitze, d. h. auf beiden Seiten je eine Ausstiilpung zeige, welche vom Blastoporus ausgehen. Ich vermuthe nun, dass diese Ausstiilpungen denjenigen, welche ich bei Paludina geschildert habe, entsprechen duirften. Auch bei Fou, in der Untersuchung iiber die Heteropodenentwicklung (8), finde ich auf Taf. I Fig. 12 eine ähnliche Form des Urdarmes abgebildet.

Ans dieser Übersicht geht nun zunächst herror, dass bei den Gasteropoden die Bildung des Mesoderms auf eine sehr mannigfache Art sich vollzieht. Trotzdem möchte ich glauben, dass sich diese 
Bildungsweise auf ein gemeinsames Schema zurückführen lassen dürfte, etwa in derselben Art, wie es O. HerTwig für die Wirbelthiere versucht hat.

Ohne die Möglichkeit eines ektodermalen Ursprunges von Bestandtheilen des mittleren Keimblattes ganz in Abrede stellen zu wollen, bin ich, trotz vieler Widerspriiche. der Ansicht, dass dasselbe bei den Gasteropoden in allen Fällen vom Entoderm abzuleiten ist.

In den meisten Fällen wird der ektodermale Ursprung nur vermuthungsweise, oder ohne genügende Beweise angegeben. Mit aller Bestimmtheit wird dies nur von Sarasin und SALEnsky behauptet. Die Angaben von Sarasin scheinen mir aber sehr unwahrscheinlich, wie ich es schon oben sagte, eben so auch diejenigen Salenskx's, besonders in Bezug auf die Art der Kerntheilung.

Wenn nun aus der Bildungsweise des Mesoderms bei Paludina ein Schluss auf die Entstehung des mittleren Keimblattes der Gasteropoden gemacht werden soll, so frägt es sich zunächst, ob das Ei der Urform einen Nahrungsdotter besaß oder nicht.

MacMurRich meint, dass, da die Gasteropoden ursprïinglich alle marin gewesen sein mïssen, und die marinen Formen meistens nit reichlichem Nahrungsdotter ausgeriistet sind, die Urform ebenfalls einen reichlichen Nahrungsslotter gehabt haben muss. Nun pflegt man aber in der Embryologie zur Erklärung der Verhältnisse bei dotterreichen Eiern in der Regel von denen dotterarmer Keime auszugehen, da man annimmt, dass durch den Dotter die Verhältnisse vielfach getruibt und komplicirt werden. Ferner werden die Chitonen von vielen Forschern als diejenigen Schnecken angesehen, welche der Urform sehr nahe stehen dürften und von derselben wahrscheinlich nur durch wenige sekundär erworbene Eigenthiimlichkeiten abweichen. Nun besitzen gerade die Chitonen eine nahezu äquale Furchung und sehr geringe Mengen von Nahrungsdotter. Die Bildungsweise des Mesoderms scheint mir hier principiell mit der bei Paludina beschriebenen iibercinzustimmen. Es wäre demnach möglich, dass Paludina, welche jedenfalls von einer marinen Form abstammt, durch Verlust des Nahrungsdotters wieder zu dem urspriinglichen Bildungsmodus des Mesoderms zurückgekehrt ist. Man mïsste dann, von dieser Bildungsweise ausgehend, zu Formen mit reichlicherem Nahrungsdotter übergehen und hier die Entstehung des Mesoderms auf eine mehr oder weniger modificirte Ausstiilpung vom Urdarm zurïckführen. Ein Beispiel dafür scheint mir nach 
Bobretzky's Beschreibung Fusus zu bieten. Für meine Annahme spricht ferner der Umstand, dass in der Mehrzahl der Fälle die Anlage des Mesoderms in der Nähe des Blastoporus gefunden wird, also an der Stelle, wo Ektoderm in Entoderm uibergeht, eine Erscheinung, welche bei zahlreichen zu ganz verschiedenen Phylen gehörigen Formen wiederkehrt, für die ein entodermaler Ursprung des mittleren Keimblattes vindicirt wird.

Ein principieller Unterschied ist wohl zwischen der Bildung des Mesoderms durch Ausstülpung vom Urdarm und derjenigen durch Urmesodermzellen nicht vorhanden, wie neuerdings HatscheK in seinem Lehrbuch der Zoologie hervorgehoben bat. Es finden sich ja alle Übergänge von einer, zwei, bis vielen Urmesodermzellen, zu einer Ausstülpung, welche nur aus wenigen Zellen besteht, weiter giebt es auch Formen, wie Amphioxus, wo Ausstülpung und Urmesodermzellen neben einander vorkommen. Bei der Entstehung: durch Ausstülpung tritt nur die Differenzirung des mittleren Keimblattes später auf als bei der Entstehung durch Urmesodermzellen. Beide Bildungsweisen kommen, wie es die Litteraturiibersicht gezeigt hat, bei den Gastropoden vor, es wird aber wohl kaum hier zu entscheiden sein, welcher von beiden Vorgängen der ursprünglichere ist.

Die Thatsache, dass die Leibeshöhle bei Paludina durch Ausstïlpung des Urdarmes entsteht, bildet übrigens einen Widerspruch zur Hertwig'schen Cölo m theorie (15), wonach die Mollusken zu den sogenannten Schizocöliern gerechnet werden, d. b. bei welchen die Leibeshöhle durch Auseinanderweichen oder Spaltung des Mesoderms resp. Mesenchyms entsteht. Ich brauche nicht hervorzuheben, dass bei Paludina, in Folge der besprochenen Bildungsweise des Mesoderms, von einem Mesenchym im Gegensatz zum Mesoderm nicht die Rede sein kann, obgleich gerade die Mollusken nach der HeRTwiG'schen Theorie ein ausgezeichnetes Beispiel fuir mesenchymführende Thiere sind und gar kein eigentliches Mesoderm besitzen sollen.

Schon die Beobachtungen von Ganin bei Cyclas (3) und in noch höherem Grad die Arbeit BüTschur's über Paludina (10) ließen mich an der Richtigkeit der HerTwig'schen Cölom- und Mesenchymtheorie in ihrer Anwendung auf die Mollusken zweifeln, auch SALENSKY (26) kann sich nicht damit einverstanden erklären, da nach ihm viele Thatsachen und seine eigenen Beobachtungen dagegen sprechen. $\mathrm{Zu}$ derselben Ansicht gelangte HALLER durch Untersuchung. 
der Anatomie der Chitonen ${ }^{1}$. Endlich sind die Resultate, zu welchen ich in dieser Arbeit gelangt bin, gar nicht mit der HenTwiG'schen Theorie zu vereinbaren, so dass ich sie mindestens in Bezug auf die Mollusken für verfehlt erklären muss.

Ich möchte glauben, dass, wie ich es am Schlusse der Litteraturübersicht angedeutet habe, die Bildung des Mesoderms durch Ausstiilpung nicht ganz isolirt für Paludina dasteht, und dass spätere Untersuchungen dasselbe noch für andere Formen zeigen werden.

Kehren wir nun zur weiteren Entwicklung des mittleren Keimblattes zuriick. In Fig. 9 auf Taf. XX sahen wir den ganzen Raum zwischen Darm und Ektoderm, d. h. die Leibeshöhle von den Spindelzellen des Mesoderms durchsetzt. Bald legen sich Mund und Schlund als eine Verdickung und darauffolgende Einstiulpung des äußeren Keimblattes auf der Ventralseite, dicht hinter dem Velarfeld, in der ventralen Mittellinie an. Die Einstiulpung wird allmählich tiefer und stößt zuletzt auf den nach vorn noch geschlossenen Darm.

Auf diesem Stadium findet man am Hinterende, dicht vor dem mehr ventralwärts gerückten After, zwischen Enddarm und Ektoderm eine größere Auhäufung von Mesodermzellen. Fig. 16 (Taf. XX) stellt einen Querschnitt durch das Hinterende eines derartigen Embryo vor. Man sieht ventralwärts von der ventralen Darmwand $D$, deren Zellen den der Leber eigenthümlichen Bau zeigen, zwei unregelmäßige Haufen von Spindelzellen, welche unter einander lose verbunden sind. In jedem dieser Haufen ist ein Lumen $P$ und $P^{\prime}$ zu sehen.

Die Untersuchung einer größeren Anzahl von Embryonen dieses Stadiums ergab, dass die Gestalt dieser Mesodermanhäufungen, welche die erste Anlage des Herzbeutels vorstellen, eine sehr unregelmäßige ist. Es lässt sich im Allgemeinen nur so viel sagen, dass die Anlage eine deutliche paarige Entstehung sowohl auf Schnitten als bei Betrachtung von der Bauchfläche verräth. Die beiden Zellhaufen, von welchen der rechts gelegene $P$ fast immer der ansehnlichere ist, hängen gewöhnlich durch feine Züge von langgestreckten Mesodermzellen zusammen.

Die beiden Zellhaufen, in denen die Lumina schon sehr früh-

1 B. Haller, Die Organisation der Chitonen der Adria. Arbeiten aus dem zoolog. Institut in Wien. Bd. IV. 1882. V. 1883. 
zeitig auftreten, rücken im Laufe der Entwicklıng immer näher zusammen, bis sie mit einander verschmelzen. Fig. 2 auf Taf. XXII ist nach einem horizontalen Schnitt durch das Hinterende eines solchen Embryo entworfen und zwar ist der Schnitt gerade durch den weitesten Theil des Perikards geführt worden. Die Wände der zwei Säcke $P$ und $P^{\prime}$ sind schon theilweise mit einander verschmolzen. Das Lumen des rechten Abschnittes des Perikards $(P)$ ist etwa doppelt so groß wie das des linken und ist von diesem durch ein mittleres Septum getrennt, welches durch die vereinigten Wände der zwei ursprïnglich getrennten Säcke gebildet wird. Der Herzbentel wird mit der Wand des Magens $(\boldsymbol{M})$ einerseits, und dem Ektoderm andererseits, durch zahlreiche verästelte Mesodermzellen verbunden. Der rechte Abschnitt selbst ist hier durch einen mittleren Zellbalken durchsetzt, der aber tiefer liegt, kein eigentliches Septum bildet und welchem keine weitere Bedeutung zukommt.

Im Laufe der Entwicklung nimmt das Perikard immer mehr an Größe zu, während seine Wand sich entsprechend verdïnnt. Ein derartiges Stacium ist auf Taf. XXI Fig. 1 von der rechten Seite abgebildet.

Da sich die Gestalt des Embryo schon bedeutend verändert hat, so muss sein Bau eingehender geschildert werden.

Die früher eiförmige Gestalt des Embryo ist durch das Auswachsen des Fußes $(F u)$, welcher die ventrale Seite bezeichnet, modificirt worden. Dem Fuße gegenïber liegt das Velarfeld, welches vom Velum $(V V)$ umsäumt wird. Dieses besteht aus einer doppelten Reihe von Zellen, welche zahlreiche ziemlich lange und dicht gestellte Wimpern tragen. Die Färbung der Velarzellen ist im Leben eine gelbliche und persistirt auch auf Präparaten, wo sie durch größere Durchsichtigkeit anffallen und sehr wenig von den Tinktionsmitteln aufnehmen. Sie zeigen eine große Neigung zur Vactolenbildung. Am Vorderende des Embryo, zwischen Velarfeld und Fuß, befindet sich der Mund, der durch den bereits in den Darm durchgebrochenen Ösophagus $(S)$ in den spindelförmigen Magen $(\boldsymbol{M})$ führt. Unter dem Magen lieg't die Leber $(L)$, welche sich vom Darm stark abgeschniirt hat, aber durch eine noch sehr weite Offnung mit dem Magen zusammenhängt. Dieser führt durch einen ventralwärts im rechten Winkel gebogenen Enddarm $(E)$ zum After $(A)$, welcher nicht mehr terminal sondern in der Mittellinie im hinteren Theil der Bauchfläche lieg't. Mag'en, Leber und Enddarm sind sämmtlich aus der Darmanlage hervorgegangen.

Das Velarfeld zeigt rechts und 
links eine Hervorwölbung (Füi). die Fỉhleranlagen, an deren Basis die Augengrube $(A u)$ liegt. Am Fub ist jederseits die Anlage der Otolithenblase $O$ bemerklich, welche wie das Auge durch Einstiilpung des Ektoderms entsteht. Die Schalendriise $(S c h)$ hat eine Scbale (Scha) abgesondert, welche bereits den größeren Theil des Hinterendes bedeckt und von der Mantelfalte $M f$ umsäumt wird! Zwischen den beiderseitigen Wülsten der Mantelfalte hat sich am Hinterende gerade vor dem After, auf der Bauchfläche, eine kleine Grube $(\boldsymbol{M} h)$ die Anlage der Mantel- oder Kiemenhöhle gebildet $(\boldsymbol{M} h)$.

Ich will gleich in Bezug auf die Entwicklung der Mantelhöhle vorausschicken, dass dieselbe, wenigstens bei den Anfangsstadien, nicht als eine wirkliche Grube aufgefasst werden muss, sondern nur einer Stelle der Bauchwand entspricht, welche mehr und mehr von der nach vorn auswachsenden und sich allmählich erhebenden Mantelfalte umwallt wird. Der von der Mantelfalte gebildete Wall rerleiht nun der Mantelhöhle das Aussehen einer Grube. Da nun der After gerade an dem hinteren Ende des von der Mantelfalte umfassten Feldes sich befindet, so erklärt sich daraus, wie derselbe in der Mantelhöhle zu liegen kommt.

Das Perikard $\left(P P^{\prime}\right)$ liegt in der Figur iiber Magen und Leber und stößt auf das Ektoderm der Mantelhöhlenaulage auf. Durch Heben und Senken des Tubus und besser noch bei Betrachtung des Embryo von der Bauchfläche sieht man, dass das Perikard noch aus zwei Abschnitten $P$ und $P^{\prime}$ besteht, welche durch ein mittleres Septum getrennt werden.

Der hier geschilderte Embryo ist äußerlich noch ganz symmetrisch gebaut, innerlich aber schon ganz asymmetrisch, wie die Lagerung der Eingeweide zeigt. Die ersten Spuren der Asymmetrie treten jedoch schon friiher auf, da sie sich im Inneren des Embryo, durch die Ungleichheit der beiden Abschnitte des Perikards äußern; auch bedingt die Leber, sobald sie sich vom Darm abzuschnïren beginnt, einen gewissen Grad innerer Asymmetrie. Weiter bemerkt man, dass im Vergleich zu früheren Stadien die dorsale Seite des Hinterendes stärker gewachsen ist als der Rest des Embryo, was die Verlagerung des Afters nach der ventralen Seite zur Folge gehabt hat. Ich lege

1 Ich möchte bei dieser Gelegenheit erwähnen, dass am lebenden Embryo öfter Spermatozoen an dem von Bütschli beschriebenen Schalenknopf festhaften und demselben ein behartes Aussehen verleihen. Im Darm findet man auch zahlreiche, vom Embryo mit dem umgebenden Eiweiß verschluckte Samenfäden. 
nämlich die morphologische Längsachse des Embryo, den Ansichten Bürschli's (25) gemäß, durch Mund und After, da Messungen und der Vergleich sehr zahlreicher Entwicklungsstadien die Schlüsse, zu welchen Bütschli gekommen ist, bestätigt haben.

Auf Taf. XXII Fig. 5 wird ein Querschnitt, der durch den Herzbeutel eines Stadiums, welches nur wenig juinger als das eben besprochene war, gefuihrt worden ist, abgebildet. Der Größenunterschied zwischen den zwei Abschnitten tritt schärfer hervor, das Septum, sowie der größte Theil der Herzbeutelwand ist bedeutend diinner geworden als es in Fig. 4 derselben Tafel zu sehen ist. Dag'egen zeigt jetzt die linke Wand des linken Sacks eine Verdickung $(N)$, auf deren Bedeutung später eingegangen werden soll. Weiter bemerkt man, dass das Ektoderm der Bauchwand aus hohen cylindrischen Epithelzellen besteht, sich also verdickt hat, es ist nämlich die Stelle, an welcher sich die Mantelhöhle bilden wird, hier getroffen worden.

In Fig. S und 14 von Taf. XXI ist das Hinterende eines etwas älteren Embryo als der in Fig. 1 dargestellte einmal aus Querschnitten, das andere Mal aus horizontalen Schnitten, mit einer ventralen Ansicht des ganzen Embryo kombinirt, rekonstruirt worden, hauptsächlich um die Entstehung der Mantelhöhle zu erläutern.

Fig. 8 (Taf. XXI) ist aus einer Querschnittserie rekonstruirt worden und entspricht der Ansicht, welche man bekommen wiirde, wenn man das betreffende Stadium mittels eines durch die vorderste Stelle der Kiemenhöhlenanlage gefiihrten Querschnittes in zwei Theile zerlegen und auf die Schnittfläche des hinteren Theiles sehen wïrde. Die Schnittfläche hat annähernd die Gestalt eines Dreiecks, dessen Spitze dem Riicken entspricht. Auf der Ventralseite sieht man die Einsenkung ( $M h)$, welche der Mantelhöhlenanlage entspricht. Diese ist noch ziemlich flach, und zwar bleibt sie in ihrer mittleren Region seichter und dringt rechts und links mit zwei Zipfeln tiefer ein.

Dorsal ron der Mantelhöhle, und an das Ektoderm ihrer Wand anstoßend, liegt der Herzbeutel $(P)$, dessen Septum sich schon ganz zurïckgebildet hat. Der Vorgang ist hierbei folgender: das Septum, welches, wie schon erwähnt wurde, stark an Dicke abnimmt, reißt ein und wird allmählich resorbirt.

Taf. XX Fig. 12 ist ein Querschnitt durch den Herzbeutel eines etwas juingeren Stadiums wie Fig. 8 auf Taf. XXI. Das Septum hat sich eben zuriickgebildet, aber die Stelle, welche es frither ein- 
nahm, ist an der Einschnïrung des Herzbeutels noch ganz deutlich zu erkennen. Weiter bemerkt man auf Fig. 12 (Taf. XX), dass die eben besprochene Verdickung der Wand des linken Abschnittes $N^{\prime}$ zu einer Ausstiilpung geworden ist, welche der Schnitt jedoch etwas flach getroffen hat, so dass der Hohlraum der Ausstülpung. als ein Lumen erscheint. Diese Ausstuilpung bildet sich jedoch bald zuriick und ist in Fig. 8 (Taf. XXI) nur noch als eine Verdickung, welche sich noch eine Zeit lang erhält, zu erkennen. Es hat sich aber mittlerweile eine ganz ähnliche Verdickung durch Ausstïlpung im rechten Abschnitt des Perikards gebildet $(N)$, welche die Anlage der bleibenden Niere darstellt. Die beiden Zipfel der Mantelhöhle stoßen gerade auf jene beiden Ausstiilpungen des Her'zbeutels. Da nun der rechte Zipfel zum Ausführgang der rechten Ausstiilpung, d. h. der bleibenden Niere wird, so glaube ich die linke Ausstiilpung als rudimentäre linke Niere betrachten zu dürfen, und den linken Zipfel der Mantelhöhle als deren rudimentären Ausführgang. Dieser linke Zipfel der Mantelhöhle entwickelt sich iibrigens auch nicht weiter.

Die eben besprochene Fig. 8 erläutert auch die Lagerungsverhältnisse des Perikards. Man sieht, dass es iiber dem Enddarm $E$ und unter dem Magen und der Leber $(\boldsymbol{M}$ und $L$ ) liegt. Seine Längsachse ist ziemlich parallel der Bauchfläche gelegen, doch greift der Herzbeutel auf der rechten Seite viel weiter dorsalwärts herüber als auf der linken Seite.

Die Fig. 14 (Taf. XXI), welche das Hinterende eines entsprechenden Stadiums, von der Bauchseite betrachtet, darstellt, und aus der ventralen Ansicht eines ganzen Embryo und aus einer horizontalen Schnittserie rekonstruirt ist, soll zeigen, dass die Mantelhöhle (IIh) als eine nach hinten und dorsalwärts gerichtete Tasche sich anlegt. Weiter erkennt man die beiden Zipfel der Mantelhöhle, und die Beziehungen des rechten $N a$ zu der Nierenanlage $N$ treten auf dieser Ausicht klar hervor. Der After $(A)$ liegt immer noch in der Mittellinie der Bauchfläche in der Mantelhöhle, jedoch ergiebt ein Vergleich mit Fig. 8, dass der Enddarm schon etwas schräg zur Längsachse geneigt ist. Man sieht aus dieser ventralen Ansicht, dass die beginnende äußere Asymmetrie sich schon geltend macht, da die Mantelhöhle rechts viel tiefer eindringt als links, was sich ebenfalls in den zwei Zipfeln $N a$ und $N a^{\prime}$ äußert, von denen der rechte bedeutend weiter und tiefer ist als der linke, auch reicht die Mantelfalte links weiter nach vorn als rechts. Der rechte Zipfel 
oder der Nierenausfuihrgang setzt sich bereits deutlich vom Rest der Mantelhöhle ab.

Bei einem etwas älteren Stadium (Taf. XXI Fig. 2) ist die äußere Asymmetrie noch mehr ausgeprägt, was am besten bei Betrachtung von der dorsalen oder ventralen Fläche hervortritt, jedoch in der seitlichen Ansicht nicht gut zu sehen ist. Der Vergleich mit Fig. 1 zeigt, dass der Fuß schon durch eine Abschniirung sich absetzt und dass das Velarfeld im Verhältnis zur Längenzunahme des Embryo nicht zugenommen hat. Obgleich die Schale nicht sonderlich an Ausdehnung gewonnen hat, ist die Mantelhöhle (Mh) bedeutend umfangreicher und tiefer geworden, man bemerkt an ibrer Wand in $N a$ den optischen Querschnitt durch den Nierenausfübrgang, der ja nur ein Theil der Mantelhöhle ist. Der einheitliche Herzbeutel fuillt einen sehr großen Theil des beschalten Hinterendes aus.

Betrachten wir nun eine Rekonstruktion aus Querschnitten des Hinterendes eines entsprechenden Stadiums (in derselben Art wie Fig. 8 hergestellt und gedacht), so erkennt man, dass das Hinterende, welches gerade so orientirt ist wie Fig. 8, eine Drehung im Sinne des Uhrzeigers gemacht haben muss. Es wurden sämmtliche Querschnitte in Bezug auf eine Linie, welche durch den Mittelpunkt des Velums und die äußerste Spitze des Fußes gezogen wurde, orientirt. Diese Drehung erklärt sich aus der beginnenden Asymmetrie des Embryo. Leber und Magen liegen jetzt auf der linken Seite, der Enddarm ist noch schräger zur Mittellinie gestellt, während der After noch ziemlich median liegt. Der Herzbeutel liegt jetzt mit dorsoventral gerichteter Längsachse, und zwar so, dass die Verdickung $N^{\prime}$ ganz ventral sich befindet, während die Niere dorsalwärts geriickt ist. Der linke Abschnitt des Perikards ist in seinem Wachsthum stehen geblieben, während der rechte bedeutend an Größe zugenommen hat. Dieser Zuwachs ist aus der Figur nicht ersichtlich, da sich der Herzbentel auf diesem Stadium besonders nach hinten erstreckt, wie es aus Fig. 2 (Taf. XXI) hervorgeht. Auch die Mantelhöhle ist hauptsächlich auf der rechten Seite tiefer geworden, und der Durchbruch ihres rechten Zipfels in die Niere ist schon erfolgt, was in der Figur daraus zu erkennen ist, dass das Lumen der Niere in die Mantelhöhle mïndet. Diese erscheint ventralwärts nahezu abgeschlossen, was sich daraus erklärt, dass die Mantelfalte unterdessen stärker nach vorn ausgewachsen und viel höher g'eworden ist, so dass die auf dem Querschnitt hervor- 
tretenden Wülste nach hinten zu einander sehr genähert sind, da der Schnitt in der Höhe des Afters gefuhrt wurde.

Fig. 1 auf Taf. XXIII zeigt einen einzelnen Schnitt aus der eben besprochenen Serie, welcher die histologischen Verhältnisse veranschaulichen soll. Er trifft den Herzbeutel in seiner ganzen Ausdehnung. Die dorsale Wand des Herzbeutels besteht aus einer einfachen Schicht von sehr abgeplatteten Zellen, während die ventrale dicker ist. Die rudimentäre Niere $\left(N^{\prime}\right)$ ist als eine Verdickung der Perikardialwand zu sehen, die Niere $(N)$ als eine Ausstiilpung. derselben, und besteht aus hohen Cylinderzellen. Links vom Her'zbeutel liegen Magen $(\boldsymbol{M})$ und Leber $(L)$, welche durch eine sehr weite Öffnung zusammenhängen. Der Magen besitzt ein hohes Cylinderepithel, während die Leber aus sehr großen Zellen besteht, welche die fuir sie charakteristischen Einschliisse, Fetttropfen, Deutolecith etc. enthalten, was hier nicht näher ausgefuihrt ist. Der Raum zwischen den eben besprochenen Organen und dem Ektoderm wird von Mesodermzellen ausgefuillt. Der dorsale Umriss des Schnittes wird von der Schale (Scha) gebildet, welche aus einem sehr feinen Häutchen besteht, unter dem eine außerordentlich dünne Ektodermlage sich befindet. Die Schale erstreckt sich ventral bis zu der Mantelfalte $(M f)$, in welcher sie eingefalzt ist. Ich will daher diese Stelle des Mantelwulstes Schalenfalz $(S r f)$ nennen. Hier verdickt sich das Ektoderm ganz plötzlich und geht allmählich in den Boden der Mantelhöhle iiber, welcher ebenfalls aus einem hohen Cylinderepithel besteht. Der Schalenfalz bezeichnet jedenfalls diejenige Zone der Mantelfalte, welche die Schale absondert und somit die Thätigkeit der Schalendruise uibernommen hat. Man sieht rechts und links die beiden Zipfel der Mantelhöhle $N a$ und $N^{\top} a^{\prime}$, von denen die rechte viel tiefer und bis zur Niere $\left(\lambda^{\top}\right)$ eindringt. Die Durchbruchsstelle ist auf diesem Schnitt nicht getroffen.

In Fig. 3 Taf. XXI ist ein etwas älteres Stadium von der linken Seite abgebildet. Die Gestalt ist im Ganzen eine schlankere geworden, das Velarfeld erscheint bereits viel kleiner, der Fuß ist stark ausgewachsen und hat sich noch deutlicher zu einer Kriechsohle abgeplattet. Der Ösophagus ist sehr lang und diinn geworden und der auf den Magen folgende Abschnitt des Darmes ist stark nach vorn gekriimmt, so dass der After in der Mantelhöhle gleich hinter der Mitte der Körperlänge zu liegen kommt. Die Schale ist bedeutend größer g'eworden und bedeckt das ganze Hinterende, welches sich deutlich von der vorderen Körperhälfte absetzt. Der 
Mantelrand, welcher noch in Fig. 2 etwa einen Winkel von $45^{\circ}$ mit der Längsachse des Embryo bildete, steht jetzt nahezu senkrecht zu derselben, da die Mantelfalte bedeutend weiter nach vorn ausgewachsen ist. Die Mantelhöhle erscheint demgemäß stark erweitert und vertieft und liegt zum größten Theil auf der rechten Körperhälfte. Der Herzbeutel füllt ungefähr die Hälfte des beschalten Hinterendes aus und zeigt an seiner hinteren Wand eine Einstülpung $(H)$, welche die erste Anlage des Herzens ist.

Fig. 11 ist das aus Querschnitten rekonstruirte Hinterende eines entsprechenden Embryo, in derselben Weise dargestellt wie Fig. 8 und 9, wobei die Durchschnittsfläche etwa hinter dem Mantelrand gefuibrt ist. Man sieht sofort, dass die Verlagerung der inneren Organe in Folge der sich weiter entwickelnden Asymmetrie große Fortschritte gemacht hat. Leber und Magen sind scheinbar ganz auf die linke Seite geriickt, was sich aus der Drehung des hinteren Körperendes erklärt, und liegen ziemlich ventral, sie fangen bereits an die Wand des Embryo bruchsackartig nach außen zu drängen und bilden somit die Anlage des Eingeweidesackes, was man bei Betrachtung des ganzen Embryo von der dorsalen Fläche am besten konstatiren kann. Der Enddarm erstreckt sich nahezu horizontal und mündet vorn und rechts durch den After aus, welcher innerhalb der Mantelhöhle liegt und gerade von dem Schnitt g'estreift wurde. Der sehr ansehnliche Herzbeutel hängt noch mit der Niere durch eine schon etwas enger gewordene Kommunikation zusammen. Die Niere liegt auf der rechten Seite, und zwar dorsal und ganz hinten, an dem entgegengesetzten Ende des Perikards, d. h. ventral, sind die letzten Reste der rudimentären linken Niere in Gestalt einer unbedeutenden Verdickung $\left(\boldsymbol{N}^{\prime}\right)$ erhalten. An der nach hinten gerichteten Wand des Perikards und dorsalwärts ïbergreifend ist die Herzeinstülpung $(H)$ zu sehen, welche faltenförmig in den Herzbentel hineiuragt. Die Mantelhöhle, welche sehr tief ist, liegt zum größten Theil auf der rechten Seite des Schnittes, zieht aber dorsalwärts in einem Bogen herum. Ihre größte Tiefe erreicht sie auf der rechten Seite, indem sie sich in den Nierenausfiihrgang fortsetzt, welcher ja ein specialisirter Theil der Mantelhöhle ist.

Zwei auf einander folgende Schnitte ans dieser Serie (Taf. XXIII Fig. 2 und 3) sollen die erste Anlage des Herzens veranschaulichen. Der in Fig. 3 abgebildete, welcher dorsalwärts gelegen ist, ist ganz wiedergegeben. Vergleicht man ihn mit Fig. 1 derselben Tafel, so sieht man gleich, dass die Wand des Herzbeutels noch diinner 
geworden ist, sie besteht jetzt fast in ihrer ganzen Ausdehnung aus einer einzigen Schicht sehr abgeplatteter Zellen. Man erkennt die Niere $(N)$ als eine Ausstulpung derselben, an welche das äußerste Ende des Nierenausführganges stößt. Weiter ist hier noch ein kleiner Rest des Septums (Sept) erhalten geblieben, welcher zeigt, wie sehr der linke Abschnitt des Herzbeutels im Vergleich zum rechten reducirt ist. Dorsal und links von der Niere ist die Wand des Herzbeutels verdickt und bildet einen kleinen Wulst, welcher das Oralende der Herzeinstiulpung ist. Von dem folgenden Schnitt ist nur ein kleiner Theil dargestellt, und zwar die Gegend der Niere und der Herzanlage. Die Wand der Niere ist ganz flach getroffen, so dass kein Lumen mehr vorhanden ist, die Herzanlage ebenfalls, aber man kann doch erkennen, dass dieselbe keine einfache Verdickung der Herzbeutelwand, sondern eine Einstülpung derselben ist. Deutlicher lässt sich die Bildungsweise des Herzens an einem etwas älteren Stadium erkennen, dessen beschaltes Hinterende, von der rechten Seite gesehen, in Fig. 7 auf Taf. XXI dargestellt ist. An diesem Präparat kann man die Mantelhöhle in ihrer ganzen Ausdehnung: iibersehen, da sie ja zum größten Theil auf der rechten Seite liegt. Der dorsale Theil, welcher sich nach links erstreckt, führt durch den Nierenausführgang in die Niere $(N)$, welche hier an dem ganzen Präparat deutlich gesehen werden kann. Die dorsale Wand der Mantelhöhle zeigt einige kleine ektodermale Höcker $(\boldsymbol{K} i)$, welche die Anlage der Kiemenblättchen sind. Dicht hinter der Niere und unter, d. h. rechts von dem Enddarm $E$ liegt der Herzbeutel, welcher verhältnismäßig viel kleiner ist, da jetzt der Eingeweidesack immer mehr an Volum zunimmt. An der dorsalen Wand des Perikards liegt das Herz $(H)$, welches die Gestalt einer Rinne hat, die die ganze Länge des Herzbeutels einnimmt und in der Mitte etwas eingeschnürt ist. Untersucht man nun ein gefärbtes und aufgehelltes Präparat dieses Stadiums nach der in der Einleitung beschriebenen Methode, d. h. indem man dasselbe wendet und von verschiedenen Seiten betrachtet, so kann man ïber die Art der Herzbildung ins Klare kommen.

Die Herzanlage des eben kurz besprochenen Stadiums ist in Fig. 5 (Taf. XXI) bei stärkerer Vergrößerung und von der linken Seite abgebildet, da von jetzt ab Perikard und Herz mehr und mehr auf die linke Körperhälfte hiniiberriicken und dem entsprechend in seitlicher Ansicht am besten von links beim ganzen Embryo beobachtet werden können. Man erkennt, dass die ganze dorsale Wand 
des Herzbeutels zu einer langen Rinne eingestülpt ist, welche sich schon sehr frühzeitig in der Mitte etwas einschniirt. Betrachtet man die Herzanlage von oben, $d$. $h$. indem man auf die dorsale Wand des beschalten Hinterendes sieht (Taf. XXI Fig. 6), so bemerkt man, dass dieselbe nicht ganz gerade sich erstreckt, sondern etwas gekrümmt ist. Stellt man sich einen optischen Querschnitt durch die Herzanlage her, indem man auf die Hinterfläche der Schale blickt, so kann man sich auf das deutlichste davon überzeugen, dass man es hier mit einer rinnenförmigen Einstülpung der dorsalen Herzbeutelwand $\mathrm{zu}$ thun hat. Dasselbe zeigen auch Schnitte, welche die Herzanlage quer getroffen haben. Diese sind aber schwer herzustellen, da die Längsachse der Herzanlage nicht mit derjenigen des Embryo zusammenfällt. Man ist daher einigermaßen auf den Zufall angewiesen. Ich habe jedoch eine so große Anzahl ron Schnittserien durch das betreffende Stadium geftihrt, dass ich unter diesen zahlreiche Belege für die oben entwickelte Ansicht gefunden habe, zu welcher ich auch zuerst durch die auf Schnitten zu konstatirenden Befunde gelangt bin. Es ist viel leichter durch Beobachtung der Herzanlage in toto und zwar von verschiedenen Seiten $\mathrm{zu}$ einer Vorstellung von der allgemeinen Gestaltung derselben zu kommen, wesshalb ich auch derartige Ansichten abgebildet habe.

Fig. 10 (Taf. XXI), welche aus einer Serie von horizontalen Schnitten, nach der Art der Fig. 8 und 11 dargestellt ist, soll einen Überblick ïber die gegenseitigen Lagerungsverhältnisse von Herzbeutel, Herz und Niere geben. Der größeren Deutlichkeit halber sind die obersten Schnitte bei der Rekonstruktion weggelassen worden, man sieht an die dorsale Fläche des Hinterendes. Der Herzbeutel liegt zwischen Magen und Kiemenhöhle iiber der Leber und dem Darm, welcher ihn in einem Bogen umziebt, um rorn und rechts an der Decke der Mantelhöhle in derselben auszumïnden. Links, dicht neben der Niere, welche ganz hinten durch ibren Ausfiihrgang $\left(\mathrm{N}^{\top} a\right)$ mit der Nantelböhle im Zusammenhang steht. liegt das Herz $(\boldsymbol{H})$.

Die weitere Ausbildung des Herzens vollzieht sich nun in der Weise, dass die Rinne sich allmählich zu einer Röhre abschließt und gleichzeitig sich mehr und mehr ron der Herzbentelwand abschniirt, bis sie mit derselben nur noch rorn und hinten in Zusammenhang bleibt. Dem entsprechend steht auch rorn und hinten die Herzanlage mit der sekundären Leibeshöble in Kommunikation.

Während diese Vorgänge sich abspielen, rollzieht sich auch die 
Scheidung des Herzens in einen Vorhof und eine Kammer, was schon durch die mittlere Einschniirung der Herzanlage angebahnt war. Dieses Stadium ist in Fig. 1 Taf. XXII abgebildet. Der Embryo hat bereits die Gestalt der erwachsenen Schnecke und ist desshalb in der Lage gezeichnet, welche das ausgebildete Thier beim Kriechen einnimmt. Der Fuß ist ganz deutlich zu einer Kriechsohle abgeplattet und zeigt hinten an seiner dorsalen Fläche die Anlage des Deckels, welcher, beiläufig' gesagt, ganz auf dieselbe Weise als die Schale durch eine der Schalendrüse entsprechende Einstülpung des Ektoderms abgesondert wird. Der Ösophagus $(S)$ ist sehr lang und schmal geworden. Gleich hinter der Mundöffnung, welche einen chitinösen Rand hat, liegt die Radulatasche $(R)$, die, wie der Vergleich mit jüngeren Stadien ergiebt, sich als eine Ausstiilpung der Schlundwand anlegt. Das Velum $\left(I^{\top}\right)$ ist noch deutlich zu sehen, sein Feld ist aber sehr klein geworden, da es nur noch die dorsale Fläche der Kopfregion einnimmt und dicht hinter den Fühlern umbiegt. Da der Embryo ron der linken Seite gezeichnet ist, kann man nur einen kleinen Theil der Kiemenhöhle iibersehen, in welcher sich bereits eine größere Anzahl von Kiemenhöckern (Kï) zeigen. Der Herzbeutel, welcher an die hintere Grenze der Kiemenhöhle anstößt, trägt an seiner dorsalen Wand das Herz, dessen vordere Häifte dem Vorhof und dessen hintere Hälfte der Kammer entspricht.

Das Hel\% dieses Stadiums zeigt Fig. 15 (Taf. XXI) bei stärkerer Vergrößerung und von hinten gesehen. Die Rinne hat sich zu einer Röhre abgeschniurt, da man jetzt die obere Wand des Herzbeutels von derjenigen des Herzens vollkommen isolirt sieht, so dass dasselbe nur noch an beiden Enden mit der Perikardwand in Zusammenhang bleibt. Die Öffnung des diinnwandigeren Vorhofs entspricht dem Anfang der Kiemenvene, diejenige der Kammer dem Anfang: der Aorta. Das Herz tritt nun in Zusammenhang mit den Gefäßen, welche als Sinuse im Mesoderm entstehen, zuerst sehr weit sind, später immer enger werden.

Fig. 12 Taf. XXI ist das rekonstruirte Hinterende eines etwas älteren Stadiums, welches die Entwicklung des Eingeweidesackes veranschaulicht. Magen und Leber bilden einen großen Sack, welcher links und ventral liegt. Der Herzbeutel nimmt einen viel kleineren Raum ein als in Fig. 11. Die Niere liegt jetzt ziemlich in der Mittelebene, während das Herz nach links heriiber geriickt ist. Man bemerkt ferner, dass der Nierenausfiuhrgang $(\mathrm{N} a)$ sich immer schärfer von der eigentlichen Mantelhöhle absetzt. 
Dies tritt auf einem folgenden Stadium, welches von der linken Seite gesehen ist (Taf. XXII Fig. 2) noch deutlicher hervor. Der Nierenausführgang, über welchen der Enddarm wegzieht, wächst allmählich in die Länge aus und wird durch einen Wulst (wu) von dem oberen Theil der Kiemenhöhle getrennt; er mündet rechts und ganz unten durch eine sich mehr und mehr verengernde Öffnung in die Mantelhöhle. In letzterer selbst hat sich links neben dem Kiemenwulst eine Hervorwölbung des Ektoderms $(S p)$ gebildet, welche die Anlage der sogenannten falschen Kieme oder des Spexael'schen Geruchsorgans vorstellt.

Das Herz wird in der Ansicht von rechts von den dartibergelagerten Organen verdeckt, wesshalb die Topographie des betreffenden Stadiums in Fig. 13 Taf. XXI im Querschnitt abgebildet wurde. Die Drehung des Hinterendes und das Auswachsen des Eingerveidesackes sind noch weiter vorgeschritten. Letzterer liegt jetzt ganz rentral, während der Herzbeutel, der friiher am besten von der rechten Seite zu sehen war, wie schon erwähnt wurde, jetzt auf die linke Seite gerückt ist. Das Herz hat natiurlich dieselbe Wanderung mitgemacht und ist ebenfalls ganz nach links geriickt. Die Kiemenhöhle hat bei der Drehung des Hinterendes gleichfalls ihre Gestalt verändert, sie wächst allmählich tiefer und tiefer auf der linken Seite, ungefähr bis zum Niveau des Vorhofs herab.

Nun beginnt auch die Niere sich bedeutend zu vergrößern, wobei ihr Zusammenhang mit dem Herzbentel undeutlicher wird; gleichzeitig nähern sich die Muindung des Perikards in die Niere und die Ausmiindung der Niere in den Ureter, so dass erstere auf Querschnitten schwerer wahrzunehmen ist. Eine Rekonstruktion der Niere dieses Stadiums aus einer sagittalen Schnittserie ist in Fig. 3 auf Taf. XXII gegeben. Die Zellen der Nierenwand nehmen in demselben Maß, wie die Niere sich vergrößert, an Höhe ab und bilden jetzt ein nahezu kubisches Epithel. Sie sind sehr regelmäßig ang'eordnet, zeigen einen deutlichen Kern und ein feinwabiges Protoplasma, in welchem keine Exkretkörnchen zu bemerken sind. An der Mündung in den Herzbentel werden die Nierenzellen niedriger und gehen einfach in die flachen Zellen der Perikardwand ïber.

Das älteste in dieser Arbeit beriicksichtigte Stadium wurde auf Taf. XXII Fig. 5 abgebildet: es entspricht demjenigen, welches Lexdic (1) als reifen Embryo beschreibt und zeichnet sich dadurch aus, dass der rechte Mantelrand vier stumpfe Fortsätze entwickelt hat und die Schale lange, steife Haare, oder besser gesagt, Borsten 
trägt. Dieses Stadium hat im Wesentlichen denselben Bau wie das ausgewachsene Thier, abgesehen von dem der Geschlechtsorgane, welche sich gerade anlegen und der Anzahl der Windungen des Eingeweidesackes, dessen Einrollung ganz unabhängig von der Torsion des Hinterendes erfolgt; bekanntlich wird aber der Embryo erst, nachdem er die drei- bis vierfache Größe dieses Stadiums erreicht hat, geboren.

Die Figur 5 ist halbschematisch, nach einem gefärbten und aufgehellten Präparat eines ganzen Embryo und je einer queren und sagittalen Schnittserie entworfen. Das Velum ist bereits bis auf Spuren, welche auf Schnitten zu sehen sind, zurïckgebildet. Die Leber, welche beim erwachsenen Thier dreilappig ist, hat bereits die charakteristischen Drüsenschläuche gebildet, ist aber nicht eingetragen worden, um die Abbildung nicht zu kompliciren. Sie ist jetzt mit dem Eingeweidesack ganz auf die rechte Seite des Thieres gerückt.

Der Darm $(E)$ bildet gleich hinter dem Magen eine Schlinge, steigt, dem hinteren Umriss der Schale folgend, im Bogen empor und mündet rechtsseitig und an der rechten Wand der Mantelhöhle tief in derselben. Diese Verlagerung des Afters, welcher bis zum vorhergehenden Stadium (Taf. XXII Fig. 2) am vorderen Rande der Mantelhöhle gelegen war, zeigt, dass die Mantelhöhle sich jetzt wirklich etwas vertieft hat, während sie vorher nur durch Auswachsen der Mantelfalte nach vorn sich entwickelte.

Die Mantelhöhle (Taf. XXII Fig. 5) zieht von rechts unten nach links oben herüber und steigt im Bogen auf der linken Seite herab, um linksseitig an den Herzbeutel anzustoßen, wo sie in der Nähe des Vorhofs, welcher durch die Kiemenvene an das innere Ende der Kieme befestigt ist, endet. Denselben Verlauf nimmt die Kieme an der Decke der Kiemenhöhle, und hat bereits eine große Anzahl von Kiemenblättchen entwickelt. Das SPEngel'sche Organ oder die sogenannte Nebenkieme erscheint als breiter Wulst $(S p)$ an der Decke der Mantelhöhle links und ventral von der Kieme und erstreckt sich, wie man an Schnittserien sieht, nach hinten allmählich flacher werdend, fast eben so weit wie die Kieme, deren hinteres Ende zugespitzt bis an den Vorhof reicht, in welchen ja die Kiemenvene einmïndet. Von der hinteren Wand der Kiemenhöhle entspringt ein durch Ausstülpung aus ihr entstandener, also ektodermaler Gang, welcher die Anlage des Geschlechtsleiters ist und an welchen sich ein driisiger, ventralwärts gerichteter Anhang (gd) 
anschließt, welcher hart an der Leber endigt. Dieser Anhang entsteht, unabhängig von dem Gang, aus dem Mesoderm der Herzbeutelwand und ịst die Anlage der Keimdrüse. Die Niere liegt an der hinteren Schalenwand, dorsal über der Leber und mündet durch den langen Ureter $(N a)$, welcher parallel dicht unter dem Enddarm und etwas links davon verläuft, gerade hinter dem After in die Mantelhöhle. Die Ausmündung des Ureters hat sich jetzt sehr verengert.

Den histologischen Bau der Niere dieses Stadiums veranschaulicht Fig. 4 (Taf. XXIII). Diese Abbildung ist nach einer sagittalen Schnittserie konstruirt, entspricht dem optischen Längsschnitt und zeigt die sehr enge Einmündung in den Herzbeutel, welcher auf einer Art von Papille liegt. Die Nierenwand hat nun in Folge stärkeren Wachsthums ihrer inneren Oberfläche Falten gebildet, welche von einem kubischen Epithel bekleidet sind und in die Höhle hineinragen. In die Falten selbst dringen von außen Bindegewebszellen ein. Die Räume zwischen den Falten erscheinen entsprechend als Ausbuchtungen des Hohlraumes der Niere und zeigen einen rundlichen Querschnitt, sie verleihen der Niere dieses Stadiums das Aussehen einer tubulösen Drüse.

Einen ganz ähnlichen Bau zeigt die Niere von Haliotis, welche die einfachste Form der Prosobranchierniere darstellt und von HALLER (30) als eine acinöse Driise beschrieben wurde. Perrier (37) verwirft diese Auffassung und zeigt, dass die Gasteropodenniere durchweg keinen tubulösen oder acinösen Bau besitzt, sondern dass ihr Hohlraum von zahlreichen mit einander anastomosirenden Lamellen durchsetzt wird, welche nichts Anderes als Falten der Wand des Nierensackes sind. Diese Ansicht, zu welcher Perrier auf Grund vergleichend-anatomischer Studien an zahlreichen Prosobranchier- und Gasteropodenarten gelangte, wird durch die Entwicklungsgeschichte von Paludina bestätigt. Die Nierenhöhle ist bekanntlich bei der ausgewachsenen Paludina fast vollständig durch die lamellösen Einfaltungen der Nierenwand ausgefüllt, wodurch das ganze Organ ein spongiöses Gefüge erhält. Dies kommt durch starke Vermehrung und Vergrößerung der zuerst in geringer Anzahl vorhandenen Falten zu Stande. Die relativ hoch differenzirte Niere von Paludina zeigt demnach im Laufe der Entwicklung ein Stadium, welches der sehr einfachen Niere von Haliotis entspricht.

Beim ausgewachsenen Thier nimmt der Ureter aus einer Art Urinkammer, in welche auch der Verbindungskanal der Niere mit 
dem Herzbeutel miindet, seinen Ursprung (WolfF ${ }^{1}$ und Perrier [37]). Diese Kammer ist auf einem wenig älteren Stadium, als das letzte in dieser Arbeit abgebildete, zu erkennen, und entspricht einem Theil des ursprünglichen Hohlraumes des Nierensackes, welcher durch die Einfaltungen nicht verdrängt wird. Auf diesem Stadium besitzt auch der Nierenherzbeutelgang seine definitive Gestaltung, bildet einen kurzen, sehr engen Kanal, lässt sich aber an ganzen gefärbten und aufgehellten Embryonen erkennen.

Kehren wir nun zu Fig. 5 (Taf. XXII) zuriick. Der Herzbeutel $(P)$ liegt, wie erwähnt, nun ganz auf der linken Seite und dorsal iiber der Schlinge, welche vom Enddarm gebildet wird. Wie beim erwachsenen Thier nimmt er einen verhältnismäßig großen Raum im beschalten Theile ein, wenigstens in der Portion des Schaleninhaltes, welche nicht vom eigentlichen Eingeweidesack in Anspruch genommen wird. Seine Gestalt wird, wie beim erwachsenen Thier, eine sehr unregelmäßig'e, indem er sich zwischen alle anliegenden Organe hineindrängt. Dieser Umstand verleitete die ersten Untersucher der Paludina zu der Behauptung, dass diese Schnecke iiberhaupt keinen Herzbeutel besitze.

Fig. 5 auf Taf. XXIII zeigt einen Querschnitt durch den Herzbeutel des eben besprochenen Stadiums. Die Wand des Herzbeutels, welche jetzt zu eimem ganz diunnen Häutchen geworden ist, besteht aus sehr abgeplatteten Zellen, an welchen der Kern eine Hervorwölbung bildet. Das Perikard wird direkt vom Bindegewebe umgeben, dessen verästelte Spindelzellen es an die anliegenden Organe befestigen. Der Schnitt ist gerade durch die Stelle geführt, wo der Vorhof $(V)$ in die Kiemenvene $(K v)$ übergeht. Demgemäß stößt die ventrale Wand der Mantelhöhle $(\boldsymbol{M} h)$ hier an den Herzbeutel an. Man sieht zwei Kiemenblättchen (Ki) auf einem Durchschnitt, welcher zeigt, dass dieselben als hohle Hervorstiulpungen der Kiemenhöhlenwand entstehen, in welche Bindegewebszellen einwandern; aus letzteren geht auch das innere Septum der einzelnen Kiemenblättchen hervor. Die Wand des Vorhofs ist ziemlich verdickt, was, wie ich glaube, darauf beruht, dass die von Perrier neuerdings genau beschriebene Vorhofsdruise (glande de l'oreillette) im Entstehen begriffen ist. Dorsal von dem Herzbeutel liegt die noch ziemlich weite Aorta $(A o)$. Ein anderer Schnitt derselben Serie (Taf. XXIII Fig. 5 a)

1 G. Wolff, Einiges iiber die Niere einheimischer Prosobranchiaten. Zool. Anzeiger. X. 1887. 
zeigt die etwas flach getroffene Herzkammer ganz in der Nähe der Stelle, wo dieselbe in die Aorta $(A o)$ fuihrt. Die äußere Wand der Kammer (wie anch des Vorhofs; wird ron den großen hellen Zellen gebildet, welche. schon von LErDig (1) beschrieben worden sind, darunter folgt die Muskelschicht, deren Fasern im Schnitt längs getroffen sind. Dieselben anastomosiren vielfach mit einander und durchsetzen den Hohlraum der Kammer in Gestalt ron Bälkchen.

Vorhof und Kammer (Taf. XXIII Fig. 5 sind sehr scharf ron einander abgesetzt und hängen nur durch einen sehr engen Kanal mit einander zusammen.

Paludina besitzt eine Uruiere wie die ibrigen Gasteropoden. Während dieselbe bei manchen Formen eine äußere ist und in Gestalt einiger großen, bläschenförmigen Zellen des Ektoderms. deren Protoplasma eingelagerte Exkretkörner enthält. erscheint. wie zum Beispiel bei Bythynia, hat Paludina ein Paar innere Urnieren, welche rechts und links hinten und rentralwärts rom Velum gelegen sind Taf. XXI Fig. 2 und 3 U).

Die erste Anlage der Uniere findet sich auf dem Stadium, wo Mund und Ösophagus durch Einstiilpung des Ektoderms entstehen, zu beiden Seiten des Embryo dicht hinter dem Rande des Velar feldes (Taf. XXIII Fig. 9), und stellt einen kompakten Haufen von Mesodermzellen ror $\left(C^{\top}\right)$, welcher ron unregelmäßig gelagerten Spindelzellen umgeben wird. Bald bildet sich darin ein Lumen aus (Taf. XXIII Fig. 10), und gleichzeitig nähert sich die Uruierenanlage der Oberfläche, so dass sie schließlich an das Ektoderm anstößt. Die Urniere erscheint nun, ron außen gesehen (etwa auf dem in Fig. 1 Taf. XXI abgebildeten Stadium), als ein ziemlich dickwandiges, allseitig abgeschlossenes Säckchen. Jetzt durchbricht das distale Ende der Urnierenanlage das Ektoderm und ragt als ein unregelmäßiger Zellhaufen $(U)$ etwas iiber die Oberfläche des Embryo herror (Taf. XXIII Fig. 6). Die Zellen der Urniere unterscheiden sich bereits dentlich ron den anliegenden Zellen des Mesoderms sowohl als auch des Ektoderms durch ihre Größe und hellere Färbung. Letztere Eigenthimlichkeit scheint darauf zu berthen, dass die Urnierenzellen ron nun ab eine viel geringere Affinität zu Farbstoffen haben als alle anderen embryonalen Zellen, abgesehen ron denen des Velums. Dieser Umstand ermöglicht es, die Urniere auf Schnitten ziemlich rasch aufzufinden.

Nun streckt sie sich etwas in die Länge, wird röhrenförmig und 
erhält 'eine Ausmündung nach außen (Taf. XXIII Fig. 8). Fig. 2 auf Taf. XXI entspricht dem eben geschilderten Stadium und zeigt die Urniere $(U)$ in situ. Die Ausmündung ist schon am ganzen Embryo deutlich zu sehen, an sie schließt sich ein röhrenförmiger, allmählich enger werdender Abschnitt, welcher sich hinten in ein Büschel von Spindelzellen auflöst, die gewissermaßen als Aufhängezellen der Urniere fungiren. Fig. 7, 8 und 11 auf Taf. XXIII sind Querschnitte durch den eben beschriebenen Embryo. Auf Fig. 8 ist die ziemlich enge Ausmiindung $(O e)$ getroffen. Man bemerkt, dass die Zellen, welche die Urniere bilden, noch immer etwas ïber die Oberfläche des Ektoderms hervorragen und sich durch Größe, Färbung und Beschaffenheit ihrer Kerne deutlich von den unmittelbar anliegenden Ektodermzellen unterscheiden, in welche sie nicht allmählich iibergehen, wie es der Fall sein müsste, wenn die Ausmündung durch Einstiilpung des Ektoderms erfolgt wäre. Der auf Fig. 11 abgebildete Schnitt wurde etwas schräg durch den röhrigen Theil gefuihrt. Endlich zeigt Fig. 7 einen Längsschnitt durch das innere Ende der Urniere und seine Umgebung. Die Endzellen tragen Wimpern, welche in das Lumen hineinragen und beim lebenden Embryo eine Flimmerung hervorrufen, die schon Bürschl beobachtete. Ich bin mir nicht ganz klar dartiber geworden, ob die Wimpern von einer oder von mehreren der ziemlich ansehnlichen Endzellen des Urnierenganges ausgehen, halte aber letztere für das Wahrscheinlichere. Weiter sind die Aufhängezellen auf dem Schnitt sehr deutlich zu sehen; sie befestigen das innere Ende der Urniere.

Im Laufe der Entwicklung streckt sich die Urniere noch etwas in die Länge, ohne aber im Wesentlichen ihren Bau zu ändern, und erreicht bei dem in Taf. XXII Fig. 1 abgebildeten Embryo den höchsten Grad ihrer Ausbildung. Sie erstreckt sich hier, von vorn nach hinten verlaufend, von der binteren Grenze des Velarfeldes bis zur Mantelrinne, in welche sich die zum größten Theil auf der rechten Körperhälfte befindliche Mantelhöhle fortsetzt, um hier nach außen auszumiinden. Auf diesem Stadium schien mir, bei Untersuchung des lebenden Embryo, als ob ich eine innere Öffnung der Urniere in die Leibeshöhle erkennen könnte; da ich dieselbe jedoch auf Schnitten nicht nachzuweisen vermochte, kann ich ihr Vorhandensein nicht mit voller Sicherheit behaupten und damit eine größere Übereinstimmung im Bau der Urniere von Paludina und derjenigen der Pulmonaten beweisen. Existirt wirklich keine innere Ausmiindung, so ließe sich die Urniere von Paludina am besten mit den Exkre- 
tionsorganen der Plathelminthen vergleichen. Doch wäre denkbar, dass diese Abweichung nur die Folge einer gewissen Rückbildung sein könnte. Es ist mir übrigens niemals gelungen, irgend welche Konkremente oder Exkretkörner in den Urnierenzellen zu konstatiren.

Die Ansichten fritherer Beobachter iber die eben besprochenen Punkte der Gasteropodenentwicklung gehen zwar vielfach ans einander, dennoch zeigen die letzten Arbeiten eine gewisse Übereinstimmung, welche mit den von mir gewonnenen Resultaten harmonirt. Dies bezieht sich namentlich auf die Bildung des Herzbeutels, der Niere und des Herzens.

Was zunächst Paludina anbelangt, so ist diese Art in Bezug auf die Entwicklung des Herzens und der Gefäße mit einer größeren Anzahl von anderen Formen von Ganis (3) untersucht worden. Derselbe lässt das Herz als eine Verdickung der riickenständigen Herzbeutelwand entstehen. In der Mitte des soliden Herzwulstes bilde sich eine Einschnitrung, die das Herz in Atrium und Ventrikel scheidet; aus den Theilen des primären Herzens, welche in Verbindung mit dem Perikard bleiben, entwickle sich ein kleiner Theil der Aorta und der Kiemenvene, der größere Theil der Blutgefäße entstehe ganz unabhängig vom Herzwulst. Während diese Beobachtungen im Allgemeinen mit den in meiner Untersuchung mitgetheilten uibereinstimmen, giebt GANIN an, dass die Niere aus dem Ektoderm sich bildet.

Bürschli (10), welcher speciell Paludina untersuchte, sah das Perikard vor dem Herzen entstehen und beschreibt dasselbe als einen großen Sack, welcher auf der linken Seite des Darmes zwischen Magen, Leber und der Leibeswand liegt. Er vermuthet, dass der Herzbeutel mesodermalen Ursprunges ist. Das Perikard verkleinert sich zu einem birnförmigen Bentel, welcher etwa die Größe des Magens hat und auf der linken Seite liegt, mittlerweile hat sich das eigentliche Herz ausgebildet. Es ist ihm nicht gelungen, den Ursprung des Herzens zu ermitteln, er glaubt aber, annehmen zu diurfen, dass es sich als eine Einfaltung des reducirten Herzbeutels anlegt. Weiter lässt er die Niere als eine schlanchartige Einstiilpung der Mantelhöhle entstehen, und unterscheidet daran einen vorderen ausführenden und einen hinteren secernirenden Abschnitt, welcher mit dem Herzbeutel in Kommunikation steht. Er erkennt die Urniere als solche, beschreibt die Flimmerung in ihrem Inneren und vermuthet, dass sie eine äußere Öffnung besitzt, ist aber iiber 
ihren Ursprung nicht ins Klare gekommen. Meine Untersuchungen haben die in Bezug auf den Ursprung des Herzbentels und Herzens gemachten Vermuthungen Bürschlis bestätigt.

SALEnsky (2) lässt Niere und Herz bei Calyptraea sinensis aus einer gemeinsamen Anlage, welche in neiner Höhlung im Inneren der Mantelfalte sich befindet", entstehen, und schreibt der rechts gelegenen Niere sowie dem Herzen einen mesodermalen Ursprung zu. Die gemeinsame Anlage des Herzens und der Niere erklärt er daraus, dass von allen Theilen des Herzens zuerst das Perikard sich bildet.

For ist bei den Pteropoden ( $\bar{i}$ ) zu Ansichten gelangt, welche den bis jetzt mitgetheilten widersprechen. Er behauptet nämlich, dass das Her'z zeitlich vor dem Perikard, und zwar aus einer soliden Anhäufung von Mesodermzellen entstehe. Die unvollständige Umhüllungsmembran des Herzens, d. h. das Perikard (er stellt nämlich die Existenz eines wirklichen abgeschlossenen Perikards in Abrede), soll sich durch Verdichtung des anliegenden Gewebes bilden, tritt dann mit der Niere in Verbindung, welche ron der ektodermalen Mantelhöhleneinstülpung, aus der sie entstanden ist, sich ablöst. Bei den Pulmonaten (13) dagegen findet er einen Herzbeutel. welcher aber erst nach der Bildung des Herzens aus dem Mesoderm entsteht und wur nach und nach das Aussehen einer kontinuirlichen Membran erhält. Das Herz bildet sich als eine einfache Differenzirung des Mesoderms. Die ektodermale Nierenanlage tritt mit dem Herzbeutel in Verbindung. $\mathrm{Er}$ beschreibt weiter eine innere Urniere und einige große gelbe Ektodermzellen, welche iiber dem Velun eine Reihe bilden und wohl mit dem larvalen Exkretionsorgan in einer gervissen Beziehung stehen diirften. In dieser Arbeit befindet sich eine Bemerkung iiber den Herzbentel der Paludina. Fou bestreitet nämlich, dass der von BüTschl beschriebene Sack das Perikard vorstelle, jedoch unterlässt er, seine eigene Ansicht darüber mitzutheilen.

Bobretzky (11) sieht bei Nassa mutabilis das Herz am Grunde der Kiemenhöhle als eine kompakte Anhäufung von Mesodermzellen, in welcher sich eine Höhle bildet, entstehen. Die Urnierenanlage ist ektodermal, eben so auch diejenige der bleibenden Niere, welche sich ron der Wand der Kiemeuhöhle abschniirt.

Da RABL in der Entwicklungsgeschichte von Planorbis 12 hinsichtlich vieler Punkte Ansichten vertritt, welche den von ihm in seiner Ontogenie der S ï ßwasserpulmonaten (5) friiher entwickelten 
entgegengesetzt sind, so soll nur die spätere Arbeit hier berücksichtigt werden. Bei Planorbis ist die Nierenanlage mesodermal und tritt erst nachträglich mit dem Ektoderm in Verbindung, indem sie als ein langgestreckter Schlauch links vom Enddarm ausmündet, sie hängt an ihrem inneren Ende mit dem Herzbeutel zusammen. Aus der Darstellung RABL's geht mit Sicherheit hervor, dass er auch den ausführenden Theil der Niere vom Mesoderm ableitet. Ursprung und Bildung des Herzbeutels und Herzens sind nicht festgestellt worden, jedoch soll das Herz aus dem Mesoderm stammen.

In dem Auszug der Wolfsohs'schen Arbeit iiber Lymnaeus ist nichts von den in Bezug auf Herz und Niere gewonnenen Resultaten mitgetheilt.

Joyeux Laffuie (21) findet bei Onchidium die erste Anlage der Niere rechts, und diese soll auftreten, ehe noch etwas vom Herzen zu sehen ist. Sie entsteht als eine ektodermale Einstiilpung des Mantelrandes und tritt mit dem Perikard in Zusammenhang; jedoch erhält sich die Kommunikation nur kurze Zeit und existirt beim erwachsenen Thiere nicht mehr ${ }^{1}$. Das Herz legt sich ebenfalls rechts an und ist von Joyeux LAFFuie erst dann gesehen worden, wie es schon eine Trennung in Vorhof und Kammer zeigte. Das Perikard entsteht nach ihm erst nach dem Herzen, doch ist seine Anschauung über die Bildungsweise eine so eigenthümliche, dass ich es vorziehe, dieselbe wörtlich wiederzugeben. "Dans les premiers moments de leur apparition les deux résicules qui vont former le coeur en essayant pour ainsi dire de se contracter ne montrent pas la limite de leurs parois; leur cavité seule est visible; mais en même temps que les contractions deviennent mieux caractérisées, les parois se montrent avec plus de netteté, se séparent des sinus environnants et ainsi se forme la cavité péricardique dans laquelle ou voit nettement l'oreillette et le rentricule animés de contractions brusques."

Nach Sarasin (18) entsteht bei Bythynia das Perikard als Hohlraum im Mesoderm, und das Herz als eine Wucherung der Herzbeutelwand. Die Niere bildet sich rechts als eine ektodermale Verdickung und kommt nach der Torsion links zu liegen.

Bei Vermetus entsteht nach SALexsky (26) der Herzbeutel,

${ }_{1}$ Die Richtigkeit dieser Angabe ist von verschiedenen Seiten bezweifelt worden. R. BERGH hat in einer Arbeit "Über die Verwandtschaftsbeziehungen der Onchidien «. Morph. Jahrb. Bd. X. 1885 den Zusammenhang zwischen Perikard und Niere bei Onchidium tumidum nachgewiesen. 
welcher dem Cölom entspricht, durch Auseinanderweichen der Zellen des perikardialen Mesoderms. Das Herz bildet sich darin als eine Verdickung des splanchnischen Mesoblasts, faltet sich allmählich von diesem $a b$ und schniirt sich in der Mitte ein, wodurch es in einen Vorhof und eine Kammer zerfällt. Die Niere tritt relativ spät auf. und zwår ganz in der Nähe des Herzbeutels, entsteht aus dem Mesoderm und vereinigt sich bald mit einer Einstiilpung der Mantelhöhle, welche zu ihrem Ausführgang wird.

Schalfeew (33) ist, in Bezug auf die Bildung der Niere bei Limax agrestis, zu beinahe denselben Resultaten gelangt wie ich für Paludina. Der Herzbeutel ist bei Limax zuerst ein kompakter Haufen von Mesodermzellen, in welchem später durch Delamination eine Höhlung entsteht. Diese entspricht dem Cölom und wird von einer ein Mesenterium darstellenden Falte in zwei Abschnitte zerlegt, ron denen der rechte zur Niere wird. Der Ausfiihrgang der Niere bildet sich als eine ektodermale Einstiilpung, das Herz als eine Verdickung der »unteren " Perikardwand, höhlt sich aus und bleibt mit dem Herzbeutel an seinem vorderen und hinteren Ende in Zusammenhang.

Ich glaube, dass eine Kritik der eben im Auszug mitgetheilten Untersuchungen iiber die Entwicklung der Gasteropoden, im Wesentlichen die von mir bei Paludina gemachten Beobachtungen bestätigt und zu einigen allgemeineren Schliissen berechtigt. Der Herzbeutel, welcher aus dem mittleren Keimblatt entsteht, repräsentirt zweifellos das bei den Mollusken mehr oder weniger reducirte Cölom. Es bildet sich ja principiell durch Auseinanderweichen des splanchnischen und des somatischen Blattes des Mesoderms, wenn auch der urspriingliche Vorgang gewöhnlich etwas verwischt wird. Auch hat schon die vergleichende Anatomie zu demselben Schluss gefiihrt, da ja die Durchbohrung des Perikards durch den Enddarm, eine Erscheinung, welche bekanntlich bei vielen Formen beobachtet wurde, sich nur durch die Annahme erklären lässt, dass das Perikard der sekundären Leibeshöhle entspricht.

Es ist mir bei Paludina nicht gegliickt, den unmittelbaren Übergang des Cöloms in das Perikard nachzuweisen, weil ja die ganze sekundäre Leibeshöhle sehr früh von den Spindelzellen des Mesoderms vollkommen unregelmäßig durchsetzt wird, jedoch bildet sich die Anlage des Herzbeutels zwischen den zwei Mesodermschichten, von denen die eine die Innenfläche des Ektoderms, die andere die äußere Fläche des Darmes bekleidet. 
Es frägt sich daher, ob der Herzbeutel der ganzen sekundären Leibeshöhle, welche dann bedeutend reducirt wäre, oder nur einem Theile derselben entspricht, so dass dann der Rest des Cöloms mit der primären Leibeshöhle oder Furchungshöhle zusammenfallen würde. Ich neige nun zu der zweiten Ansicht und glaube, dass das Cölom nur theilweise als solches im Herzbeutel persistirt, während der weitaus größere Theil desselben durch die ihn durchwachsenden Spindelzellen undeutlich gemacht wird und daher sich mit der primären Leibeshöhle deckt. Die in dieser Arbeit beschriebene Entwicklung des Cöloms der Paludina scheint mir diesen Schluss zu rechtfertigen und meine, ïbrigens noch nicht abgeschlossenen Untersuchungen über die Bildungsweise der Gefäße bestärken mich in dieser Ansicht.

Weiter geht die Anlage des Herzens aus einer Einstülpung der Herzbeutelwand hervor, welche Einstillpung zuerst die Gestalt einer Rinne, dann einer nur an beiden Enden mit dem Perikard zusammenhängenden Röhre besitzt.

Nach Salensky (26) entsteht das Herz aus dem splanchnischen Blatt des Mesoderms, doch kann ich nicht dasselbe von Paludina behaupten, da hier meine Erfahrungen eher dagegen sprechen.

Was die Niere anbelangt, so bin ich der Ansicht, dass der secernirende Abschnitt derselben aus dem Mesoderm stammt und dass diejenigen Beobachter, welche ihn aus dem Ektoderm entstehen lassen, entweder nur den ausführenden Theil der Niere beriicksichtigt haben oder, was noch häufiger geschieht, die beiden Abschnitte nicht in ihrem Zusammenhang erkannten: Der ausführende Theil wird nämlich von Allen, mit Ausnahme von RABL, aus einem Theil der Mantelhöhle abgeleitet.

SCHALFEEw's Mittheilung und diese Arbeit erklären den Zusammenbang der Niere mit dem Herzbeutel auf ganz ungezwungene Weise.

Es wird jetzt allgemein angenommen, dass die Urform der Gasteropoden ein Paar von Nieren besessen haben muss, welche rechts und links rom Herzbeutel lagen, mit demselben in offener Verbindung standen und rechts und links vom After ausmündeten. Einige Prosobranchiaten entsprechen wirklich noch einigermaßen diesem Schema und sind ${ }^{1}$, da sie zwei Vorhöfe besitzen, unter dem Namen

1 E. Bouvier, Système nerveux, morphologie et classification des Gastéropodes Prosobranches. Thèse. Paris 1887. 
Diotocardier und Heterocardier zusammengefasst und den anderen Formen, welche nur einen Vorhof besitzen, oder den Monotocardiern, entgegengestellt worden. Zu den Diotocardiern gehören Fissurella, Haliotis, Trochus, und zu den Heterocardiern Patella. (Die Neritiden, welche ebenfalls zwei Vorböfe besitzen, von denen der linke bedeutend größer ist, haben nur eine Niere.) Die eben aufgezählten Formen haben im ausgebildeten Zustand zwei Nieren, von denen die rechte stets die größere ist und stets als Exkretionsorgan fungirt, während die linke bedeutend kleiner ist und nur noch bei Fissurella physiologisch als Niere thätig ist (Perrier 37). Daraus ist nun von v. Ihering, Béla Haller (30) und Perrier der Schluss gezogen worden, dass die einzige erhalten gebliebene Niere der Monotocardier der rechten Niere der Diotocardier entspreche.

Die entgegengesetzte Ansicht vertritt RAy LANKester ${ }^{1}$, welcher aus dem Umstand, dass bei zahlreichen Prosobranchiern, welche nur eine Niere besitzen, die Ansmïndung des Ureters sich gewöhnlich auf der linken Seite des Afters befindet, die Behauptung aufstellt, dass die Niere dieser Formen der linken kleineren Niere von Patella entspreche.

Perrier bestreitet die Richtigkeit der Hypothese des englischen Forschers, da seine (PERRIER's) Untersuchungen ergeben haben, dass die Lagerung der Miindung des Lreters in Bezug zum After bei den Monotocardiern eine sehr variable ist und seiner Ansicht nach diejenige Hypothese den Vorzug verdient, welche die größtmögliche Einheitlichkeit und Übereinstimmung im Bauplan der Prosobranchiaten begriundet.

Wie verhalten sich nun die der Entwicklungsgeschichte von Paludina entnommenen Daten zu der eben erörterten Streitfrage? Die Embryologie von Paludina zeigt auf das dentlichste, dass die beim erwachsenen Thier allein erhaltene Niere vor der Torsion die rechte war, nach der Torsion aber, $d . h$. bei der ausgebildeten Schnecke, links vom Enddarm liegt, wie auch die Ausmündung des Ureters links vom After sich befindet.

Dageg'en würde die rechte Niere eines erwachsenen Diotocardiers vor der Torsion, welche diese Formen wie alle Schnecken durch-

1 Ray Lankester, 1) On some undescribed points in the anatomy of the Limpet. Ann. Mag. Nat. Hist. 3 Series. XX. 1S67. 2) On the originally bilateral character of the renal organ of Prosobranchia, and on the homologies of the yolk-sac of Cephalopoda. Ann. of Nat. Hist. 5 Series. VII. 1851. 
machen, ursprünglich die linke gewesen sein. Da aber bei Paludina die ursprïnglich (vor der Torsion) linke Niere zurückgebildet wird, so ist es klar, dass die erhaltene Niere der linken Niere des erwachsenen Diotocardiers entsprechen muss. Also spricht die Embryologie ganz entschieden zu Gunsten der sonst ziemlich ohne ausreichende Stiitzen aufgestellten Hypothese Ray Lankester's. Der historische Überblick, den ich über die Litteratur der Entwicklungsgeschichte der Gasteropoden gegeben habe, zeigt, dass bei allen auf ihre Entwicklung untersuchten Formen, bei denen nur eine Niere erhalten ist, die Anlage derselben sich zuerst auf der rechten Körperhälfte befindet und erst mit der Torsion allmählich von rechts nach links wandert.

Wie steht es aber in vergleichend-anatomischer Hinsicht des Zusammenhanges der beiden Nieren der Diotocardier mit dem Herzbeutel?

Bei Fissurella (Perrier) mündet die rechte Niere in den Herzbentel, die linke nicht, bei Haliotis ist das Umgekehrte der Fall, die linke Niere (welche dem sogenannten Papillargang HaLLer's entspricht und nicht mit der rechten in Zusammenhang steht) mündet allein in den Herzbeutel, eben so verbält sich Trochus, während wieder bei Patella nach den nenesten Untersuchungen nur die rechte Niere in den Herzbeutel münden soll ${ }^{2}$. Daraus scheint mir die Kommunikation der Nieren mit dem Herzbentel, ein mindestens eben so wichtiger Punkt als die relative Größe der einen oder der anderen Niere, keineswegs eine vollkommene Übereinstimmung zu zeigen.

Ich glaube daher, dass in allen den Fällen, wo die Lagertungsbeziehungen der Niere und ihres Ausführganges in Bezug zum After am erwachsenen Thiere nicht festgestellt werden können, die Entwicklungsgeschichte allein den Ausschlag geben kann. Weiter wäre es nöthig, die Entwicklung eines Diotocardiers auf das Schicksal beider Nieren zu untersuchen, um daraus einen Schluss auf die Verhältnisse bei den Monotocardiern machen zu können. PAtren's (27) Untersuchung iiber die Embryologie von Patella erstreckt sich nur

1 RAY LANkester behauptete zuerst den Zusammenhang beider Nieren von Patella mit dem Herzbentel, darauf verbesserte er diese Angabe nach einer mit G. Bourne unternommenen Untersuchung dahin, dass nur die rechte Niere eine Verbindung mit der Herzbeutelhöhle besitze. Cunninghay (The renal organs [nephridia] of Patella. Quart. Journ. of Micr. Science. T. XXIII. 1883) findet wieder auf Schnitten eine Kommunikation beider Nieren mit dem Herzbeutel, während Perrier dieselbe nur fiur die rechte zugiebt. 
auf die ersten Entwicklungsstadien, und Boctan's (31) Arbeit iiber die Entwicklung von Fissurella giebt iiber diesen, sowie zahlreiche andere interessante Punkte, gar keinen Aufschluss.

Der Ureter von Paludina soll nach v. Inering keineswegs dem sekundären Harnleiter der Heliceen (25) homolog sein. Ich stimme darin v. Inering rollkommen bei und schließe aus den Untersuchungen von Brate (34) und Behme ${ }^{1}$ (35), dass der Ureter von Paludina nur dem sogenannten primären Harnleiter von Helix entspricht. Damit wäre der sekundäre Harnleiter der Heliceen eine neuerworbene Eigenthümlichkeit der Nephropneusten v. Iherisg's.

Die Bildung des seceruirenden Abschnittes der Niere aus dem Epithel des Cöloms (Perikard) rechtfertigt den Vergleich der Niere mit den Segmentalorganen der Würmer, zu welchem schon der Zusammenhang der Niere mit dem Herzbentel geführt hatte.

Auf das Vorkommen zweier Paare von Exkretionsorganen: bleibende Niere und innere Urniere, welche beide im Wesentlichen denselben Bau besitzen und daher mit Segmentalorganen übereinstimmen, ist die Hypothese gegriundet worden, die Mollusken ließen in ihrer Entwicklungdie Anlage ron zwei Segmenten erkennen.

Am Schlusse dieser Arbeit sei mir gestattet, meinem hochrerehrten Lehrer, Herrn Prof. Bütschl, für die Anregung und mannigfache Förderung dieser Untersuchung zu danken. Auch bin ich Herrn Prof. Blochnans für manchen freundlichen Rath, besonders hinsichtlich der Technik, verpflichtet.

Heidelberg, den 2S. Januar 1891.

1 Behme scheint mir mit U̧nrecht die Beobachtungen Schalfeew's bei Limax zu bestreiten, da er selbst offenbar eine zu geringe Anzahl von Embryonen, und vor allen Dingen nicht hinreichend junge Stadien untersucht hat, um zu einer richtigen Vorstellung von der Entwicklung der Niere zu gelangen. 


\section{Litteraturverzeichnis.}

1) F. Leydig, Über Paludina vivipara. Zeitschrift für wiss. Zoologie. Bd. II. 1850.

2) W. Salensky, Beiträge zur Entwicklung der Prosobranchiaten und Referat. Zeitschrift für wiss. Zoologie. Bd. XII. 1872.

3) M. Ganin, Beitrag zur Lehre von den embryonalen Blättern bei den Mollusken. Warschaner Universitätsberichte. 1873 (war mir nicht zugänglich). Referat dariiber im Jahresbericht iiber Anat. und Physiol. Bd. II. 1872, und in Zeitschrift fuir wiss. Zoologie. Bd. XII. '1872.

4) E. Ray Lankester, On the development of the Pond Snail. Quart. Journ. of microscopical Science. 1874.

5) C. RABL, Die Ontogenie der Süßwasserpulmonaten. Jenaische Zeitschrift fuir Naturwissenschaft. Bd. IX. 1875.

6) H. v. IHERING, Entwicklungsgeschichte von Helix. Jenaische Zeitschrift für Naturwissenschaft. Bd. IX. 1875.

7) H. Fol, Etudes sur le développement des Ptéroporles. Archives de zoologie expérimentale. Vol. IV. 1875.

8) —_ Etudes sur le développement des Hetéropodes. Archives de zoologie expérimentale. Vol. V. 1876.

9) H. v. Ihering, Zur Morphologie der Niere der sogenannten "Mollusken «. Zeitschrift für wiss. Zoologie. Bd. XXIX. $18 \div$.

10) 0. BÜTSCHLI, Entwicklungsgeschichtliche Beiträge. Über Paludina vivipara. Zeitschrift für wiss. Zoologie. Bd. XXIX. 1877.

11) N. Bobretzky, Studien uiber die embryonale Entwicklung der Gasteropoden. Archiv für mikr. Anatomie. Bd. XIII. 1877.

12) C. RABL, Über die Entwicklung der Tellerschnecke. Norph. Jahrb. Bd. V. 1879.

13) H. Fol, Développement des Gastéropodes pulmonés. Archives de zoologie expérimentale. Vol. VIII. 1879-1850.

14) W. WoLfsohn, Die embryonale Entwicklung von Lymnaeus stagnalis. Bulletins de l'Académie imperiale des sciences de St. Pétersbourg. Bd. XX. 1850. (Die russische Originalarbeit war mir nicht zugänglich.)

15) 0. und R. Hertwig, Die Cölomtheorie. Jena $1 S \$ 1$.

16) J. W. Spengel, Die Geruchsorgane und das Nervensystem der Mollusken. Zeitschrift für wiss. Zoologie. Bd. XXXV. 1881.

17) F. Blochmann, Über die Entwicklung der Neritina fluviatilis. Inaug.Dissertation. Zeitschrift für wiss. Zoologie. Bd. XXXVI. 1881.

18) P. SARAsin, Die Entwicklungsgeschichte der Bythynia tentaculata. Inaug.Dissertation. Wiesbaden 1882.

19) C. A. Haddon, Notes on the development of Mollusca. Quart. Journal of micr. science. Vol. XXII. 1882. 
20) A. Kowalevsky, Embryogénie du Chiton Polii. Annales du Mus. Hist. Nat. de Marseille. Tome I. 1882.

21) Joyeux Laffuie, Organisation et développement de l'Oncidie. Archives de zoologie expérimentale. T. X. 1882.

22) L. Manfredi, Le prime fasi dello sviluppo dell' Aplysia. Atti acad. Napoli. Vol. IX. 1882.

23) C. RaBL, Beiträge zur Entwicklungsgeschichte der Prosobranchier. Sitzber. der k. Akademie der Wiss. Wien. LXXXVI. Jahrgang. $18 \delta 3$.

24) F. Blochmann, Beiträge zur Kenntnis der Entwicklung der Gasteropoden. Zeitschrift für wiss. Zoologie. Bd. XXXVIII. 1883.

25) v. Ihering, Der uropneustische Apparat der Heliceen. Zeitschrift für wiss. Zoologie. Bd. XLI. 1884.

26) W. Salensky, Etudes sur le développement du Vermet. Archives de Biologie. Vol. VI. 1585.

27) W. Patten, The embryology of Patella. Arbeiten des zoolog. Instituts Wien. Bd. VI. 1855.

28) 0. BüTsCHLI, Bemerkungen iiber die wahrscheinliche Herleitung der Asymmetrie der Gasteropoden, speciell der Asymmetrie im Nervensystem der Prosobranchiaten. Norph. Jahrb. Bd. XII. 1886.

29) J. Playfair MacMurrich, Notes on the embryology of the Gasteropods. Preliminary notice und A contribution to the embryology of the prosobranch Gasteropods. Stud. biol. laboratory of the Johns Hopkins University Baltimore. Vol. 3. 1856.

30) B. Haller, Beiträge zur Kenntnis der Niere der Prosobranchiaten. Morph. Jahrb. Bd. XII. 1856.

31) Boutan, Recherches sur l'anatomie et le développement de la Fissurelle. Arch. Zool. exp. 2. série. 'T. III bis 1855.

32) F. Rно, Studii sullo sviluppo della Chromodoris elegans. Atti acad. Napoli. Vol. I. 1 sss.

33) W. Schalfeew, W. Schimkevitsch, Sur le dévoloppement du coeur des mollusques pulmonés d'aprés les observations de M. Schalfeew. Zool. Anzeiger. 11. Jahrgang. pag. 65. 1888.

34) M. Braun, Über die Entwicklıng des Harnleiters bei Helix pomatia. Nachr.Bl. Mal. Ges. Frankfurt. 20. Jahrgang. 1885.

35) Tн. Beнue, Beiträge zur Anatomie und Entwicklungsgeschichte des Harnapparates der Lungenschnecken. Archiv fiir Naturgesch. 55. Jahrgang. Bd. I. 1. Heft. 1589.

36) C. RaBL, Theorie des Mesoderms. Morph. Jahrb. Bd. XV. 1 ss9.

37) R. Perrier, Recherches sur l'anatomie et l'histologie du rein des Gastéropodes. Annales des sciences naturelles Zoologie. T. VIII. 1889. 


\section{Erklärung der Abbildungen.}

Folgende Buchstaben gelten fïr alle Abbildungen :

$A$ After, Ao Aorta, $A u$ Auge.

$B$ Blastoporus.

$C$ Cölom.

$D$ Darm, De Deckel (Operculum).

$E$ Enddarm.

$F$ Furchungshöhle, $F u$ Fuß, Fü Fühleranlage.

$G$ Anlage des Geschlechtsganges, $G d$ Geschlechtsdrïse $=$ Keimdrüse.

$K$ Herzkammer, $K i$ Kieme, $K v$ Kiemenvene.

$L$ Leber.

II Magen, $M f$ Rand der Mantelfalte ( $r$ rechter, $l$ linker) oder Mantelwulst, IIh Mantelhöhle $=$ Kiemenhöhle, Mhb Boden derselben.

$N$ Niere, $N^{\prime}$ rudimentäre linke Niere. Na Nierenausführgang. $N c^{\prime}$ rudimentïrer Ausfuihrgang der linken Niere.

$O$ Otolithenblase, Os Mund.

$\ddot{o}$ Öffnung der Niere in den Herzbeutel. Oe Öffnung der Urniere nach außen.

$P$ Perikard, $P^{\prime}$ linker Abschnitt desselben.

$R$ Radulasack, $r$ Richtungskörper.

$U$ Urniere, $U_{r}$ Urdarm.

$S$ Ösophagus, $S p$ Spengel'sches Organ, Sch Schalendrüse, Scha Schale. Srf Schalenfalz, Sept Septum des Herzbeutels.

$V$ Velum, Vo Vorhof.

Die Umrisse sämmtlicher Figuren sind mit dem ABBÉ'schen Zeichenapparat und dem ZeIss'schen Kompensationsocular Nr. 4 gezeichnet. Es wurden die ZEIss'schen Apochromate verwendet, und zwar die Trockensysteme 16, $s$ und $t$ (Brennweite in Nillimeter) und die homogene Immersion $2 \mathrm{~mm}$. Eine Angabe der Vergrößerung ist jeder Figur beigefuigt, in so fern nicht die wirkliche Länge des betreffenden Stadiums angegeben ist. Sämmtliche Schnitte sind so gezeichnet, dass man auf die vordere Schnittfläche sieht.

\section{Tafel XX.}

Fig. 1. Ausgebildete Gastrula im optischen Lïngsschnitt. Länge 0,06 mm.

Fig. 2. Anfang der Mesodermbildung im horizontalen optischen Längsschnitt. Länge $0,1 \mathrm{~mm}$.

Fig. 3. Sagittaler optischer Schnitt durch einen Embryo, bei welchem Cölom und Darm durch Abschniirung vom Urdarm entstehen. Länge 0,09 mm.

Fig. 4. Derselbe Embryo im horizontalen optischen Lïngsschnitt. 
Fig. 5. Horizontaler optischer Längsschnitt eines Embryo, bei welchem sich der Cölomsack vom Darm ganz getrennt hat. Länge $0,18 \mathrm{~mm}$.

Fig. 6. Ein entsprechendes Stadium im sagittalen optischen Schnitt.

Fig. 7. Sagittaler optischer Durchschnitt eines Embryo, bei welchem das Mesoderm in Auflösung begriffen ist. Vergr. 400.

Fig. 8. Sagittaler optischer Durchschnitt eines Embryo, dessen Mesoderm schon in Spindelzellen zerfallen ist. Vergr. 400.

Fig. 9. Sagittaler optischer Durchschnitt eines älteren Embryo: die verästelten Mesodermzellen durchsetzen die Leibeshöhle ganz unregelmäßig. Vergr. 400.

Fig. 10. Horizontaler wirklicher Längsschnitt durch einen Embryo, dessen Mesoderm sich in ein viscerales und ein parietales Blatt gesondert hat. Vergr. 400.

Fig. 11. Sagittaler wirklicher Schnitt durch ein der Fig. 7 entsprechendes Stadium. Vergr. 400.

Fig. 12. Querschnitt durch das Perikard, bei welchem das Septum sich eben zurückgebildet hat. Vergr. 400 .

Fig. 13. Querschnitt durch die mittlere Gegend eines der Fig. 5 entsprechenden Stadiums. Vergr. 400.

Fig. 14. Querschnitt durch einen der Fig. 3 und 4 entsprechenden Embryo. Der Schnitt ist durch das Hinterende etwas vor dem Blastoporus geführt. Vergr. 450 .

Fig. 15. Querschnitt durch dasselbe Stadium; der Schnitt ist durch die Mitte des Embryo gleich hinter dem Velum gelegt. Vergr. 450.

Fig. 16. Horizontaler Schnitt durch die Anlage des Herzbeutels. Vergr. 400.

\section{Tafel XXI.}

Fig. 1. Ansicht von der rechten Seite eines Embryo, bei welchem das Perikard durch ein Septum in zwei Abschnitte getheilt wird. Länge $0,52 \mathrm{~mm}$.

Fig. 2. Dieselbe Ansicht eines Embryo mit einheitlichem Perikard. Länge $0,64 \mathrm{~mm}$.

Fig. 3. Dieselbe Ansicht eines Embryo, in welchem das Herz sich eben anlegt. Länge $0,7 \mathrm{~mm}$.

Fig. 4. Perikard und Herzanlage eines der Fig. 3 entsprechenden Stadiums, von hinten gesehen.

Fig. 5. Perikard und Herzanlage von der linken Seite.

Fig. 6. Von oben gesehen.

Fig. 7. Seitliche Ansicht des beschalten Hinterendes eines etwas älteren Embryo, von der rechten Seite. Gesammtlänge $0,8 \mathrm{~mm}$.

Fig. 8-14. Aus Schnittserien rekonstruirte Hinterenden von Embryonen. Fig. 10 und 14 sind aus horizontalen Schnitten, die anderen aus Querschnitten rekonstruirt.

Fig. 8. Der Embryo liegt dem Alter nach zwischen Fig. 1 und 2 derselben Tafel.

Fig. 9. Der Embryo entspricht der Fig. 2 derselben Tafel.

Fig. 10. - $\quad$ - $\quad-\quad-\quad-\quad-1$ auf Taf. XXII.

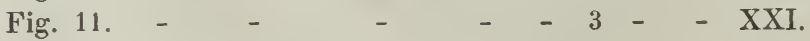

Fig. 12. - $\quad-\quad$ - $\quad-\quad-1$ - 
Fig. 13. Der Embryo entspricht der Fig. 2 auf Taf. XXII.

Fig. 14. - $\quad$ - $\quad$ - $\quad-\quad-8$ -

Tafel XXII.

Fig. 1. Ansicht von der linken Seite eines Embryo, bei welchem sich die Kiemen anlegen. Länge $0,9 \mathrm{~mm}$.

Fig. 2. Ein etwas älterer Embryo von der rechten Seite. Länge $1 \mathrm{~mm}$.

Fig. 3. Optischer Längsschnitt durch die Niere eines der Fig. 2 derselben Tafel entsprechenden Stadiums, aus sagittalen Schnitten kombinirt.

Fig. 4. Horizontaler Schnitt durch die Herzbeutelgegend eines Embryo, welcher wenig älter ist als der, dem der Schnitt Fig. 16 auf Taf. XX entnommen ist. Vergr. 400.

Fig. 5. Ein nahezu reifer Embryo, von der linken Seite gesehen. Länge $1,5 \mathrm{~mm}$.

F'ig. 6. Querschnitt durch die Herzbeutelgegend eines Embryo, welcher Fig. 1 anf Taf. XXI entspricht. Vergr. 400.

\section{Tafel XXIII.}

Fig. 1. Querschnitt durch die Herzbeutelgegend eines Embryo, welcher Fig. 2 auf Taf. XXI entspricht. Vergr. 200.

Fig. 2 und 3. Querschnitte durch einen Embryo, welcher Fig. 3 auf Taf. XXI entspricht.

Fig. 2. Der Schnitt ist durch die Herzanlage geführt.

Fig. 3. - - - - - Nierenanlage -

Fig. 4. Optischer Längsschnitt durch die Niere eines der Fig. 5 auf Taf. XXII entsprechenden Embryo, aus Längsschnitten kombinirt.

Fig. 5. Querschnitt durch Herzbeutel und Herz desselben Embryo.

Fig. 5 a. Schnitt durch die Herzkammer (dieselbe Serie).

Fig. 6. Querschnitt durch die Anlage des Urnierenausführganges. Vergr. 800.

Fig. 7. Querschnitt durch das innere Ende der Urniere eines Embryo, welcher Fig. 2 auf Taf. XXI entspricht. Vergr. 800.

Fig. 8. Querschnitt durch den Ausführgang der Urniere (dieselbe Serie). Vergr. 800 .

Fig. 9. Horizontaler Schnitt durch die eben angelegte Urniere. Vergr. 400.

Fig. 10. Querschnitt durch die Urnierenanlage, in welcher sich eben ein Lumen gebildet hat. Vergr. 400.

Fig. 11. Querschnitt durch den mittleren Theil der Urniere, dieselbe Serie wie Fig. 7 und 8 . Vergr. 800 . 


\section{Lebenslauf.}

Ich, Raphael Slidell Freiherr von Erlanger, bin am 23. Juli 1865 zu Paris geboren. Ich bin katholischer Konfession und preußischer Staatsangehöriger.

Nach siebenjährigem Besuch der Ecole libre de la rue de Madrid zu Paris, bestand ich den 13. Juli 1883 die Prüfung des Baccalauréat ès Lettres auf der Sorbonne, nach zweijährigem Besuch der Prima der Wöhlerschule in Frankfurt a. M. die Maturitätsprüfung den 17. September 1883, und erlangte schließlich das Zeugnis der Reife auf dem Gymnasium zu Gießen den 12. August 1886.

Ich studirte darauf ein Semester Medicin zu Bonn, wo ich bei Prof. von la Valette St. Georges, Clausius, Kékulé, leydig, Dr. Barfurth und MARTius hörte.

Ich zog darauf nach Heidelberg, wo ich vom Sommersemester 1857 bis zum Schluss des Sommersemesters 1888 blieb. Ich hörte bei den Professoren Bütschli, Gegenbaur, Bunsen, Pfitzer, Quinke, Kühne, Ruge, Ewaid und Blochmann.

Im Wintersemester 1888-1889 begab ich mich nach Berlin, wo ich bei Prof. Hertwig das embryologische Prakticum belegte, und kehrte dann wieder nach Heidelberg zuruick, wo ich seitdem blieb und mich speciell mit Zoologie befasste.

Ich arbeitete bei Prof. Bütschli, Pfitzer, Krafft und Andreae.

Ich habe, seitdem ich im Sommer 1888 von der Medicin zur Zoologie iibertrat, folgende schon veröffentlichte Arbeiten verfasst: Zur Kenntnis einiger Infusorien. Zeitschrift für wissenschaftliche Zoologie. Bd. XLIX. 1890, Über den Blastoporus der anuren Amphibien, sein Schicksal und seine Beziehungen zum bleibenden After. Zoologische Jahresbiicher. Bd. IV. 1890, Der Geschlechtsapparat der Taenia echinococcus. Zeitschrift für wissenschaftliche Zoologie. Bd. L. 1890.

Allen meinen Lehrern spreche ich meinen Dank aus, ganz besonders meinem hochverehrten Lehrer Herrn Prof. Bütschli. 



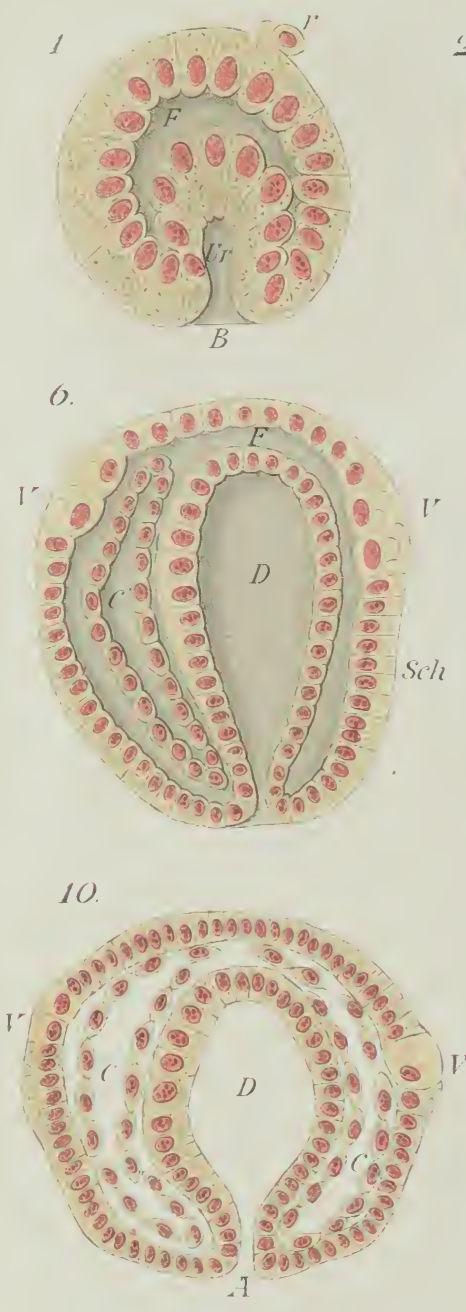

\section{5}

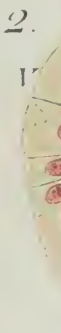

(3) $F$ (3) 3$)^{3}$ (2) (क) (2) (3) (2) (요 $I^{r} r$ (क) (19) (3) $\mathrm{C}(\mathrm{C})$ (8) (1) (2).

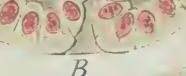

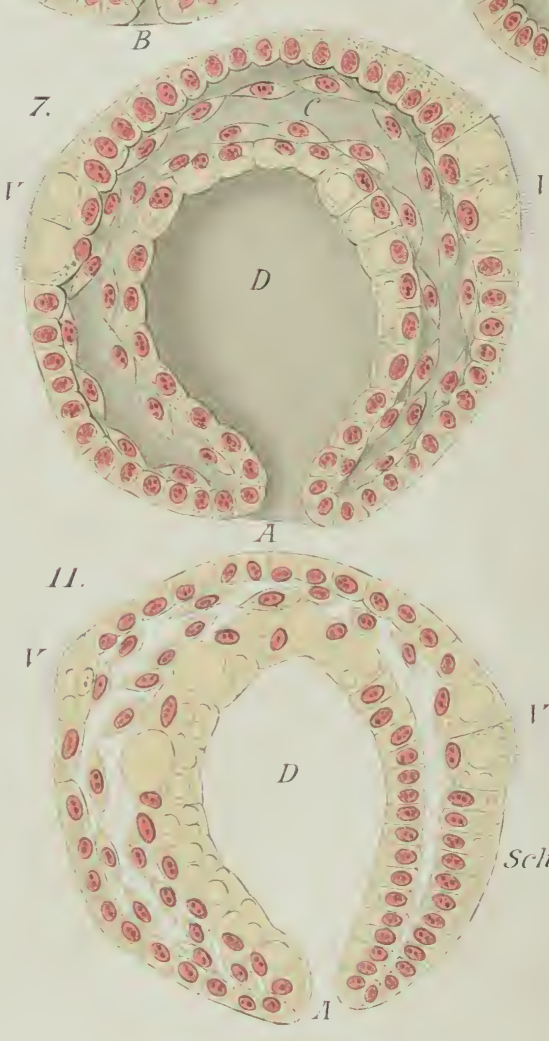

14.

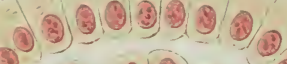

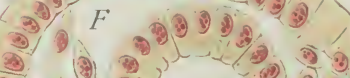

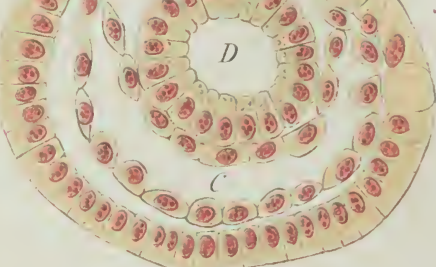

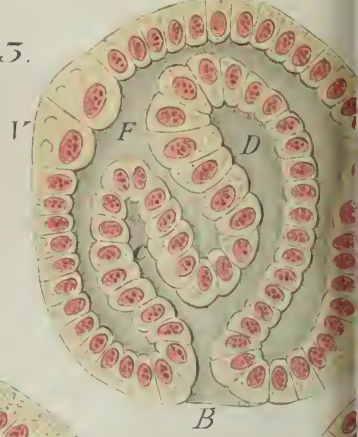

(a).

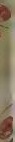

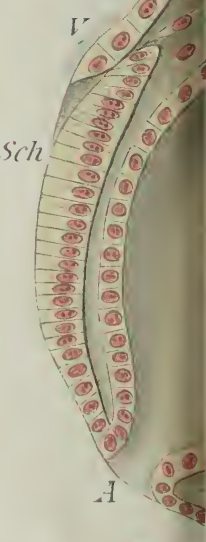

9

(1)

oó

10.

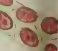

15.

-

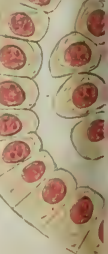




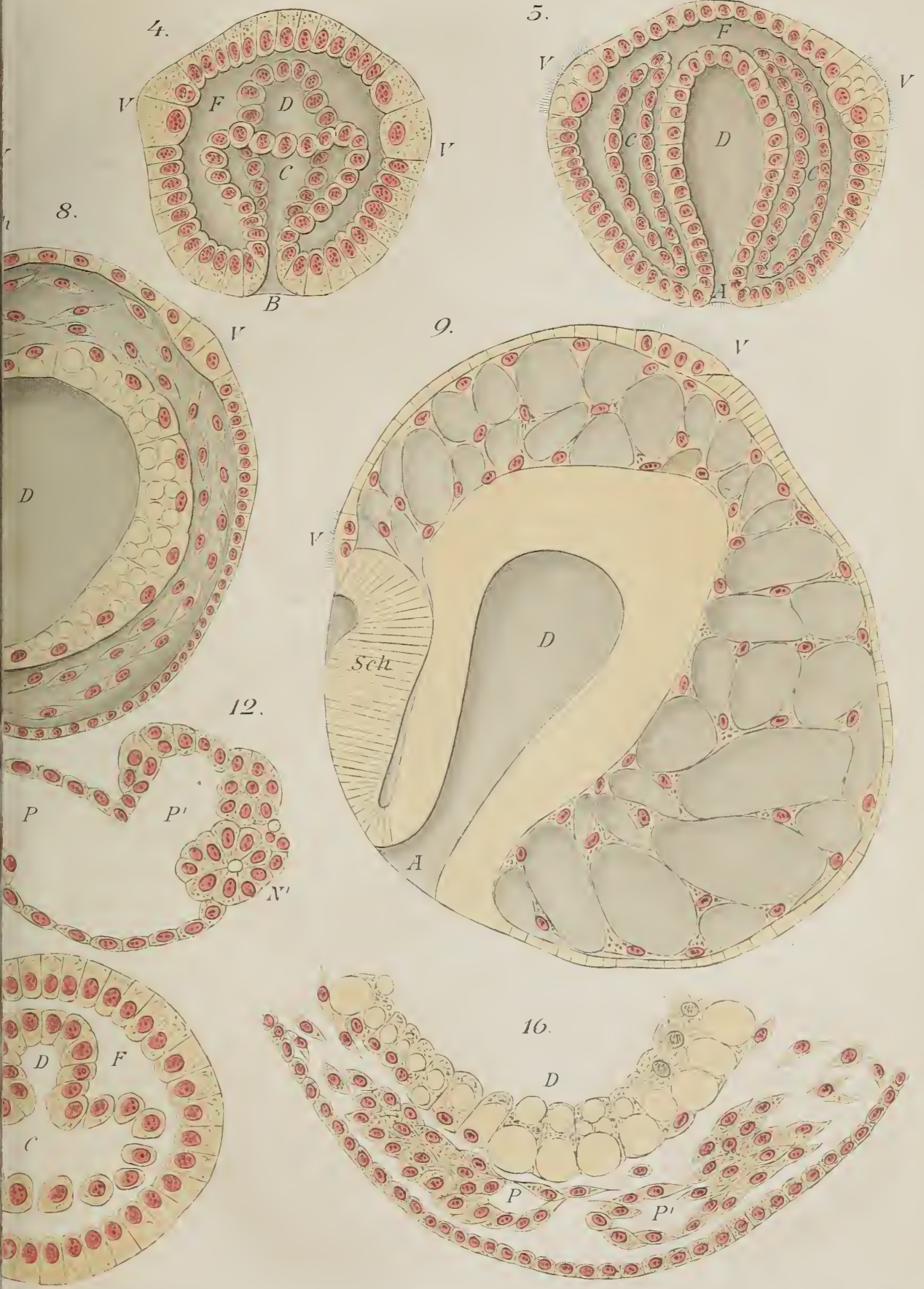




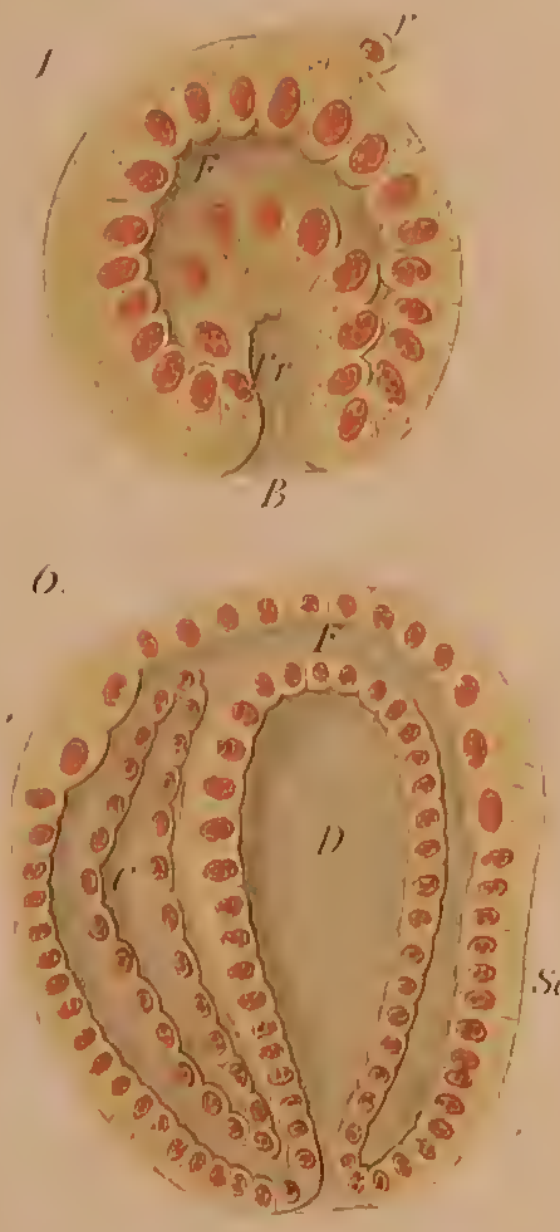

10)

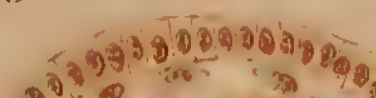

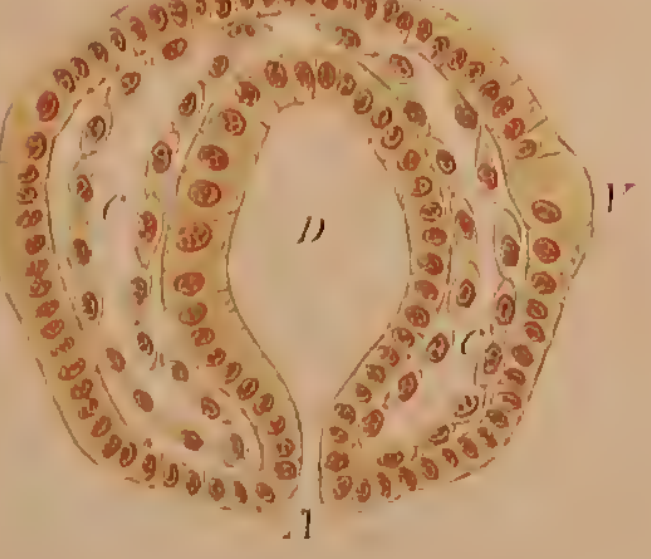

1.5.

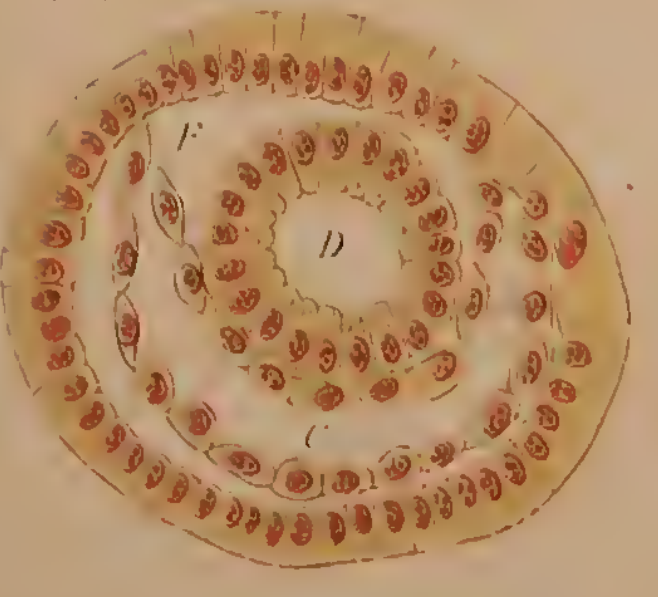

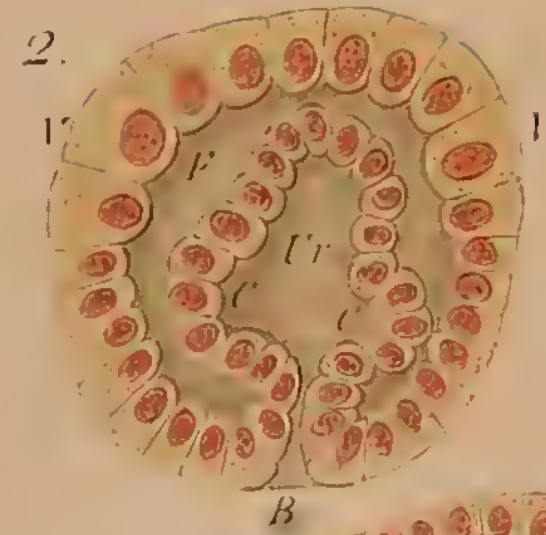

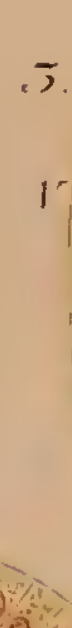

T. 0 का 7. गु के की
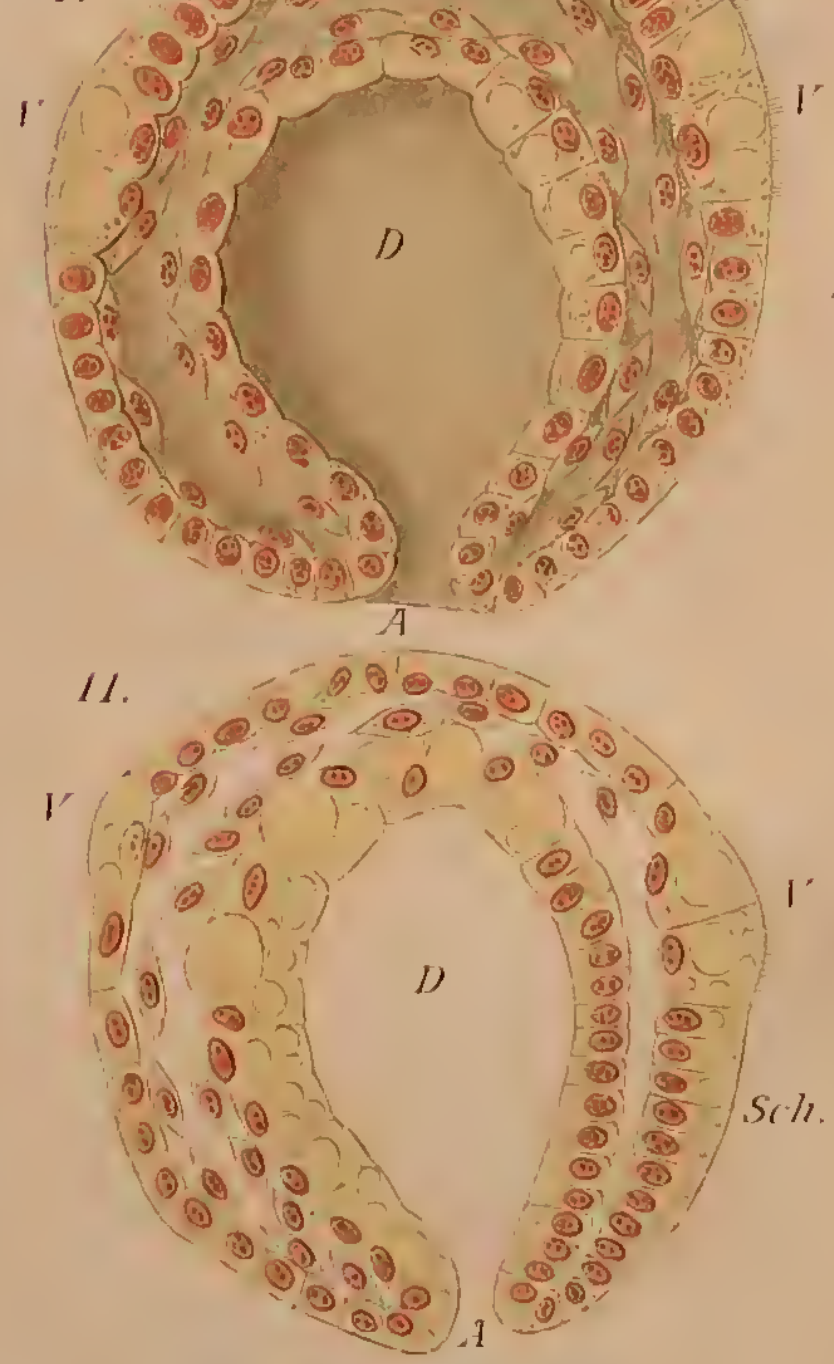

14

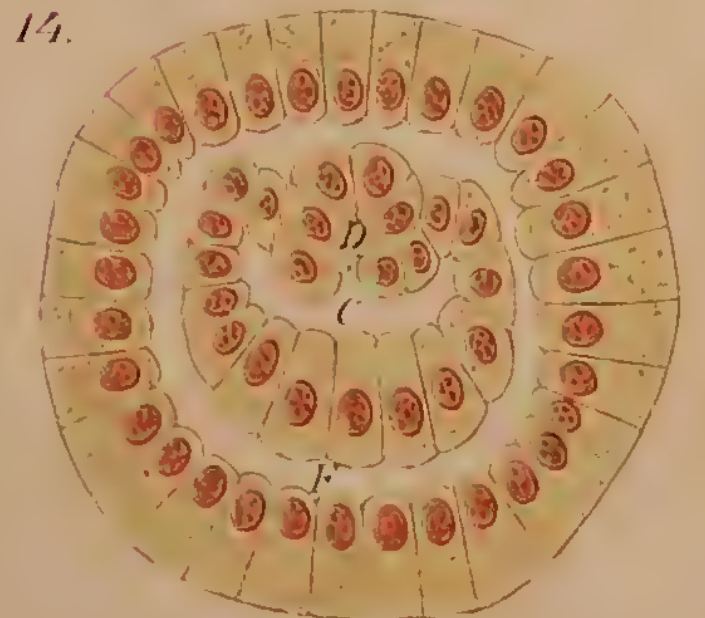

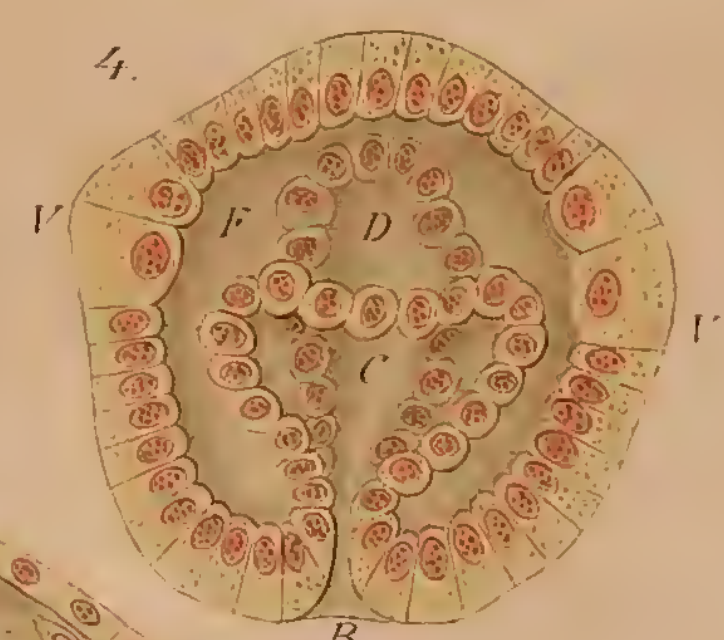
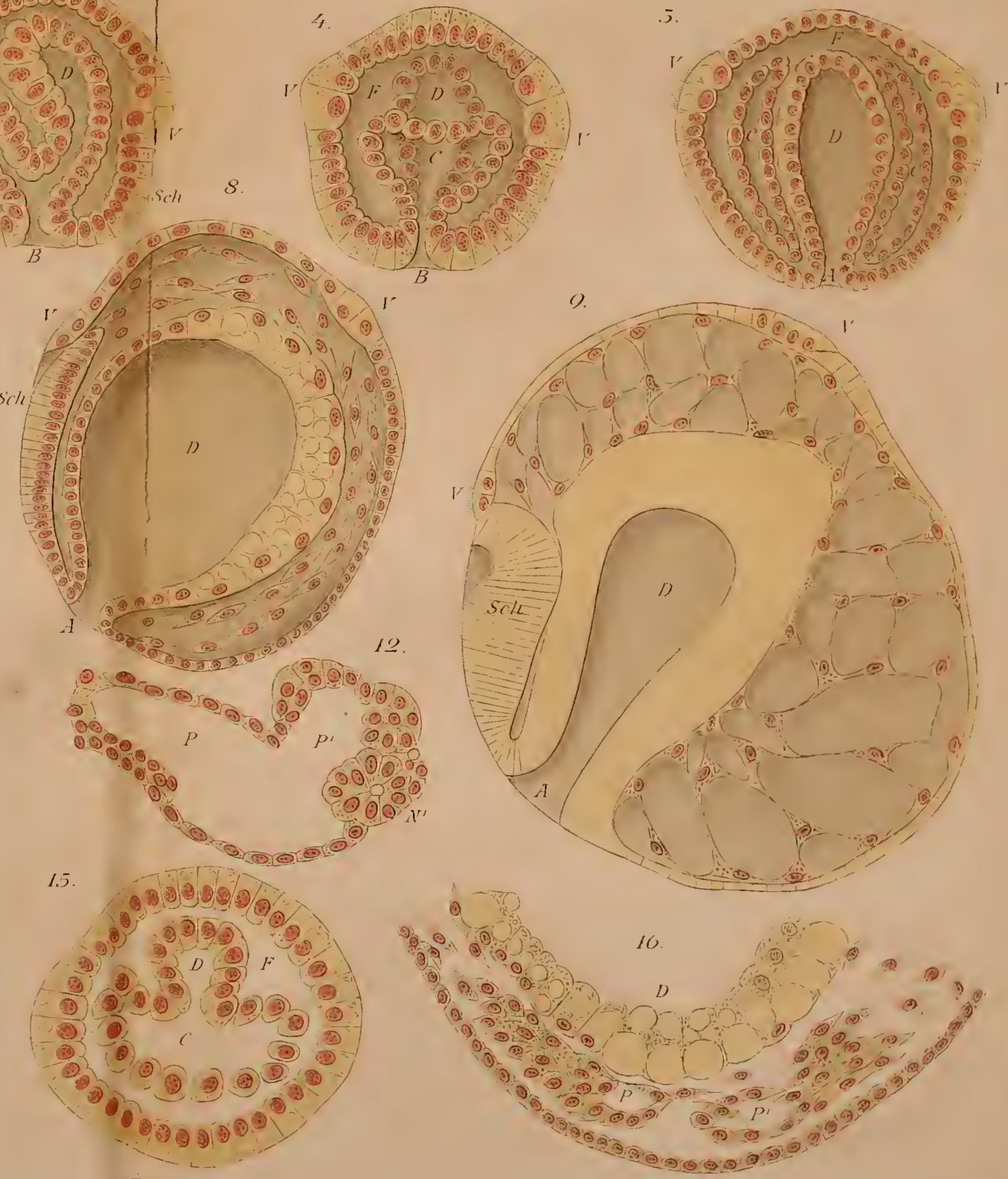



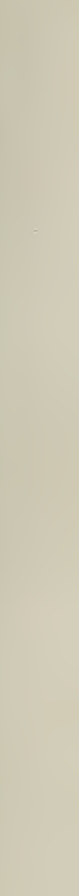




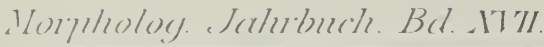
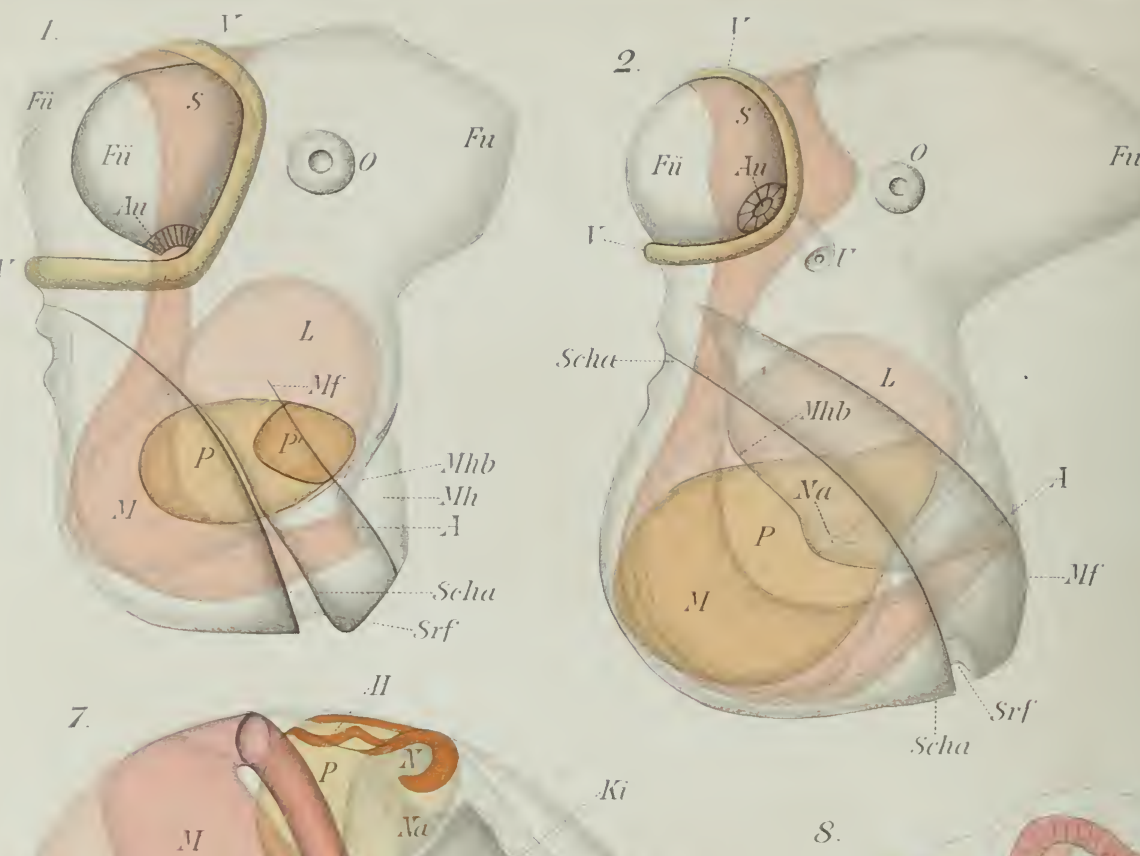

$F 11$

$k i$

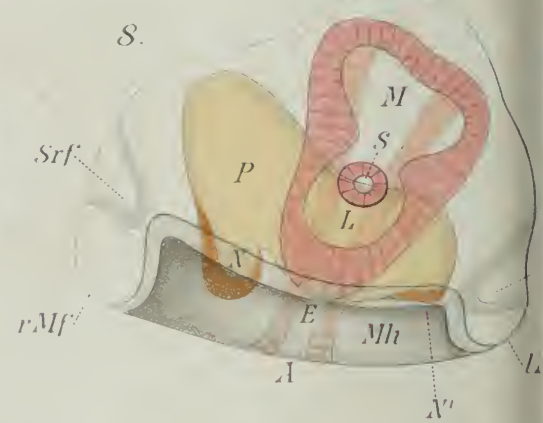

12.
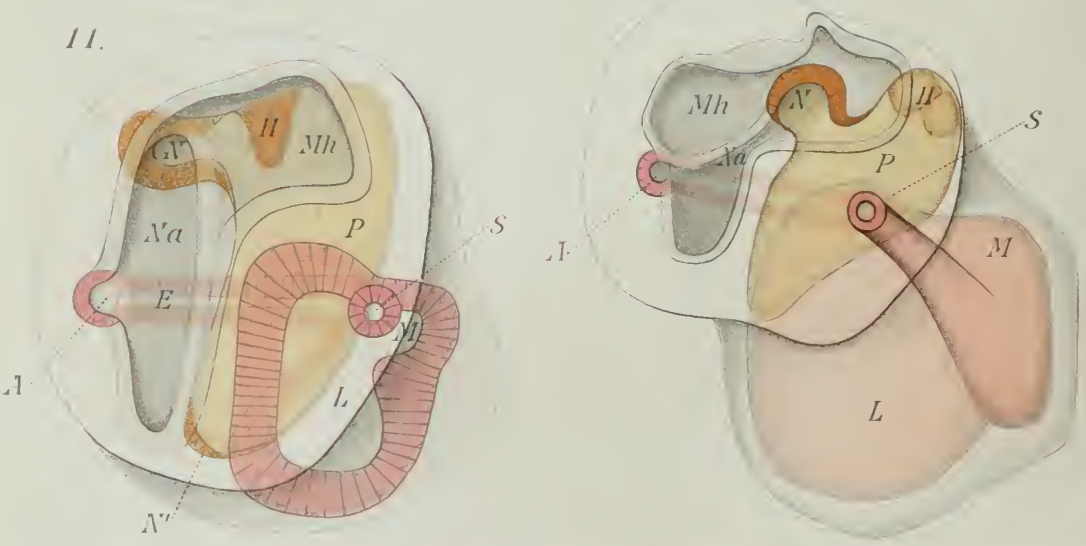
Fü
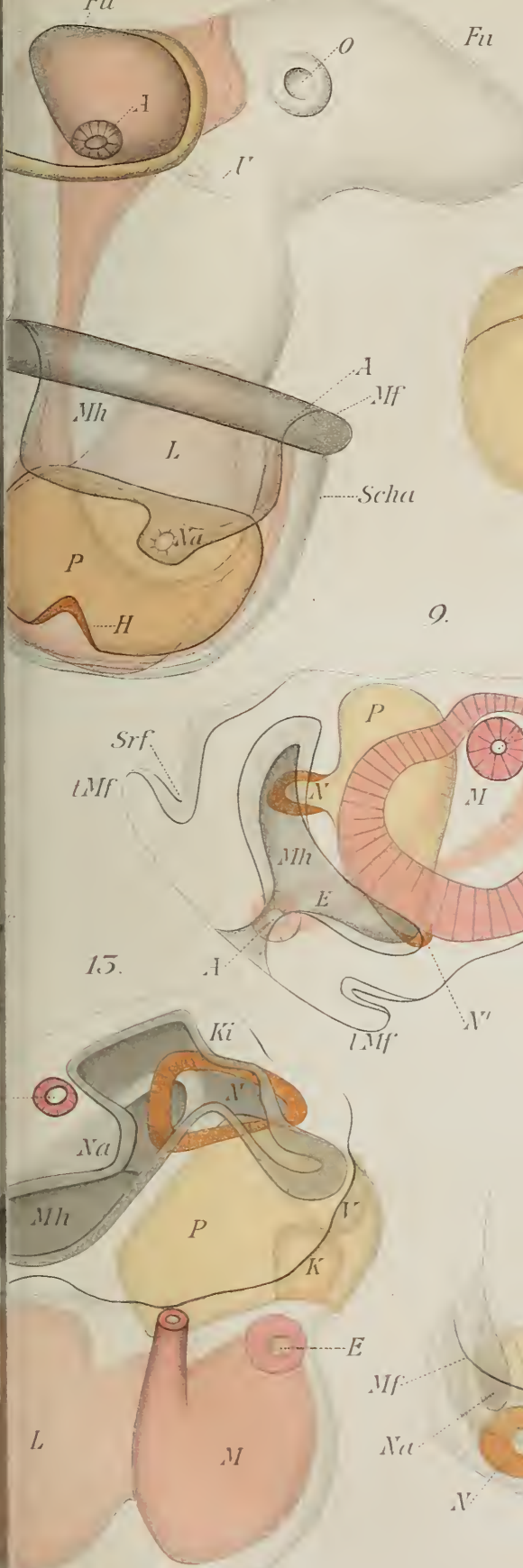

$S$
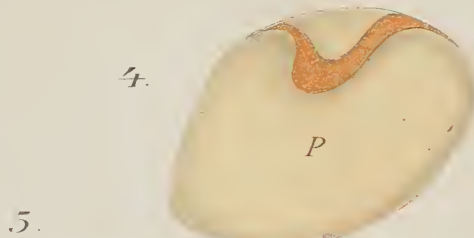

5

6

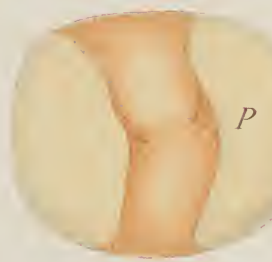

10.

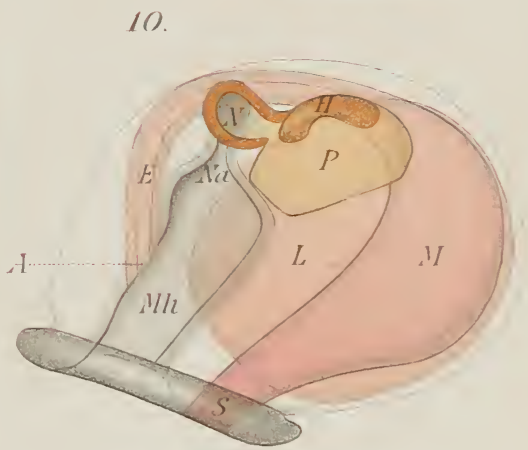

15

14.

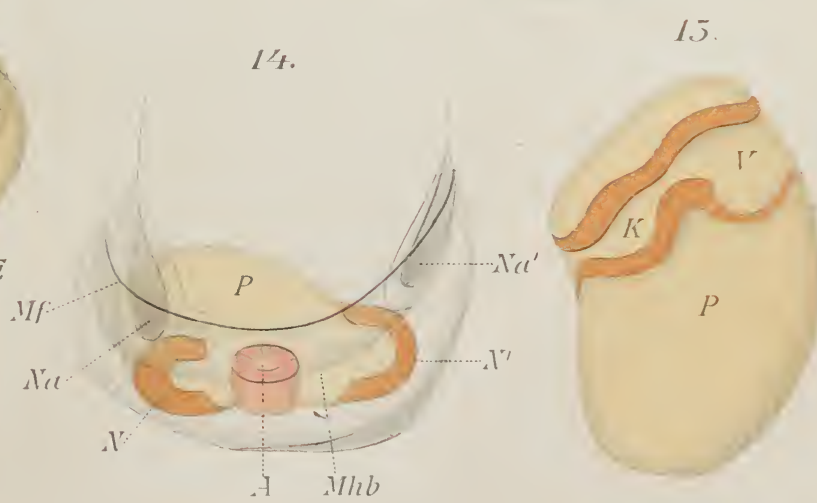




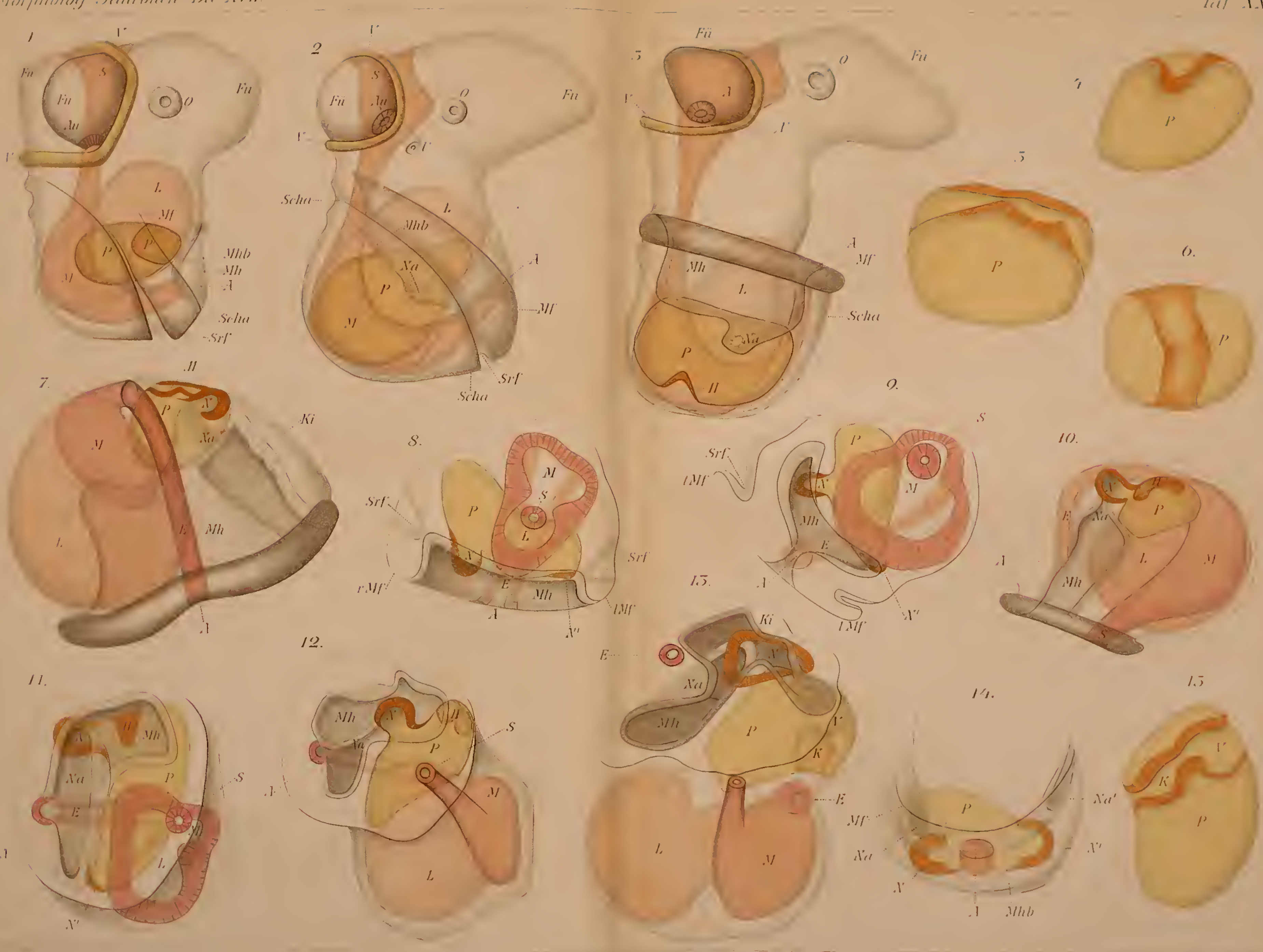

11
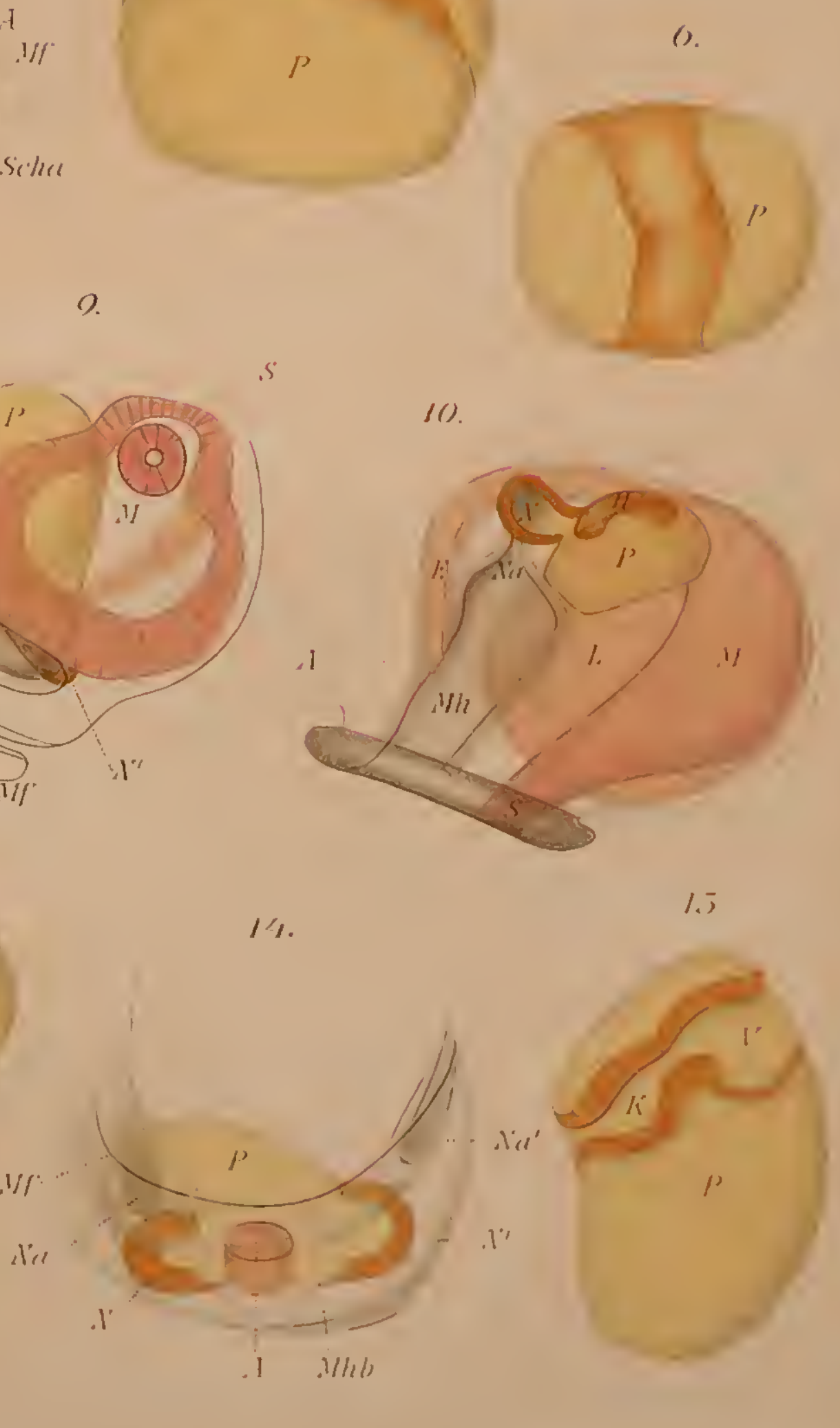



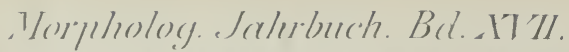

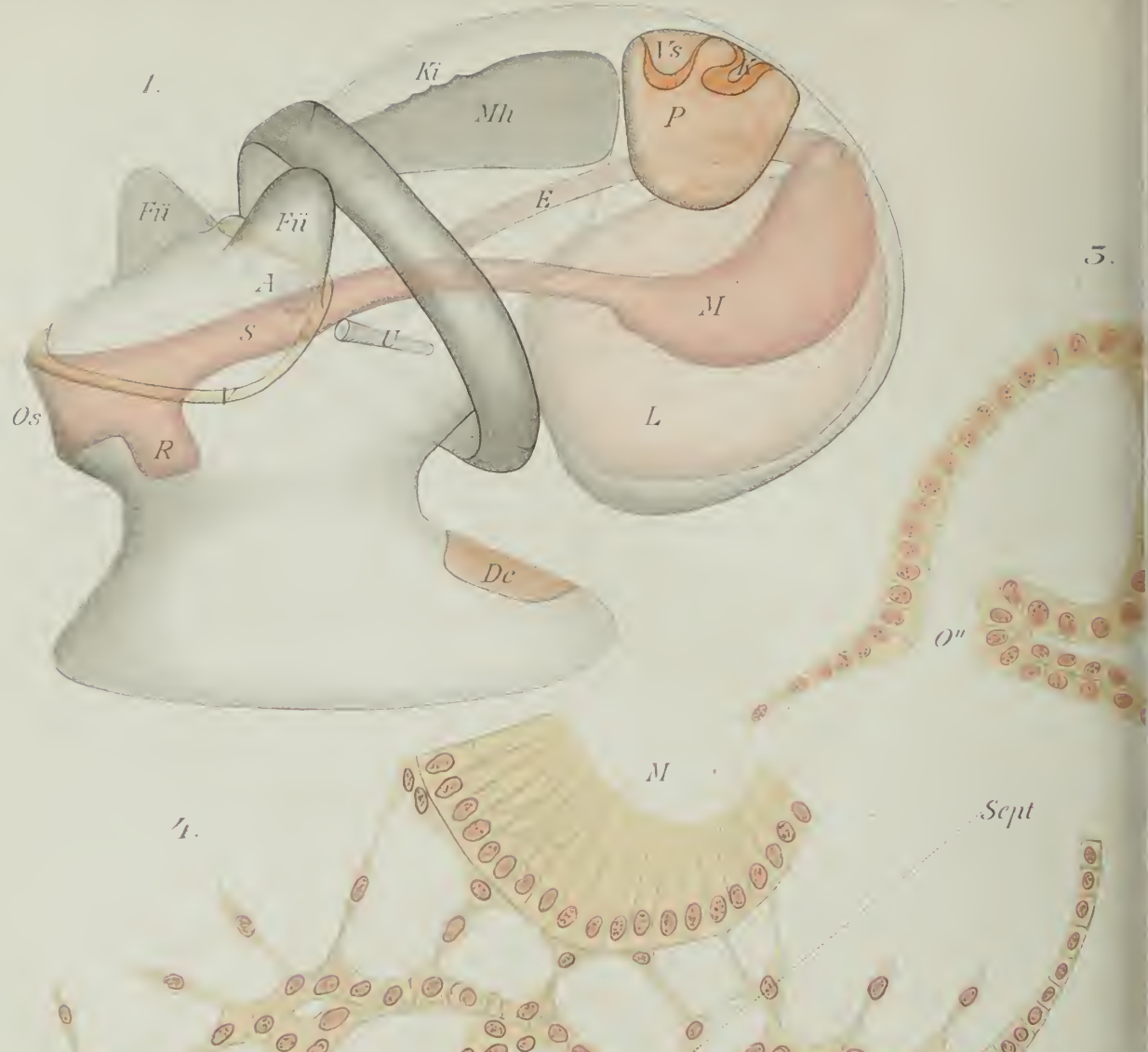

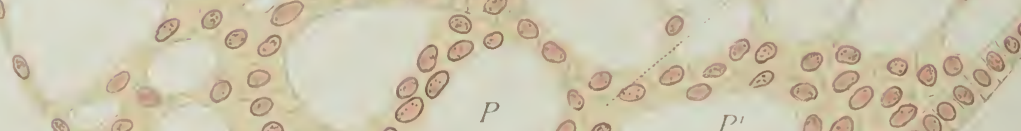

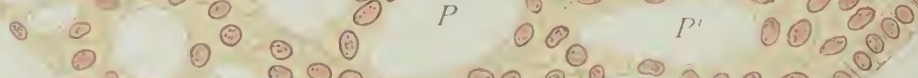

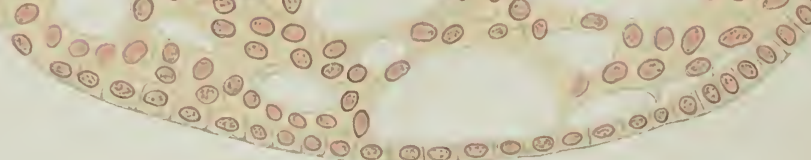

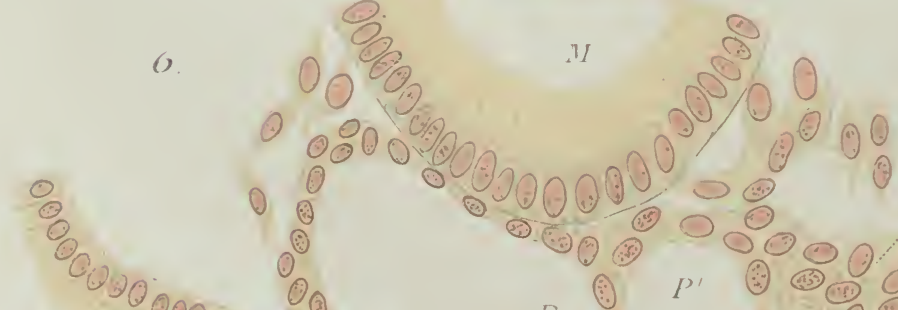

2000 

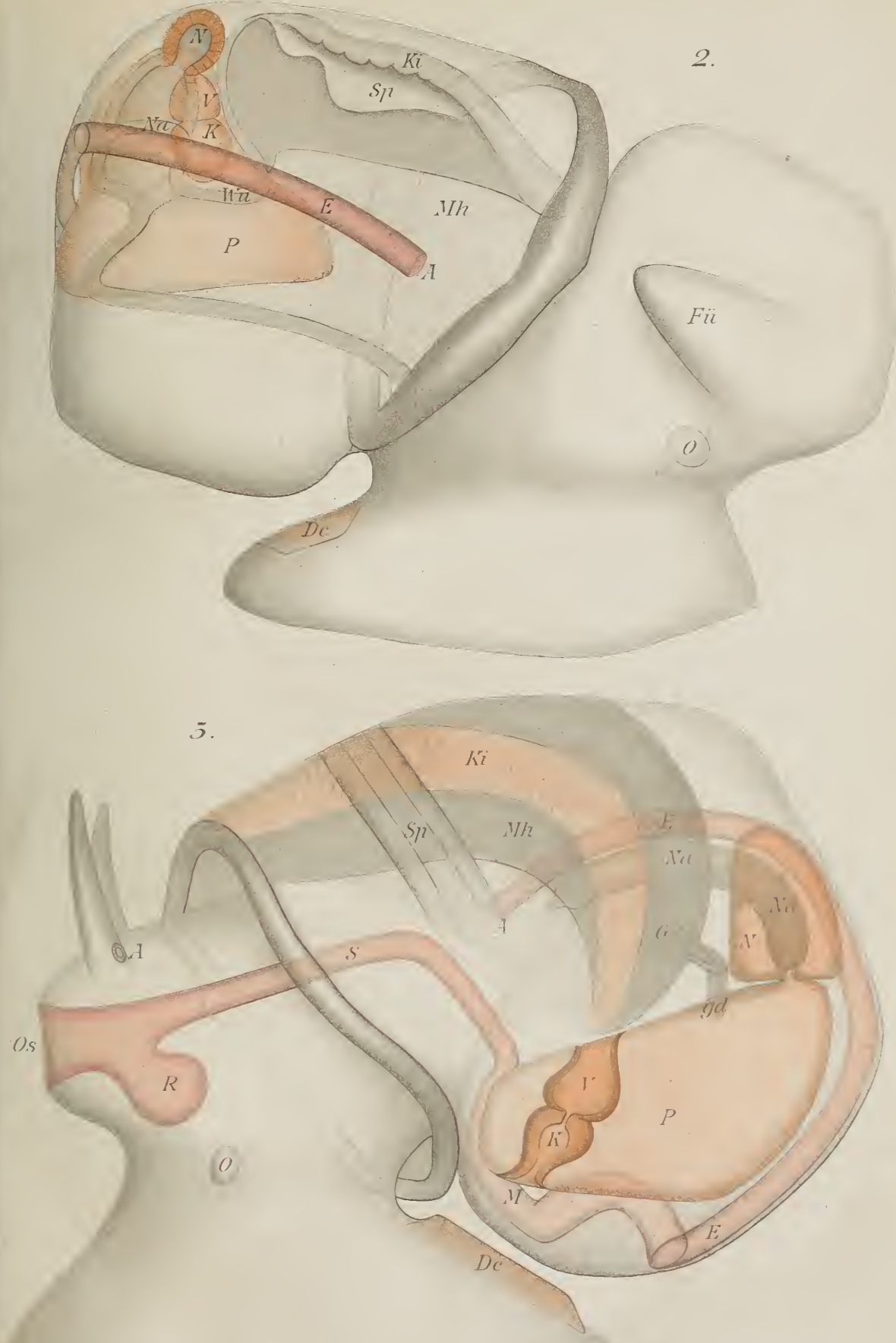



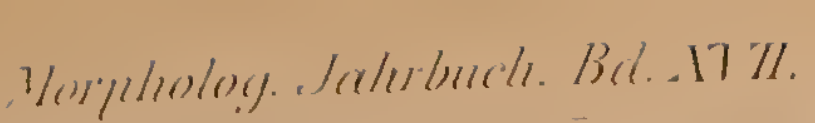

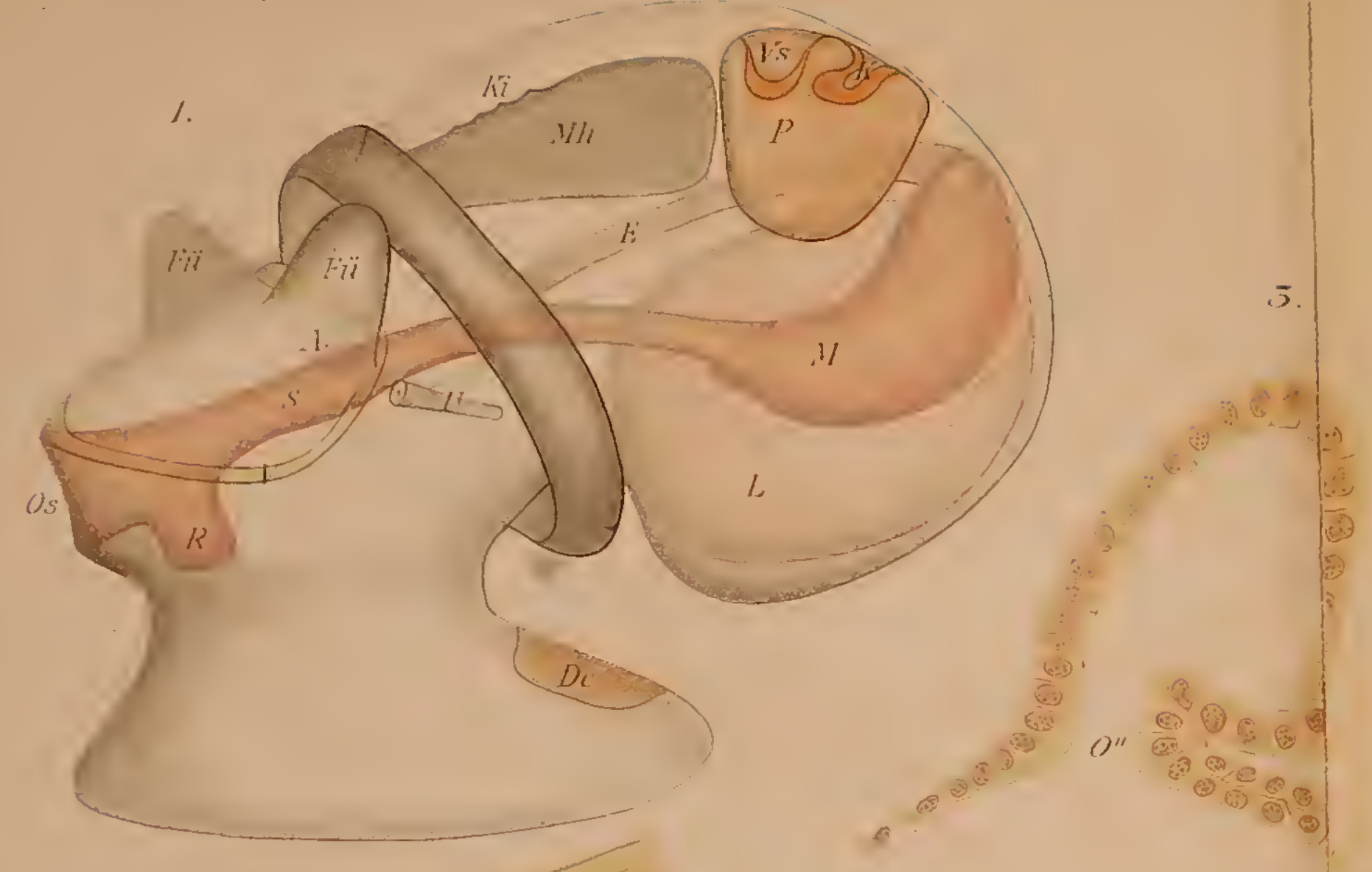

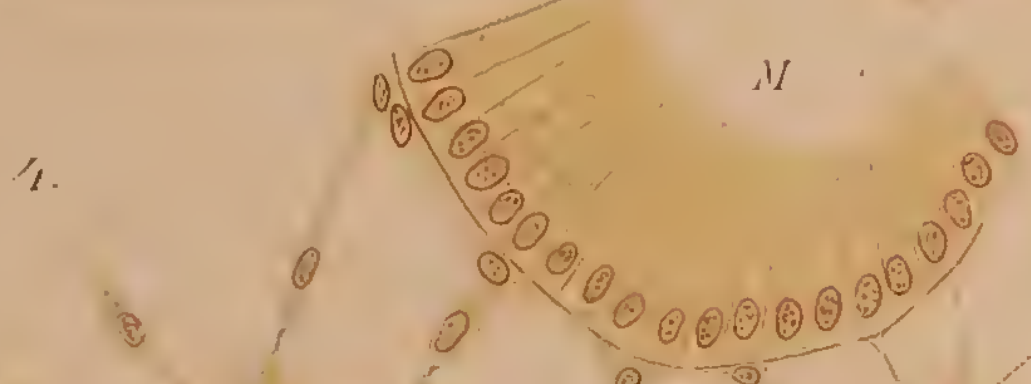

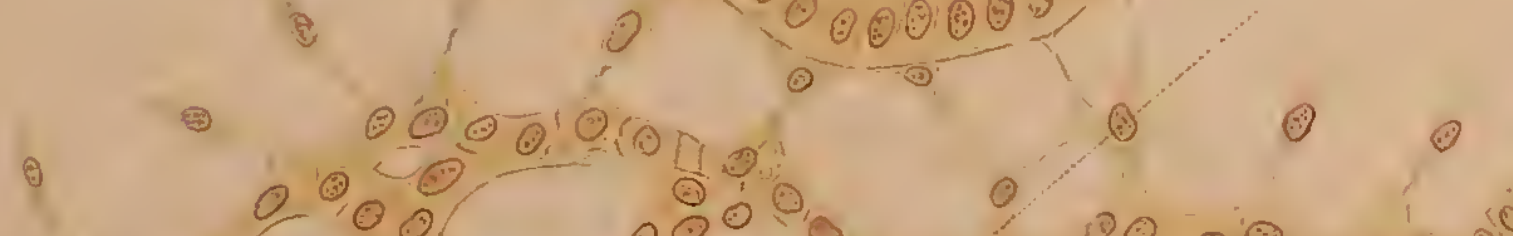

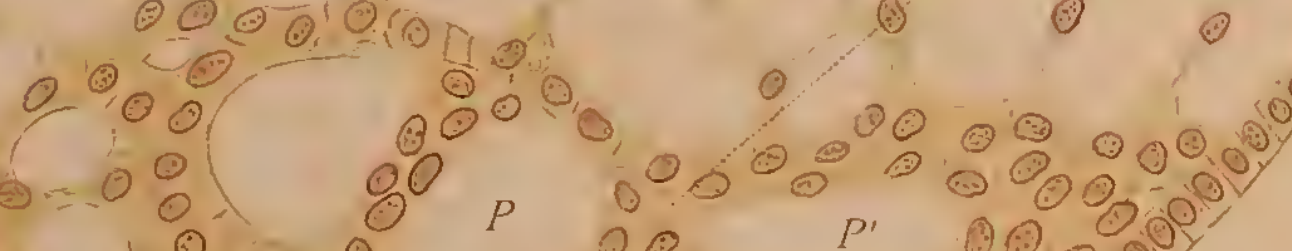

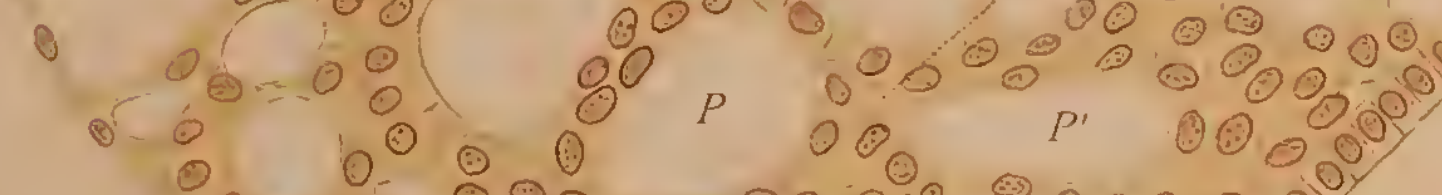

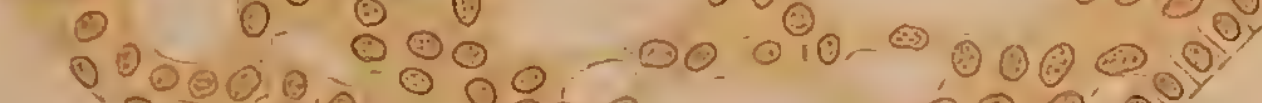

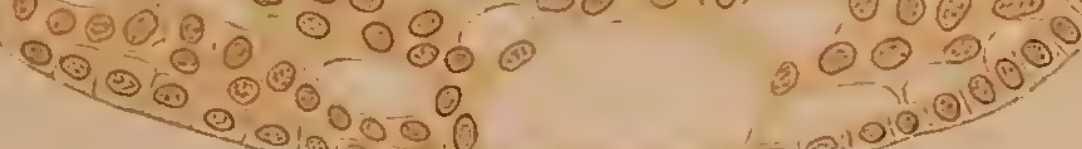
- 0.000.0

$0_{0}^{0.80}$

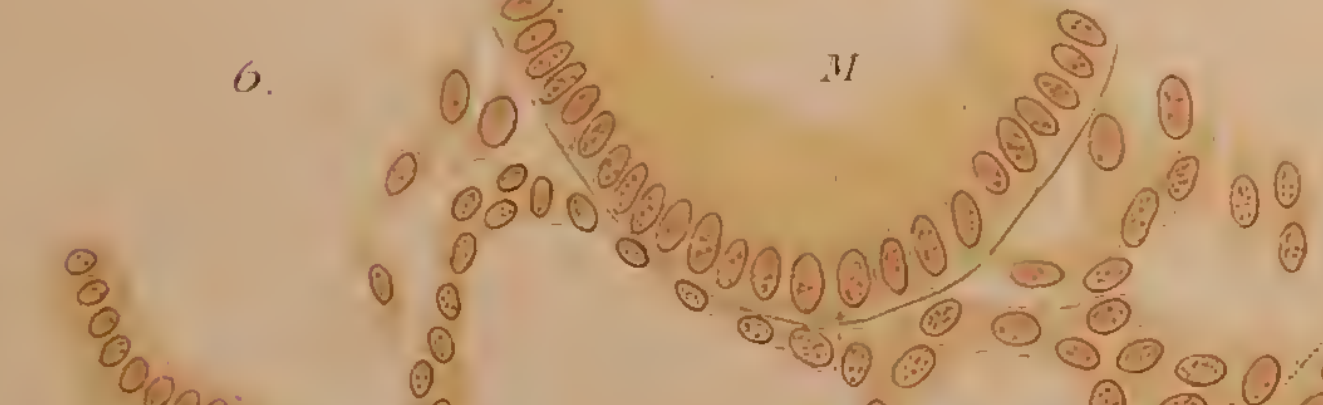

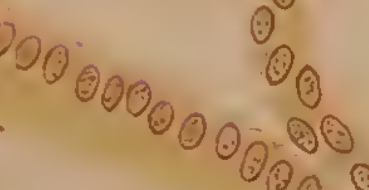

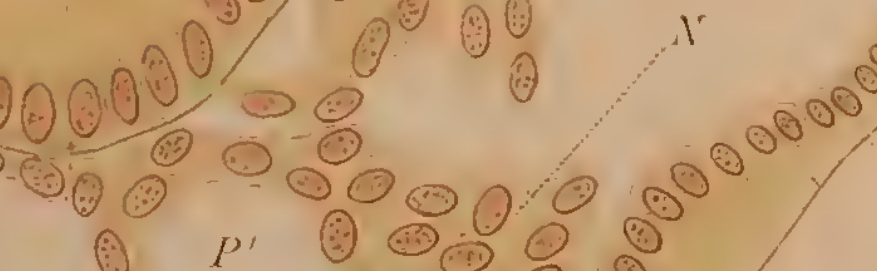

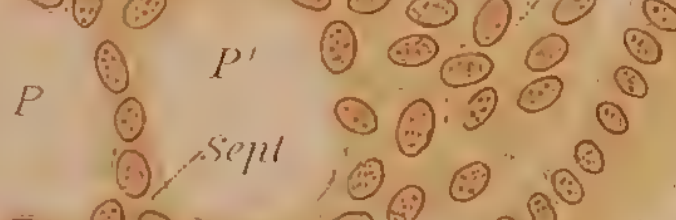

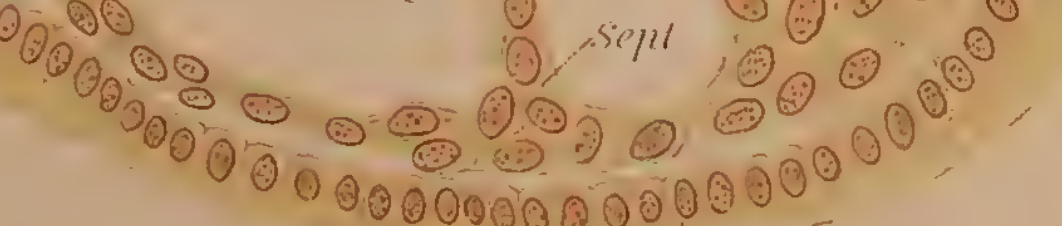

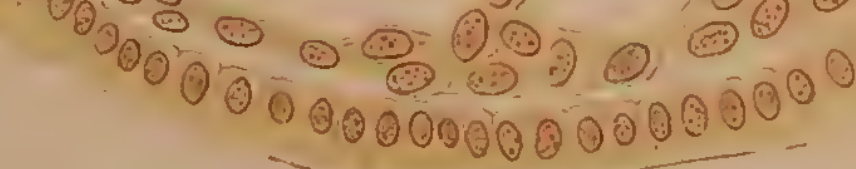
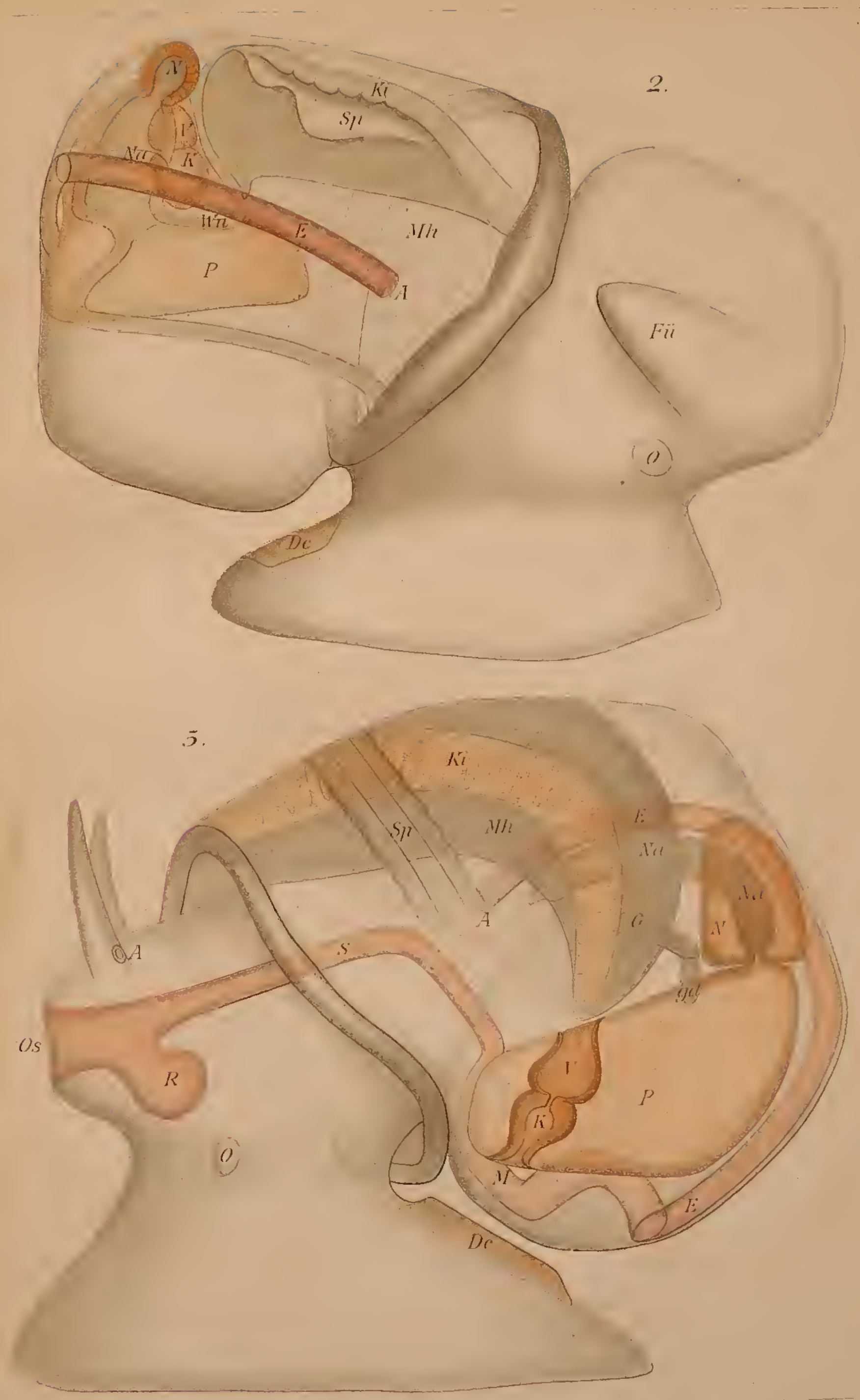




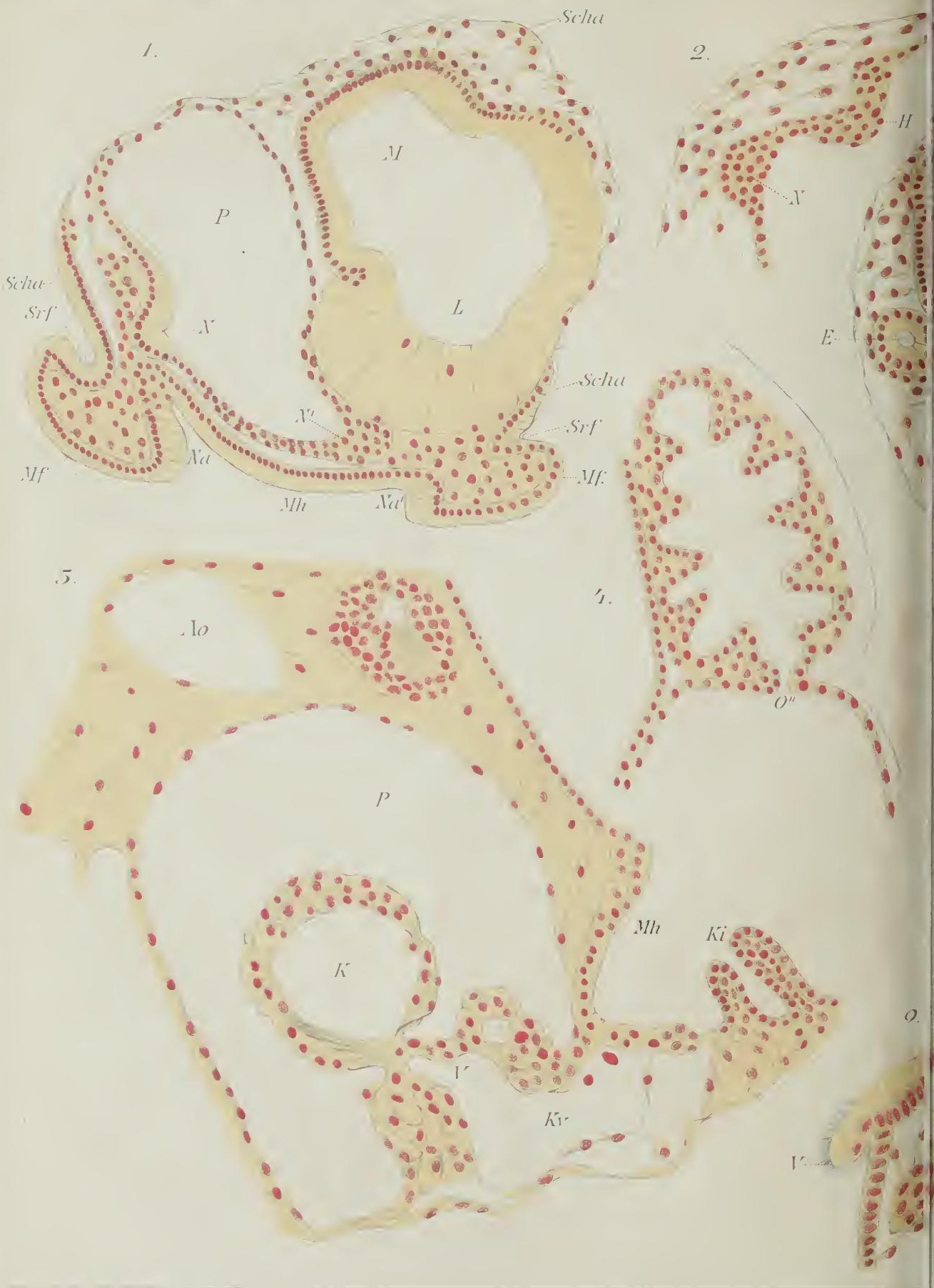





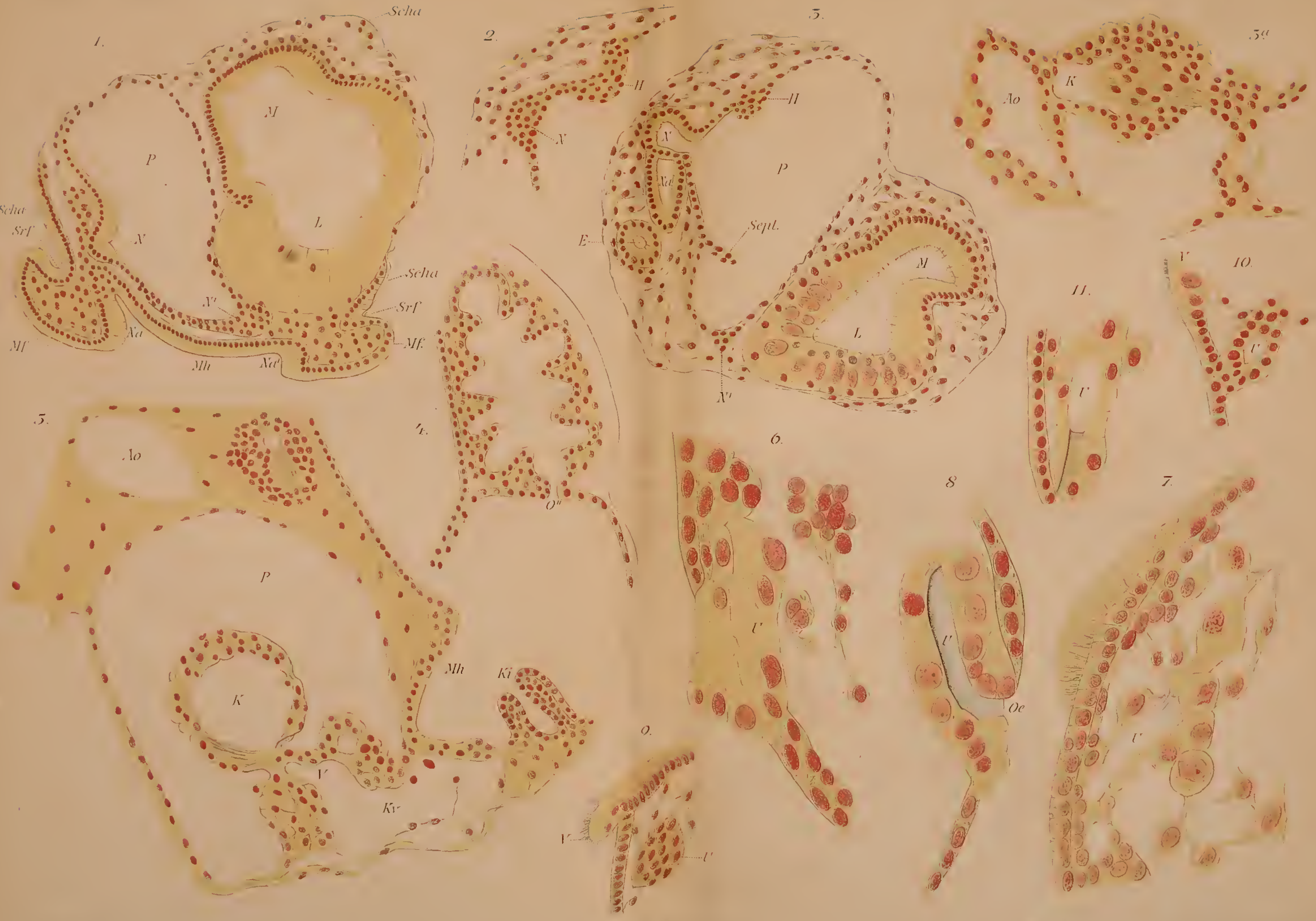





\title{
ZUR ENTWICKLUNG
}

\section{VON \\ PALUDINA VIVIPARA.}

\section{HABILITATIONSSCHRIFT}

ZUR

\author{
ERLANGUNG DER VENIA LEGENDI
}

AN DER

HOHEN NATURWISSENSCHAFTLICH - MATHEMATISCHEN

FAKULTÄT DER UNIVERSITÄT HEIDELBERG

VORGELEGT VON

DR. R. VON ERLANGER.

MIT 2 TAFELN UND 3 FIGUREN IM TEXT.

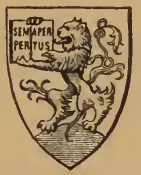

HEIDELBERG.

CARL WINTER'S UNIVERSITÄTSBUCHHANDLUNG. 1893. 



\section{ZUR ENTWICKLUNG}

\section{VON \\ PALUDINA VIVIPARA. \\ HABILITÁTIONSSCHRIFT \\ ZUR}

ERLANGUNG DER VENIA LEGENDI

AN DER

HOHEN NATURWISSENSCHAFTLICH - MATHEMATISCHEN

FAKULTÄT DER UNIVERSITÄT HEIDELBERG

YORGELEGT YON

DR. R. VON ERLANGER.

MT 2 TAFELN UND 3 FIGUREN IM TEXT.

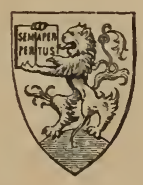

HEIDELBERG.

CARL WINTER'S UNIVERSITÄTSBUCHHANDLUNG.

1893. 
Sonderabdrnck aus: Morphologisches Jahrbuch XVII. Band. Leipzig 1891. 


\section{Zur}

\section{Entwicklung von Paludina vivipara.}

\section{Teil ${ }^{1}$.}

Im ersten Teile dieser Arbeit habe ich bei der Besprechung der Entwicklung des Herzbeutels und der Niere eine eingehende Beschreibung der Vorgänge, welche sich in der allgemeinen Gestaltung des Embryo abspielen, gegeben, so daß ich auf dieselben hier nicht wieder zurückzukommen beabsichtige. Um das ungefähre Alter der behandelten Stadien zu bezeichnen, beziehe ich mich auf die im ersten Teile in toto abgebildeten Embryonen. Es soll jetzt die Entwicklung des Nervensystems, des Cirkulationsapparates und der Geschlechtsorgane behandelt werden.

\section{A. Nervensystem.}

Ehe ich die Entwicklung des Nervensystems bespreche, halte ich es für notwendig, einen Überblick über die Beschaffenheit desselben beim erwachsenen Tiere zu geben und werde dabei die Beschreibung Bouviers (54) zu Grunde legen. Dieser Beobachter, welcher eine größere Anzahl von Prosobranchiaten aus den verschiedensten Abteilungen vergleichend anatomisch auf die Verhältnisse des Nervensystems untersucht hat, giebt von Paludina eine viel genauere Abbildung als v. IHeRING. Ich habe mich selbst, durch Zergliederung ausgewachsener Tiere und Anfertigung von Schnitt-

1 I. Teil s. Morph. Jahrb. Bd. X'III. 
serien durch ältere Embryonen von der Richtigkeit der Bouvier'schen Darstellung überzeugt.

Bouviers Abbildung ist im Holzschnitt wiedergegeben, während

Fig. 1.

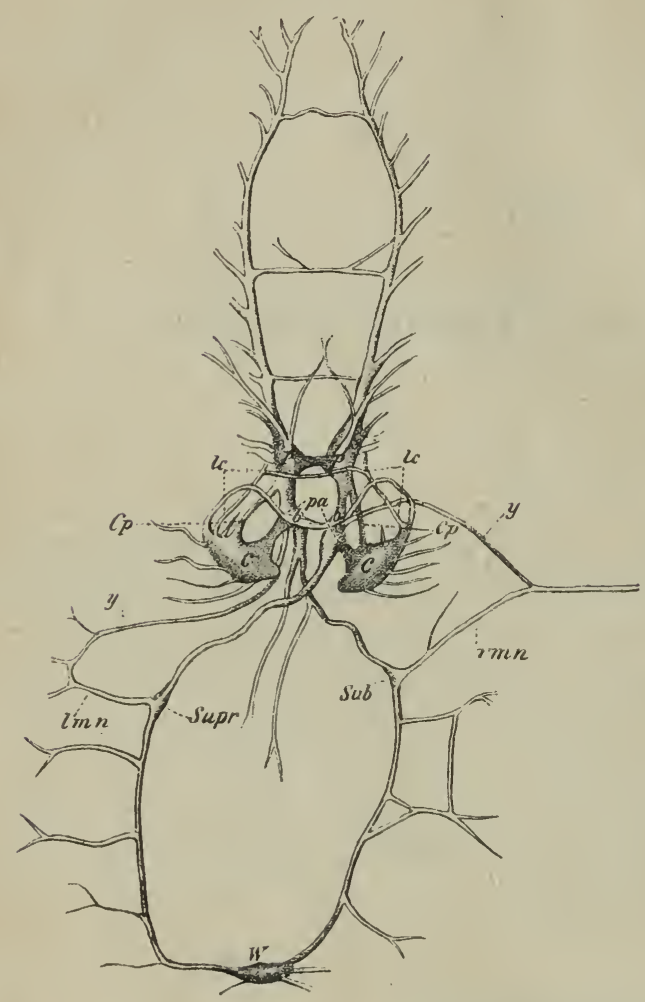

Fig. 9 auf Taf. I die Topographie eines ziemlich entwickelten Embryo veranschaulicht und eine gute Vorstellung von der Lagerung des Nervensystems in Bezug auf die übrigen Organe giebt.

Paludina besitzt zwei Cerebralganglien (c), welche über der Mundmasse und dem Anfang des Schlundes gelegen sind und durch die Cerebralkommissur verbunden werden. Letztere ist im Holzschnitt als durchschnitten dargestellt ${ }^{1}$. Von jedem Cerebralganglion führt je ein Konnektiv zu dem Pedalganglion (P) derselben Körperhälfte; da letztere untereinander durch eine kurze dicke Kommissur zusammen-

hängen, wird auf diese Weise ein geschlossener Nervenring um den Ösophagus gebildet.

Die Pedalganglien gehen ganz allmählich in die sehr dicken und ansehnlichen Pedalstränge über, welche eigentlich nur eine Fortsetzung der Ganglien sind und einen durchaus gangliösen Charakter haben. Sie durchsetzen die Fußsohle in ihrer ganzen Länge und sind durch drei Anastomosen miteinander verbunden. Sie sind in dem Holzschnitt nach vorn umgelegt und ziehen nach vorn, während sie sich in Wirklichkeit nach hinten erstrecken.

1 Den Verbindungsstrang zwischen zwei gleichnamigen Ganglien nenne ich Kommissur, den zwischen zwei ungleichnamigen Konnektiv. 
Auch die Cerebralganglien besitzen eine langgestreckte Gestalt und laufen in der Mittellinie in die ziemlich lange Cerebralkommissur aus, nach den Seiten ebenfalls ganz allmählich in je ein langes Konnektiv aus, welches das Cerebralganglion mit dem Buccalganglion (b) derselben Seite verbindet. Die, unter dem Schlund, zwischen demselben und der Radulatasche gelegenen Buccalganglien erscheinen beim erwachsenen Tiere als Anschwellungen der Buccalkommissur, welche sie untereinander verbindet.

Der Vorsprung der Cerebralganglien, der das Cerebrobuccalkonnektiv erzeugt und von Bouvier Labialvorsprung (Saillie labiale) genannt wird, schickt noch eine Labialkommissur aus, welche eine neue Verbindung zwischen den Cerebralganglien bildet.

Während die Cerebropedalkonnektive verhältnismäßig lang und dünn waren, sind die Cerebropallialkonnektive kurz und dick; sie verbinden, wie der Name besagt, die Cerebralganglien mit den Pallialganglien $(\mathrm{Pa})$ (auch Kommissural-- oder Pleuralganglien genannt). Sie schicken je ein Konnektiv zu den Pedalganglien; das Palliopedalkonnektiv geht aber in das Cerebropedalkonnektiv auf, ehe es das entsprechende Pedalganglion erreicht hat. Man sieht daher jederseits außer dem Cerebropedalkonnektiv einen dicken Strang, welcher das Cerebral- und das Pedalganglion verbindet und in dem das Pallialganglion, etwa halbwegs zwischen dem Cerebral- und dem Pedalganglion, eingelagert ist.

Die Visceralkommissur hat in dem Pallialganglion ihren Ursprung. Der Visceralstrang, welcher vom rechten Pallialganglion ausgeht, wendet sich nach links und oben, zieht (Fig. 9 Tafel I) über den langen Ösophagus weg und zeigt etwa mittervegs zum Visceralganglion $(W)$ eine kleine Anschwellung (Supr) (Holzschnitt), welche das Supraintestinalganglion vorstellt, von welchem ein starker Nerv zur linken Mantelhälfte abgeht $(\operatorname{lm} n)$. Von da zieht der rechte Strang weiter bis zum Visceralganglion $(W)$, welches sich etwas dorsal vom Herzen an dem vordersten ventralen Ende der Scheidewand befindet, die den Herzbeutal $(P e)$ von der Mantelhöhle $(M h)$ trennt.

Im Gegensatz zum rechten Visceralstrang zieht der linke aus dem linken Pallialganglion entspringende nach rechts und ventralwärts unter dem Ösophagus zum Visceralganglion (Chiastoneurie). Ein eigentliches Subintestinalganglion ist bei Paludina nicht vorhanden, jedoch ist die Lagerung desselben durch einen starken Nerv 
$(r m n)$, welcher zur rechten Mantelhälfte zieht (in Sub), angegeben. Die Folge wird zeigen, daß den beiden Intestinalganglien eine nicht unwichtige Rolle in der Entwicklung des Nervensystems zukommt.

Nach Bouvier verbinden sich die eben geschilderten rechten und linken Mantelnerven je mit einem Nerven, welcher aus dem Pallialganglion der entgegengesetzen Körperhälfte kommt ( $y$ und $\left.y^{\prime}\right)$. Somit wäre das Nervensystem der ausgewachsenen Paludina in den Hauptzügen geschildert.

Das Ziel der vorliegenden Untersuchung ist nun, den Ursprung der eben besprochenen Ganglien, ihrer Kommissuren und Konnektive zu erläutern. Auf die feineren Verästelungen, der aus ihnen entspringenden Nerven und auf die Innervierung der Organe soll nur da, wo es unbedingt nötig ist, eingegangen werden.

Was zunächst den Ursprung des Nervensystems anbelangt, so habe ich schon in einer vorläufigen Mitteilung ${ }^{2}$ betont, daß derselbe unzweifelhaft in dem äußeren Keimblatt zu suchen ist.

Die Bildungsweise sämtlicher Ganglien, aus denen die zugehörigen Kommissuren und Konnektive hervorgewachsen, ist genau dieselbe. Überall läßt sich als Anlage des Ganglions eine Verdickung des Ektoderms, welches an der Bildungsstelle des Ganglions mehrschichtig geworden ist, konstatieren. Bald darauf lösen sich einzelne Zellen aus dem Verbande los (Fig. 10 Taf. I, Anlage des linken Pedalganglions) und reichen in das Innere hinein, das heißt in den Raum, welcher sich zwischen dem Ektoderm und dem Entoderm befindet, und von den verästelten Zellen des Mesoderms durchsetzt wird. Auf die morphologische Bedeutung dieses Raumes soll in dem Abschnitt, welcher der Entwicklung des Gefäßsystems gewidmet ist, noch einmal zurückgekommen werden.

Da bekanntlich infolge der Beobachtungen Bовкетzкys (11) immer noch von einzelnen ein mesodermaler Ursprung des Nervensystems behauptet wird, so bin ich bestrebt gewesen, einen strikten Beweis für die Unrichtigkeit dieser Ansicht zu bringen. Ohgleich im allgemeinen Kernteilungen bei der Kleinheit der Zellen einiger maßen entwickelterer Stadien von Paludina nicht ganz leicht aufzufinden sind, ist es mir gelungen, solche in den ektodermalen Verdickungen der Ganglienanlagen $\mathrm{zu}$ beobachten, sowie auch in

1 v. Erlanger, Zur Entwicklung von Paludina vivipara. Zoologischer Anzeiger. Nr. 357. 1891. 
den sich davon ablösenden Zellen und zwar ließ sich wiederholt feststellen, daß die Spindelachse senkrecht zur Oberfläche des äußeren Keimblattes gerichet war, wie Fig. 10 Taf. I zur Genüge zeigt.

Ich glaube übrigens, daß das Vorhandensein einer, der Entstehung jedes Ganglions vorhergehenden Verdickung des Ektoderms, die unmittelbare Anlagerung des sich ablösenden Ganglions an das. selbe (Fig. 2-5 und 7-8 Taf. I) und die darauf folgende Dickenabnahme des äußeren Keimblattes, welches zum Schluß wieder einschichtig wird, vollkommen genügen würden, um den ektodermalen Ursprung des Nervensystems sicher zu begründen.

Wenn bei manchen Gasteropoden ein gewisser Unterschied in der Bildung der Cerebralganglien einerseits und der Pedalganglien andererseits beobachtet wird; so verdient bei Paludina ganz besonders hervorgehoben zu werden, daß sämtliche Ganglien in übereinstimmender Weise durch eine Art von Delamination ent. stehen.

Die erste Spur des Nervensystems zeigt sich schon auf verhältnismäßig sehr jungen Stadien, welche noch vollkommen symmetrisch gebaut sind, und zwar tritt sie als eine beiderseitige Verdickung der Seiten des Velarfeldes auf, an den beiden Stellen, wo sich später die Tentakeln bilden. Es sind die Anlagen der Cerebralganglien.

Fig. 2 Taf. I ist ein etwas schräger Querschnitt durch den vorderen Teil eines sehr jungen Embryo. Der Schnitt ist durch das Velarfeld und den noch sehr wenig entwickelten Fuß geführt.

Das Velum $(V)$ ist oben und in der Mittellinie längs, rechts und links quer getroffen und zeigt deutliche Cilien. Über den beiden Querschnitten des Velums, welche als je eine große bewimperte Zelle $(v v)$ erscheinen, bemerkt man jederseits eine mächtige Hervorwölbung des Ektoderms, welches hier eine größere Zahl von Zelllagen zeigt und sich sehr deutlich durch seine gedrängten Kernmassen von den spärlichen Zellen des Mesoderms abhebt.

In der Anlage der Cerebralganglien bemerkt man schon in der Mitte der Verdickung eine kleine Lücke, welche andeutet, daß ein Teil der Ektodermzellen im Begriff ist, sich von dem Mutterboden abzulösen, um das Ganglion zu bilden. Eine genaue Durchmusterung der Schnittserie zeigte, daß die Anlagen der beiden Cerebralganglien $r$ vollkommen getrennt sind, so daß man hier keineswegs berechtigt ist von einer Scheitelplatte zu sprechen. 
Fig. 3 (derselben Tafel) stellt einen Querschnitt durch einen etwas älteren Embryo vor. Man sieht, daß das linke Cerebralganglion sich jetzt vollständig vom äußeren Keimblatt abgelöst hat und eine kompakte längliche Masse (c) bildet. Man könnte, auf Grundlage der abgebildeten Figur, den Einwand gegen die weiter oben mitgeteilte allgemeine Schilderung der Ganglienbildung erheben, daß das Ektoderm nach Ablösung des Ganglions noch immer eine ansehnliche Verdickung zeigt. Die Entwicklung der Cerebralganglien steht thatsächlich hierin in einem scheinbaren Widerspruch mit derjenigen der übrigen Ganglien, was aber daher rührt, daß die verdickten Hervorwölbungen, welche sich über den abgelösten Cerebralganglien befinden und an Höhe stark zugenommen haben (wie ein Vergleich mit Fig. 2 und 3 ergiebt), die Anlagen der Tentakeln sind.

Fig. 3 zeigt auch die Anlage des linken Pedalganglions ( $p$ ). Dasselbe ist vor der dazu gehörigen Otolithenblase gelagert, entsteht aber zeitlich nach dem Gehörorgan (das in Fig. 2 abgebildete Stadium zeigt noch keine Spur von Pedalganglien) und ist im Begriff, sich vom äußeren Keimblatt zu trennen. Auch hier ist der Gegensatz zwischen der kompakten Anhäufung der Ektodermzellen des Ganglions und den Mesodermzellen scharf markiert. Sobald die Ablösung des Pedalganglions erfolgt ist, wird das Ektoderm der betreffenden Stelle der Wand des Fußes wieder einschichtig und bleibt noch einige Zeit durch seine geringere Affinität zu Farbstoffen kenntlich, was wohl auf einen Verlust von Chromatin infolge stark wiederholter Kernteilungen zurückzuführen sein wird.

Ein wenig älteres Stadium zeigt bereits die Bildung zweier weiteren Ganglienpaare. In Fig. 4, welche einem Querschnitt durch das Vorderende entnommen ist (der Radulasack $R d$ ist getroffen), bemerkt man rechts, gleich unterhalb des quer durchschnittenen Velums $(v)$, eine nach innen und oben einwachsende Verdickung des äußeren Keimblattes, welche schon auf früheren Stadien (Fig. 2 und 3) angedeutet war, es ist dies die Anlage des rechten Pallialganglions $(P a)$. Dieses Ganglienpaar entsteht ebenfalls, wie alle anderen Ganglienpaare, so, daß sich die beiden Ganglien zuerst vollkommen voneinander isoliert bilden und nachträglich untereinander verbunden werden.

Embryonen desselben Alters wie das eben besprochene Stadium zeigen die Anlage der Buccalganglien. Es geht aus Fig. 2 und 3 hervor, daß der Ösophagus, welcher bekanntlich durch eine Ein- 
stiilpung des äußeren Keimblattes entsteht, von einer Schicht von Ektodermzellen umgeben ist, welche nicht den Charakter eines Cylinderepithels wie diejenigen des eigentlichen Schlundrohres angenommen haben. Dieselben befinden sich in reger Teilung und bilden (Fig. 3) zwei mächtige Verdickungen jederseits der Radulatasche $(R d)$, welche in Fig. 3 flach getroffen worden ist. In Fig. 4 und 7, welche ebenfalls Querschnitte sind, haben sich die Verdickungen des Ektoderms, welche den Ösophagus umhüllen, zu den Buccalganglien $(f)$ zusammengeballt.

Während die bis jetzt besprochenen Nervencentren alle dem vorderen Ende des Körpers zugehören, bilden sich die Intestinalganglien viel weiter hinten, in der Gegend des vorderen Mantelrandes, wie Fig. 5 zeigt, die einen Querschnitt durch die verdünnte Stelle darstellt, welcher zwischen Kopf und Fuß und vor dem beschalten Hinterende liegt und vielleicht am passendsten als die Taille des Embryo bezeichnet werden dürfte.

An der Stelle, wo jederseits die sehr dünne Ektodermschicht der Bauchfläche in die Verdickung des Mantelrandes übergeht, bemerkt man je eine sich ablösende Verdickung des Ektoderms (supr und $s u b$ ), welche hier noch deutlich mit dem äußeren Keimblatt zusammenhängen, aus welchem sie, wie die Betrachtung etwas jüngerer Stadien lehrt, hervorgehen. Weiter möchte ich hervorheben, daß die Lagerung der beiden Anlagen zuerst eine ganz symmetrische zu beiden Seiten des Darmes und etwas ventralwärts von demselben ist. Auf dem abgebiłdeten Stadium aber ist die Gestalt des Embryo nicht mehr eine symmetrische, da, wie ich schon in dem ersten Teil dieser Arbeit hervorgehoben habe, die Asymmetrie sich schon sehr früh geltend macht. Dem entsprechend springt hier der rechte Mantelwulst stärker hervor als der linke und liegt die Anlage des Supraintestinalganglions schon eine Kleinigkeit weiter dorsalwärts als diejenige des Subintestinalganglions. Mit der zunehmenden Asymmetrie und Torsion des Embryo ändern auch die beiden Intestinalganglien ihre Lagerung. Fig. 11 (Taf. I), welche einer Querschnittserie durch einen Embryo des Stadiums $(0,7 \mathrm{~mm}$ Länge) entnommen ist, zeigt, daß das rechte Ganglion (supr) über den Ösophagus (Oes), das linke (sul) unter denselben gerückt ist, so daß jetzt die definitive Lagerung der Visceralkommissur verwirklicht ist.

Es erübrigt noch, den Ursprung des Visceralganglions zu beschreiben. Wie schon erwähnt wurde, befindet sich dasselbe $(W)$ 
am hinteren Ende des Bodens der Mantelhöhle, vor und dorsal vom Herzen, an dem ventralen Ende der Scheidewand, welche den Herzbeutel $(P e)$ von der Mantelhöhle (Mh) trennt (Fig. 9 Taf. I). Dem entsprechend ist die Bildungsstätte dieses Ganglions zwischen Herzbeutel und Mantelhöhle zu suchen, wo sie auch nicht schwer zu finden ist. Das Stadium, bei welchem es zuerst auftritt, ist schon stark asymmetrisch und entspricht ungefähr einer Länge von $0,9 \mathrm{~mm}$.

Fig. 8 Taf. I zeigt einen Querschnitt durch das beschalte Hinterende eines solchen Embryo, zwischen der Mantelhöhle (Mh) einerseits und Magen und Leber andererseits bemerkt man den durchschnittenen Herzbeutel $(P e)$, welcher hier an seinem vorderen Ende, und zwar an einer Stelle, wo derselbe noch einen sehr geringen Durchmesser zeigt, getroffen ist. Zwischen Mantelhöhle und Herzbeutel ist das Visceralganglion zu sehen, und dasselbe ist gerade im Begriff, sich vom Epithel der Mantelhöhle abzulösen. Die Anlage des Visceralganglions befindet sich deutlich ventralwärts vom Ösophagus, wie die Durchsicht der Serie lehrt. Somit wäre der ektodermale Ursprung sämtlicher Ganglien festgestellt.

Im Gegensatz zu den Resultaten anderer Arbeiten über Gasteropodenentwicklung verdient hervorgehoben $\mathrm{zu}$ werden, daß sämtliche Ganglien ganz isoliert und, wenn es sich um paarige Ganglien handelt, ebenfalls ganz getrennt von ihrem Genossen entstehen. Zeitlich bilden sich zuerst die Cerebralganglien, darauf die Pedalganglien, unmittelbar darauf und nahezu gleichzeitig miteinander die Pallialund Buccalganglien, dann folgen die beiden Intestinalganglien, und die Reihe schließt mit dem Visceralganglion.

Daraus läßt "sich entnehmen, daß die Bildung des Nervensystems progressiv von vorn nach hinten erfolgt. Ganz ähnlich verhält es sich mit der Bildung der Kommissuren und Konnektive. Die Cerebralganglien treten zuerst miteinander in Zusammenhang, und dann mit den Pallial-, den Pedal- und den Buccalganglien, darauf verbinden sich diese Ganglien untereinander in der angeführten Reihenfolge, doch ist zu bemerken, daß keine Kommissur zwischen den Pallialganglien besteht.

Es läßt sich bei Paludina schwer entscheiden, ob die Pallialganglien in näherem Verhältnisse $\mathrm{zu}$ den Cerebralganglien oder zu den Pedalganglien stehen, was in vergleichend-anatomischer Hinsicht. von Wichtigkeit ist, da bei niederen Vorkiemern die Pallialganglien noch in innigem Zusammenhang mit den Pedalganglien stehen, darauf 
in der ansteigenden Reihe in immer engere Beziehungen $\mathrm{zu}$ den Cerebralganglien treten. Bei Paludina liegen sie von Anfang an halbwegs zwischen den Cerebral- und den Pedalganglien.

Von allen Verbindungen der Cerebralganglien mit den anderen nervösen Centren tritt die direkte Verbindung derselben mit den Pedalganglien durch die Cerebropedalstränge (Holzschnitt und Fig. 9 auf Taf. I) am spätesten auf. Dem entsprechend ist sie viel schmächtiger als diejenige, welche auf dem Wege der Pallialganglien erfolgt und zuerst auftritt.

Die Intestinalganglien sind, wie erwähnt wurde, beim erwachsenen Tiere sehr schwach ausgebildet, das Subintestinalganglion existiert sogar nach Bouviers Ansicht als solches gar nicht. Das Nervensystem der Paludina besitzt aber sehr primitive Merkmale, insofern als die Ganglien sehr diffus sind, und es ist daher schwer zu sagen, wo ein Ganglion anfängt und wo es aufhört, da die Kommissuren und Konnektive auf weite Strecken hin von einem Ganglienzellenbelag überkleidet sind. Die langen Pedalstränge z. B. sind durchweg gangliöser Natur. Ebenso sind das Supraintestinalganglion und das Subintestinalganglion, welches durch den Abgang des rechten Mantelnerves angedeutet ist, nichts anderes als Anschwellungen des Ganglienbelags der Visceralkonnektive. In der Entwicklungsgeschichte kommt ihnen aber die Bedeutung $\mathrm{zu}$, daß sie die Anlagestätte des mittleren Teiles der Visceralkommissur sind. Auf dem in Fig. 5 (Taf. I) beschriebenen Stadium stehen nämlich die beiden Intestinalganglien in keinem Zusammenhang mit den Pallialganglien, wie man sich am besten aus dünnen Querschnitten überzeugen kann, ebensowenig mit dem Visceralganglion, welches auf diesem Stadium noch gar nicht vorhanden ist. Es wachsen nun Nervenfasern von den Pallialganglien nach den Intestinalganglien $\mathrm{zu}$, andererseits andere von den Intestinalganglien zu den Pallialganglien, so daß bald ein Zusammenhang zwischen dem rechten Pallialganglion und dem Supraintestinalganglion und dem linken Pallialganglion und dem Infraintestinalganglion hergestellt wird. Auf ähnliche Weise, aber erst später, kommt eine Verbindung zwischen den Intestinalganglien und dem Visceralganglion zu stande. Auf dem in Fig. 9 (Taf. I) in toto dargestellten Stadium existiert dieser Zusammenhang noch nicht vollständig, wie Querschnittserien mit aller Schärfe beweisen, jedoch ist der Zusammenhang zwischen den Pallial- und Intestinalganglien schon deutlich zu konstatieren. 
Ich bin hier absichtlich nicht auf die Frage, wie die Nerven sich bilden, eingegangen. Wie bekannt, könnte dies auf zwei verschiedene Weisen stattfinden: entweder sind die Nerven Auswüchse der Ganglienzellen oder sie bilden sich auf Kosten von Bindegewebszellen, welche sich auf der Bahn des auswachsenden Nerven befinden. Paludina bietet wegen der Kleinheit der Ganglienzellen kein günstiges Material für die Lösung dieses schwierigen Problems, welches übrigens nicht in den Rahmen dieser Arbeit paßt. Ich neige jedoch auf Grund meiner Beobachtungen an Paludina dazu, der ersten Hypothese den Vorzug zu geben.

Die Ganglien von Paludina zeigen den für die Wirbellosen im allgemeinen charakteristischen Bau in ganz typischer Weise. Ein Kern von Nervenfasern und Stützgewebe wird von einem Belag von Ganglienzellen umgeben.

\section{B. Sinnesorgane.}

Man findet bei Paludina vier lokalisierte Sinnesorgane, von welchen drei paarig sind, nämlich die Tentakeln, die Augen und die Otocysten, das vierte unpaar ist, nämlich das Spengel'sche Organ (Geruchsorgan?).

Auf die Bildung der Tentakeln braucht nicht näher eingegangen zu werden, da ihre Entstehung als seitliche Höcker des Velarfeldes schon erwähnt worden ist.

Das Gehörorgan, welches, wie bei allen Mollusken, die Gestalt eines Bläschens mit eingelagerten Otolithen besitzt, zeigt sich zeitlich zuerst. Es bildet sich durch eine grubenförmige Einstülpung des Ektoderms, welche sich allmählich zu einer Blase abschnürt.

Fig. 1 (Taf. I) zeigt links in $O t$ die Anlage des Gehörorgans, welches zwischen Kopf und Rumpf und der dorsalen Grenze des Fußes liegt. Auf dem hier abgebildeten Stadium ist der Embryo noch vollkommen symmetrisch gebaut, die Schalendrüse ist schon gebildet und der Fuß ist im Entstehen, d. h. zeigt sich jederseits als eine Verdickung des Ektoderms der Ventralseite, welche das Material für seine Bildung abgiebt.

In Fig. 2 derselben Tafel ist das Gehörorgan viel weiter entwickelt. - Es fängt bereits an sich abzuschnüren und liegt schon bei dem Stadium, welchem Figur 3 entnommen ist, vollkommen frei unter dem Ektoderm, es zeigt sich von nun an als eine Blase, deren Wandlungen aus hohen cylindrischen Epithelzellen bestehen. Die 
Zellen der Blase sind eine Zeit lang ventralwärts am höchsten, dorsalwärts am niedrigsten, bis im Laufe der Entwicklung dieser Unterschied wieder ausgeglichen wird. Was die Bildung und das Aussehen der Otolithen anbelangt, so rerweise ich auf die LeydiGsche Arbeit (1), da ich an dem konservierten Material, dessen ich mich vorzugsweise bediente, dieselben nur an reifen Embryonen fand, da allerdings in der Mehrzaehl (3-4).

Das Auge legt sich später an als das Gehörorgan. Es zeigt sich erst auf einem Stadium, bei welchem die Tentakelanlagen schon deutliche Hervorwölbungen des Velarfeldes bilden $(0,64 \mathrm{~mm})$, zwischen der Basis des Fühlers und dem Velum selbst als eine grubenförmige Einsenkung des Ektoderms. Figur 12 auf. Taf. I stellt den Augenbecher vor, welcher auf einem Querschnitt unter der Tentakelanlage $F$ und über dem quer durchschnittenen Velum $v$ zu sehen ist.

$\mathrm{Da}$ die erste Anlage der Cerebralganglien zu derselben Zeit vorhanden ist, wo sich die Otolithenblasen anlegen und die Augen erst später entstehen, so trifft die Behauptung, welche öfters für die Mollusken aufgestellt wurde, daß nämlich die Sinnesorgane sich zeitlich vor den Ganglien, welche sie innervieren, bilden, wenigstens für Paludina nicht zu. Diese Behauptung war auf die irrtümliche Ansicht gegründet, daß die Otolithenblase von dem dazu gehörigen Pedalganglion innerviert würde. Es ist aber bekanntlich von LACAZEDuthitrs nachgewiesen worden, daß das Gehörorgan der Gasteropoden nicht von den Pedalganglien, wie frïher allgemein angenommen wurde, sondern von den Cerebralganglien innerviert wird. Der Gehörnerv von Paludina entspringt nach Bouvier (44) ron dem Cerebralganglion, zieht zwischen den beiden Konnektiven, welche von diesen zum Pedalganglion verlaufen, abwärts an ihrer äußeren Fläche entlang, um sodann, sich nach außen wendend, an die Otocyste heranzutreten.

Wir hatten das Auge auf dem Stadium der Einstülpung verlassen. Der Augenbecher schnürt sich gerade wie das Gehörorgan $\mathrm{zu}$ einer Blase ab, welche schließlich ganz frei unter dem Ektoderm zu liegen kommt (Fig. 13 Taf. I au). Das Auge befindet sich bei älteren Embryonen wie beim erwachsenen Tier auf einem Höcker, welcher an der Basis des Tentakels liegt (Fig 9 Taf. I), und nimmt bald eine ellipsoidische Gestalt an. Die Hauptachse dieser Ellipse ist dorsoventral gerichtet. Es lagert sich Pigment in der der Außenfläche abgewendeten Hälfte der Augenblase ab. 
Bei der Kleinheit der Retina-Elemente ist es mir nicht gelungen, etwas über die Entwicklung derselben zu ermitteln, dagegen glaube ich einiges über die Entstehung des Glaskörpers und der Linse berichten zu können.

Die Linse tritt zuerst auf Stadien auf, welche um weniges jünger als der in Figur 9 (Taf. I) ahgebildete Embryo sind.

Fig. 6 (Taf. I) zeigt einen Querschnitt durch das Auge eines derartigen Embryo, auf welchem die Linse (l) im Verhältnis zur Augenblase noch sehr klein ist. Das Pigment dringt in die Retina ein. Die Linse ist in der homogenen Masse eingelagert, welche auch ein starkes Brechungsvermögen besitzt und von feinen Fortsätzen durchzogen wird, welche von den Retinazellen zur Linse ziehen. Ich halte 'es auf Grundlage dieser Befunde für sehr wahrscheinlich, daß Glaskörper und Linse von den Zellen der Augenblase abgeschieden werden, da beide ein homogenes Aussehen besitzen und nichts von geformten Elementen enthalten. Später zeigt die Linse eine konzentrische Streifung, auf welche HILGER ${ }^{1}$ zuerst aufmerksam machte.

Das zuerst von SPEngel bei den Prosobranchiern eingehender beschriebene Organ, welches derselbe als Geruchsorgan deutet, will ich einfach als SPEngel'sches Organ bezeichnen, da bis jetzt kein genügender Grund vorhanden ist, um in dasselbe den Sitz des Geruchssinnes zu verlegen. F. Bennhard hat dieses Organ bei einer größeren Anzahl verschiedener Prosobranchier vergleichend-anatomisch und histologisch untersucht (51) und den Bau desselben bei der Paludina, welche besonders merkwürdige Verhältnisse bietet, beschrieben.

Trennt man den Mantel einer Paludina längs seiner Insertion an der linken Körperseite ab und schlägt ihn nach rechts um, so zeigt sich das Spengel'sche Organ (von einigen Autoren Nebenkieme, von RAY-LANkester Osphradium genannt) auf der rechten Seite der Kieme. Beim unversehrten Tier oder auf Schnitten liegt es natürlich links von der Kieme. Alle anderen Organe, welche in der Mantelhöhle sich befinden, wie Rectum, Harnleiter, Uterus sind auf der rechten Seite gelagert, so daß das Spengel'sche Organ in Gestalt eines länglichen Wulstes sofort in die Augen fällt.

Bei allen übrigen Prosobranchiaten, soweit bis jetzt bekannt

1 C. Hilger, Beiträge zur Kenntnis des Gastropodenauges. Morph. Jahrb. X. 
ist, besteht dasselbe einfach aus einem Wulst, bei Paludina áber sind auf dessen rechter Seite von demselben überdeckt eine Reihe von Gruben, welche von einem besonders hohen Cylinderepithel ausgekleidet werden. Die Zahl dieser Gruben, welche eine variable ist und mit dem Alter zuzunehmen scheint, kann bis zu 20 betragen.

Die Pulmonaten besitzen keine dem Wulst des SPEngeL'schen Organs der Prosobranchier entsprechende Bildung; aber LACAZEDutHIERS $^{1}$ hat bei den Süßwasserpulmonaten in der Nähe des Atemloches, über und hinter demselben, ein kleines Ganglion entdeckt, welches sich am Ende des hinteren Mantelnerven (Nerf palléal postérieur) befindet. Über dem Ganglion fand er weiter eine grubenförmige Einsenkung des Mantels, welche bei den links gewundenen Pulmouaten einfach bleibt, sich aber bei den rechts gewundenen in zwei spaltet. Bernhard betrachtet nun dieses Gebilde als ein Homologon des Sprngel'schen Organs und findet bei Paludina beide Formen nebeneinander: einerseits den Wulst, welcher allen Prosobranchiern zukommt, andererseits die Gruben, welche in vermehrter Anzahl der einheitlichen oder doppelten Einstülpung des Pulmonaten. mantels entsprechen. Er untersuchte hierauf einen etwa $2 \mathrm{~mm}$ langen Paludina-Embryo und fand bei demselben nur neun Gruben. Er schloß daraus, daß bei jüngeren Embryonen wohl ein Stadium zu finden sein müsse, wo nur eine oder ganz wenige Einstülpungen vorhanden seien.

Diese Vermutung wird nun thatsächlich von der Entwicklungsgeschichte bestätigt.

Das Spengel'sche Organ tritt zuerst etwa auf einem Stadium von etwa $1 \mathrm{~mm}$ Länge als ein parallel zur Längsachse gerichteter wulstförmiger Vorsprung der Mantelhöhle auf, welcher sich ein klein wenig links von der dorsalen Mittellinie befindet und daher bei seitlicher Ansicht des Embryo nicht leicht zu bemerken ist. Der Wulst zieht parallel zum Kiemenwulst und fängt etwa in der Gegend des distalen Endes desselben an. Figur 14 (Taf. I) stellt einen Querschnitt durch ein derartiges Stadium vor, auf welchem das Spengel'sche Organ infolge seiner eben erwähnten Lagerung quer durchschnitten ist. Es ist in $S p$ zu sehen und besteht aus einem hohen Cylinderepithel mit sehr dicht gedrängten Kernen, und liegt zwischen dem Kiemenwulst $K i$ und dem Boden der Mantelhöhle, das heißt der

1 Siehe Bernharn, l. c. 
Rückenfläche des Tieres auf der linken Körperhälfte. Auf diesem Stadium ist keine Spur von grubenförmigen Einstülpungen zu sehen, dieselben treten aber auf wenig älteren Stadien und zwar zuerst die hinterste, an welche die übrigen, nach und nach von hinten nach vorn in einer Reihe auftretend, sich anschließen.

Fig. 9 auf Taf. I giebt eine gute Vorstellung von der Topographie eines Stadiums, wo schon zwei Gruben $\left(g r^{\circ}\right)$ angelegt sind und eine dritte im Entstehen begriffen ist. Das Spengel'sche Organ fängt bereits an, seine ursprüngliche Lagerung aufungeben und ist jetzt nahezu senkrecht zur Längsachse gerichtet und parallel zum Mantelwulst; an welchem, wie ich bei dieser Gelegenheit bemerken möchte, eine große Anzahl von fingerförmigen Drüsen $(d r)$ $\mathrm{zu}$ sehen sind.

Fig. 1 (Taf. II) zeigt einen Querschnitt durch das SPengelsche Organ eines $2,8 \mathrm{~mm}$ langen Embryo, bei welchem schon eine größere Anzahl von Gruben entwickelt sind. Eine derselben ist in gr getroffen und dokumentiert sich als eine einfache Einstülpung des Mantelhöhlenepithels. Man kann eine radiäre Anordnung der sie ausscheidenden Cylinderzellen erkennen, welche deutlich sichtbare Wimpern tragen. Links und ventral von derselben liegt der Wulst $(W u)$, welcher aus einem hohen Cylinderepithel besteht.

Die Innervierung des SpengeL'schen Organs erfolgt bekanntlich durch einen Nerv, welcher vom Supraintestinalganglion abgeht und den Wulst in seiner ganzen Länge durchzieht. Derselbe ist in $\mathrm{Ne}$ dargestellt und liegt in einem sehr lockeren Bindegewebe eingebettet, welches den Raum zwischen dem äußeren und inneren Mantelepithel ausfüllt. In dem Nerven selbst erkennt man die Nervenfibrillen, welche weitaus den größten Teil des Stranges bilden, da sie nur von einem spärlichen Belag von Ganglienzellen bekleidet sind.

Das Spengel'sche Organ der Paludina ist demnach mit keinem besonderen Ganglion ausgerüstet, es wird erst geraume Zeit nach der Anlage des Wulstes von dem aus dem Supraintestinalganglion hervorwachsenden Nerv versorgt.

Die Embryologie, sowie die vergleichende Anatomie ergeben, daß das Spengel'sche Organ keineswegs einer verkümmerten Kieme entspricht, wie lange Zeit angenommen wurde (die Prosobranchier, welche noch zwei Kiemen besitzen, zeigen ein paariges oder unpaares Spengel'sches Organ), sondern ein Sinnesorgan repräsentiert, dessen Funktion noch nicht genügend sichergestellt ist ${ }^{1}$.

1 Über die morphologische Bedeutung vergleiche Bernhard, 1. c. 
Ehe ich das Nervensystem und die Sinnesorgane verlasse, möchte ich einiges über eine besondere Art Zellen einschalten, welche bis jetzt noch nicht bis zu ihrer definitiven Gestaltung im erwachsenen Tier verfolgt, von den meisten Untersuchern aber abgebildet und verschieden gedeutet worden sind.

Fol (13) beschreibt bei den Pulmonaten unter dem Namen "Nuchalzellen" eine Anhäufung von besonders großen und eigentümlich gestalteten Zellen, welche sich, wie der Name besagt, in der Nackengegend vorfinden. Die Nuchalzellen hatten schon die Aufmerksamkeit LEREBouLLETs ${ }^{1}$ erregt, welcher sie für nervöse Elemente hielt.

Ray Lankester (4) verwechselte sie mit der Anlage der Cerebralganglien, WoLfsohn (14) hält sie für ein Embryonalhirn und RABI bezeichnet sie kurzweg als rätselhaftes Organ (12), ebenso SARAsin, während FoL sie für besondere Mesodermzellen hält, welche sich vom Ektoderm ablösen. Ganz ähnliche Zellen lassen sich auch bei Paludina in der Nackengegend beobachten.

Auf den Fig. 13 und 14 (Taf. I), 7 und $7 a$ (Taf. II) und 9 bemerkt man diese Zellen. Fig. 13 stellt einen Querschnitt durch den Kopf eines Embryo vor, welcher etwas jünger als der in Fig. 9 (Taf. I) abgebildete ist. Die Nuchalzellen erscheinen hier über dem Ösophagus, von welchem sich rechts die rechte Speicheldrüse abschnürt $(d)$. Ihre Ursprungsstätte ist der hintere Rand des Velums, welcher bei äußerer Betrachtung in der dorsalen Mittellinie eine plattenförmige Verbreiterung zeigt. Von hier wachsen die Nuchalzellen nach vorn und hinten in das Innere des Embryo, indem sie von der Oberfläche in die Tiefe rücken, sich von der Platte ablösen, wie es auf dem eben besprochenen Schnitt zu sehen ist, und vermehren sich dann in ihrer Zahl sehr bedeutend. Sie bilden darauf eine strangförmige Anhäufung, welche in Begleitung des Ösophagus nach hinten zieht (Figur 14 Taf. I).

Fig. 7 und $7 a$, welche älteren Embryonen entnommen sind, zeigen diese Zellen bei starker Vergrößerung. Sie sind bedeutend größer als die übrigen Zellen des Embryo, besitzen eine rundliche bis unregelmäßig polygonale Gestalt, einen oder mehrere Kerne mit sehr deutlichem Nucleolus und Chromatingerüst und zeigen in der Nähe des Kerns eine gewöhnlich halbmondförmige Anhäufung von stark färbbarem Protoplasma (Fig. $7 a$ Taf. II).

1 Annales des sc. nat. zool. IV. Sect. T. XVIII. 1862.

v. ERLanger, Paludina vivipara. 
Im Laufe der Entwicklung breiten sich die Nuchalzellen, wie ich sie einstweilen nennen will, in alle Gegenden des Körpers, im Bindegewebe zwischen den einzelnen Organen aus und entsprechen schließlich den eigentümlichen Bindegewebszellen, welche Brock (51) als Plasmazellen beschrieben hat. ${ }^{1}$.

$\mathrm{Da}$ die fraglichen Zellen vom hinteren Volarrand aus entstehen, und zwar gerade zur Zeit, wo das Velum sich rückzubilden beginnt, also ektodermalen Ursprungs sind, so unterscheiden sie sich scharf von den übrigen Bindegewebszellen, welche mesodermalen Ursprungs sind. Weiter glaube ich, daß das Auftreten der Nuchalzellen mit der Resorption des Velums in einen kausalen Zusammenhang zu bringen ist.

Über die Bedeutung der Nuchal- resp. Plasmazellen ist nichts bekannt. Es liegt jedenfalls kein Grund vor, sie mit WoLfsohn für ein Embryonalhirn zu halten. Fol glaubt darin einen Rest eines rückgebildeten Organs zu erkennen.

Die Entwicklung des Nervensystems bei den Gasteropoden und Mollusken überhaupt beansprucht ein ganz bésonderes Interesse, da bekanntlich von mehreren Forschern die Angabe gemacht worden ist, daß die Ursprungsstätte des Nervensystems im mittleren Keimblatt zu suchen sei, während es doch bei allen anderen Metazoen, von den Cölenteraten aufwärts, vom äußeren Keimblatt stammt. Obgleich die ersten Untersucher, welche sich mit Molluskenentwicklung befaßten, wie Ganin (3) und Salensky (2), die Anlage des Nervensystems im Ektoderm suchten, stellte BoвREтzky (11), welcher zum erstenmale die Schnittmethode bei embryologischen Studien an Mollusken verwertete, die Behauptung auf, daß das Nervensystem hier durchweg aus dem Mesoderm entstehe. Auch FoL (13) glaubte dasselbe für die Pedalganglien der Heteropoden und der Pulmonaten annehmen zu müssen. Jedoch sprechen seine Beobachtungen eigentlich für einen ektodermalen Ursprung, da er die Mesodermanhäufungen, aus welchen die Pedalganglien hervorgehen, vom Ektoderm sich ablösen läßt.

RABI (12) konnte bei Planorbis zu keinem sicheren Resultat in Bezug auf die Entstehung der Pedalganglien kommen. Da er keinen Grund findet, dieselben vom Mesoderm abzuleiten, sieht er sich zur Annahme gezwungen, sie wie die Cerebralganglien von der Sinnesplatte abstammen zu lassen.

${ }_{1}$ Der Name wurde zuerst ron WALDEYER auf gewisse Bindegewebszellen der Vertebraten angewandt. 
Dagegen findet WoLfsorn bei Lymnaeus stagnalis (14) die Anlage sämtlicher Ganglien in Ektodermwucherungen, die der Cerebralgąnglien $\mathrm{zu}$ beiden Seiten des Vorderkörpers, die der Pedalganglien zu beiden Seiten des Fußwulstes.

Sarasin (18) leitet ebenfalls das ganze Nervensystem von Ektodermwucherungen $a b$, eine Behauptung, welche hier keiner weiteren Beweise bedurfte, da er ja kein eigentliches Mesoderm. unterscheidet und dasselbe je nach Bedarf vom Ektoderm sich ablösen läßt. Weiter glaubte er den wirklichen Ursprung der Pedalganglien zuerst festgestellt zu haben, während doch WoLfsohn schon sämtlichen Ganglien, in einer ebenfalls auf Schnitten basierten Untersuchung, eine ektodermalẹ Herkunft zugeschrieben hatte. Im Gegensatz zu der Mehrzahl der Beobachter läßt SARAsin die paarigen Ganglien aus einer gemeinsamen Verdickung entstehen, dann sich trennen und erst nachträglich durch eine Kommissur wieder in Zusammenhang treten.

In demselben Jahre veröffentlichte HADDoN (19) eine kurze Notiz, in welcher er speziell die Bildung der Pedalganglien bei Janthine fragilis bespricht und einen Schnitt abbildet, welcher in überzeugender Weise die Ablösung des Ganglions vorn äußeren Keimblatt der Fußanlage zeigt.

Von nun ab findet man stets dieselbe Ansicht vertreten, nämlich, daß das Nervensystem ganz vom Ektoderm abzuleiten ist.

Kowakevsky (20) zeigte dasselbe für die Nervenstränge der Chitonen, welche als seitliche wulstförmig nach innen vorspringende Verdickungen des Ektoderms entstehen.

SALEnsky (26) läßt ebenfalls sämtliche Ganglien von Vermetus vom Ektoderm abstammen.

Patten (27) neigt zu derselben Ansicht, hat jedoch die Entwicklung des Nervensystems von Patella nur unzureichend erforscht.

Ebenso spricht sich Mac Murrich (29) für den ektodermalen Ursprung der Cerebral- und Pedalganglien aus, und belegt dies durch Abbildungen von Schnitten. Er macht auch auf den Mangel eines unterscheidenden Merkmals zwischen den Mesodermzellen und den zur Bildung der Ganglien sich ablösenden Ektodermzellen aufmerksam und erklärt hieraus, wie diejenigen Beobachter, BoвRETZKy und andere, welche die Ablösung nicht gesehen hatten, zu einem falschen Schluß gelangen mußten.

Ebenso beschreibt $\dot{\mathrm{F}}$. Schuidt $(50)$ in einer vorläufigen Mit- 
teilung die ektodermale Herkunft sämtlicher Ganglien der Pulmonaten.

Endlich studierte Annie P. Henchman (52) die Entwicklung des Nervensystems von Limax maximus und kam für diesen Pulmonaten zu genau denselben Resultaten wie ich für Paludina. Sie betont, daß alle Ganglienpaare und unpaare Ganglien ganz getrennt voneinander entstehen und konnte keine mediane Wucherung finden, wie sie Sarasin für Bythynia fand und mit dem Bauchmark der Anneliden homologisierte. Schmidts und Henchmans Arbeiten wurden mir erst nach Abschluß meiner Untersuchungen zugänglich, ich betrachtete sie daher als eine Bestätigung derselben. Ich habe inzwischen die Entwicklung der Bythynia eingehender untersucht und gefunden, daß die Entwicklung des Nervensystems bei derselben fast genau so verläuft, wie ich es bei Paludina geschildert habe.

Somit dürfte bei sämtlichen Gasteropoden der Ursprung des Nervensystems ein ektodermaler sein. Ich glaube aber, daß diese Behauptung sich auf alle übrigen Mollusken ausdehnen läßt. Zahlreiche Arbeiten haben dies für die Lamellibranchiaten gezeigt, so z. B. die Arbeiten von HATSCHeK $^{1}$ über Terode, von ZIEGLER ${ }^{2}$ über Cyclas, von Kowalevsky ${ }^{3}$ über Dentalium. Was endlich die Cephalopoden anbelangt, so darf man aus den Beobachtungen Vialletons ${ }^{4}$ bei Sepia schließen, daß auch hier das Nervensystem vom äußeren Keimblatt stammt. VIALLETON unterscheidet zwar kein eigentliches Mesoderm und steht daher auf demselben Standpunkt wie SARASIN, doch beweisen seine Abbildungen hinreichend, daß die Ganglien als Verdickungen des Ektoderms entstehen, sich ablösen und in die Tiefe rücken.

Bei dieser Gelegenheit möchte ich bemerken, daß mir die Cephalopoden zur Beurteilung der Mesodermfrage, wegen der großen Masse ihres Dotters, wenig günstig erscheinen, etwa wie hierfür das Vogelei ein weit weniger geeignetes Objekt ist, als beispielsweise die Amphibieneier.

1 B. HATSCHEK, Über Entwicklungsgeschichte von Teredo. Arbeiten des zoologischen Instituts zu Wien. III. 1880.

${ }^{2}$ H. Ersst Ziegler, Die Entwicklung von Cyclas Cornea. Zeitschrift für wiss. Zoologie. Bd. XLI. 1885.

3 A. Kowalerskx, Etude sur l'embryogénie du Dentale. Ann. du Mus. d'hist. nat. de Marseille 1883.

4 L. Vialleton, Recherches sur les prem. phases de développement de la seiche, Ann. sc. nat. Zool. 6. 1888. 
Ich glaube für Paludina den strikten Nachweis der ektodermalen Entstehung des Nervensystems geführt und ein vollständiges Bild der Entstehung der verschiedenen Ganglien, ihrer Kommissuren und Konnektive gegeben $\mathrm{zu}$ haben. Letzteres halte ich insofern für erwünscht, als die meisten Autoren sich auf die Erforschung einzelner Ganglien beschränkt haben und entweder gar nicht oder nur ganz kurz auf deren Verbindungen eingehen.

Betrachten wir nun die Bildung der Sinnesorgane, so ist ihre Entstehung vom äußeren Keimblatt nie angezweifelt worden. Während aber alle anderen Autoren Otolithenblase und Auge durch Einstülpen sich bilden lassen, läßt Fol dieselben bei den Pteropoden (7) und den Süßwasserpulmonaten durch Delamination entstehen. Diese Angabe gewinnt dadurch eine Stütze, daß bei den Pteropoden, den Landpulmonaten und Vermetus die Cerebralganglien durch Invagination entstehen sollen, während sie bei allen anderen daraufhin untersuchten Formen auf dem Wege der Delamination sich bilden. Nichtsdestoweniger erscheint mir dieser Punkt einer erneuten Untersuchung zu bedürfen, da RABL bei Pianorbis Einstülpung der Sinnesorgane beobachtete, was ich selbst bestätigen kann.

Übrigens ließe sich vielleicht auch die Invagination der Cerebralganglien mit der Bildung der Cerebraltuben in einen gewissen Zusammenhang bringen.

Von der Entstehung des Spexgel'schen Organs bei den Prosobranchiern war bis jetzt nichts bekannt, da SARAsin, welcher es allein berücksichtigt hat, den Ursprung desselben nicht feststellen konnte. Fou berichtet einiges über das Lacaze-Duthier'sche Organ der Pulmonaten und erwähnt, daß er bei den Pteropoden ein ähnliches grubenförmiges Organ in der Mantelhöhle gesehen hat.

Ehe ich die Besprechung des Nervensystems verlasse, halte ich es für notwendig, auf die Beziehungen desselben zu der Asymmetrie einzugehen. Schon im ersten Teile dieser Arbeit habe ich berichtet, daß meine Untersuchungen die Theorie Bürschuis (28) über die Entstehung der Asymmetrie bei den Prosobranchiern béstätigt haben. Dasselbe zeigt auch die Entwicklung des Nervensystems.

Ursprünglich liegen bei Paludina die beiden Intestinalganglien symmetrisch zu beiden Seiten des Ösophagus und wir sehen, daß sie Hand in Hand mit der Ausbildung der Asymmetrie ihre definitive Lagerung erreichen, indem das rechte Ganglion über, das linke 
unter den Schlund rückt. Ebenso verändert auch das Visceralganglion seine Lage. Auf dem Stadium, wo es sich vom Ektoderm der Mantelhöhle ablöst, befindet es sich dorsal vom Enddarm und kommt erst später allmählich unter denselben zu liegen. Dieser Punkt erscheint mir insofern von Wichtigkeit, als Bouvier (44) in der ventralen Lagerung der Visceralkommissur der Prosobranchier in Bezug auf den Darm, im Gegensatz zu den Chitonen, bei welchen dieselbe eine dorsale ist, eine Ableitung des Nervensystems der Prosobranchier von einer chitoähnlichen Urform für unstatthaft hält.

Der wichtigste Einwand Bouviers gegen die Bürschli'sche Ansicht ist aber auf die Untersuchung der linksgewundenen Prosobranchier gestützt. Er fand nämlich, daß bei den von ihm untersuchten Arten: Lanistes und Meladomus, die Lagerung der Organe dieselbe bleibt wie bei den rechtsgewundenen Formen, und daß das Nervensystem dem entsprechend genau dasselbe Verhalten bietet. Aus diesen Befunden zog er den Schluß, daß bei den Prosobranchiern die Torsion keinen Einfluß àu die Asymmetrie des Nervensystems hat, während die Pulmonaten, wie schon Lacaze Duthiers gezeigt hat, sich genau entgegengesetzt verhalten, je nachdem sie rechts- oder linksgewunden sind. Daher erklärt Bouvier alle Theorieen, welche die Chiastoneurie auf Grund der Asymmetrie erklären wollen, für verfehlt.

Seit dem Erscheinen seines Hauptwerkes über das Nervensystem der Prosobranchier untersuchte Bouvier eine andere linksgewundene Prosobranchierspezies, Neptunea contraria, und fand, daß sich dieses Tier genau entgegengesetzt zu den früher von ihm untersuchten linksgewundenen Formen verhält. Alle Organe, welche bei den rechtsgewundenen Formen rechts liegen, befinden sich hier auf der linken Seite und umgekehrt. Dieser Verlagerung entsprechend ist auch das Nervensystem verlagert, indem der rechte Ast der Visceralkommissur von Neptunea unter den Ösophagus, der linke über denselben zieht.

Aus diesen Beobachtungen Bouviens geht nun deutlich hervor, daß die Asymmetrie des Körpers und des Nervensystems ganz unabhängig von der Richtung der Einrollung des Eingeweidesackes ist, wie BüTschli ganz besonders hervorgehoben hat, da dieselbe »einem Prozeß von eigenartiger mit der übrigen Asymmetrie nicht direkt zusammenhängender Natur ihre Entstehung verdankt«.

Infolgedessen ist der Einwand Bouviers nicht berechtigt, da ja das Verhalten des Nervensystems der Prosobranchier eng an die 
Asymmetrie desselben gebunden ist, wie die verglęichende Anatornie und die Enbryologie zeigen. Es gilt nun folgendes Gesetz: ist die Asymmetrie mit Ausnahme des Eingeweidesackes eine linksgerwundene, so ist auch das Nervensystem entsprechend verlagert (Neptunea contraria), erstreckt sich aber die linksgewundene Einrollung nur auf den Eingeweidesack (wie bei Lanistes und Meladomus), so wird das Nervensustem nicht beeinflußt.

In einer Abhandlung über »die Windungsverhältnisse der Schale von Planorbis« bemerkt G. Pfeffer ${ }^{1}$ gegen die von Bütschli behauptete Unabhängigkeit der Asymmetrie des Eingeweidesackes der Gastopoden von der übrigen Asymmetrie des Körpers, man wisse seit recht langer Zeit, daß eine spiegelbildliche Umkehrung der Spirale einer Schneckenschale Hand in Hand gehe mit der zugleich auftretenden spiegelbildlichen Umkehrung der Lage sämtlicher Eingeweide. Deshalb ließe sich mit »gutem Recht« gegen Bütschli behaupten, „daß die Thatsachen einen Zusammenhang der Rotation des gesamten Schneckenkörpers mit der Rotation der Schale zeigten«. Bürschli hat nun in seiner Arbeit (28) auf pag. 219 ganz ausdrücklich auf diese von PFEFFÉr angezogenen Thatsachen hingewiesen und zúgegeben, daß ein "gewisser Zusammenhang der Torsion des Eingeweidesackes mit der übrigen Asymmetrie nicht zu leugnen sei«. Gleichzeitig wies er jedoch darauf hin, daß die Untersuchung dexiotroper ${ }^{2}$ (conchiologisch linksgewundener) Prosobranchiaten, so z. B. von Lanistes, welche noch ausstände, für die Entscheidung dieser Frage besonders wichtig sei. Hätte nun Pfeffer die schon vor dem Erscheinen seiner Arbeit publizierten Untersuchungen Bouviers über dje dexiotrope Art Lanistes berücksichtigt, so würde er sich überzeugt haben, daß die schon »seit recht langer Zeit « bekannte Thatsache doch nicht so allgemein gelte, wie er annehmen will, daß sie vielmehr gerade die von Bütschli aus allgemeinen Erwägungen gefolgerte Unabhängigkeit der Torsion des Ein. geweidesackes von der übrigen Asymmetrie vollkommen bestätigen. Bouvier verfiel durch ungenügendes Studium der BüTschli'schen Arbeit in den umgekehrten Fehler wie PFEFFER, indem er übersah,

1 G. Pfeffer, Die Windungsverhältnisse der Schale von Planorbis. Aus dem Jahrbuch der Hamburgischen wissenschaftlichen Anstalten. VII. 1890.

2 Dexiotrop entspricht dem, was die Conchiologen linksgewunden nennen, umgekehrt ist laeotrop dann gleich rechtsgewunden. Die Ausdrucksweise der Conchiologen widerspricht der mathematischen Definition der Spirale. 
daß Bürschli die Unabhängigkeit des Eingeweidesackes von der übrigen Asymmetrie besonders betont hat.

Neuerdings hat v. Ihering ${ }^{1}$ behauptet, daß es ganz unnötig wäre, die Theorien von SPengel, Bütschli und anderen über die Entstehung der Asymmetrie und Torsion zu diskutieren, da die Existenz von Orthoneuren beweise, daß die Verlagerung des Afters nichts mit der Bildung der Chiastoneurie zu thun habe. Obgleich nun eine so summarische Behandlung einer derartigen Frage eigentlich keine Entgegnung verdient, so möchte ich doch auf folgende Punkte aufmerksam machen. Bürsschli betonte, daß die Annahme v. Iherings, daß es unter den Prosobranchiern Orthoneuren gäbe, nur auf oberflächlichen Untersuchungen beruhe, nachdem SPENGEL, wahrscheinlich gemacht hatte, daß die Orthoneurie unter den Vorderkiemern nur eine scheinbare ist. Trotzdem stellte v. IHering ${ }^{2}$ dieselbe Behauptung von neuem auf, obgleich die Untersuchungen Bouviers die entgegengesetzte Ansicht Bütschlis bestätigt hatten. Darauf untersuchte PeLseneer ${ }^{3}$ die in Frage kommenden Formen und zeigte, daß Bouvier mit Recht Ampullaria für chiastoneurisch erklärt hatte, daß die Helicinen und Neritiden ursprünglich auch chiastoneurisch gewesen sein müßten, da bei denselben das Visceralganglion dorsal vom Ösophagus liegt, und daß die scheinbare Orthoneurie auf Rückbildung des dorsalen Zweiges der Visceralkommissur zurückzuführen sei. Die eben angeführten Untersuchungen hätten doch sicherlich eine Besprechung von seiten v. IHerings verdient, um so mehr, als sie den Schluß rechtfertigen, daß es unter den Prosobranchiern gar keine wirklichen Orthoneuren giebt.

Bekanntlich stützte sich SARASIN (18) auf die von ihm beobachtete Entwicklung des Nervensystems der Bythynia, um den von ihm als Bauchkette bezeichneten Teil des Nervensystems: Pedal-, Intestinalund Visceralganglien mit dem Bauchmark der Anneliden zu homologisieren. Er läßt nämlich diese Ganglien sämtlich aus einer Ektodermwucherung der »medianen Bauchlinie» hervorgehen. Gegen diesen Schluß erhebt Bouvier Einspruch auf Grund der Verhältnisse bei niederen Prosobranchiern.

1 H. von Ihering, Sur les relations naturelles des Cochlides et des Ichnopodes. Bull. scient. France et Belgique. XXIII. 1891.

2 H. von Ihering, Giebt es Orthoneuren? Zeitschrift für wiss. Zoologie. Bd. XLV. 1887.

3 P. Pelseneer, Giebt es Orthoneuren? Bull. scientif. France et Belg. XIX. 1888. 
Meine Ergebnisse weichen stark von denen SARasins ab. Ich glaube, daß, wie Bouviers Arbeit zeigt, das Nervensystem der Paludina ein primitiveres ist als das von Bythynia, und so eine bessere Grundlage für phylogenetische Untersuchungen liefert.

Bouvier teilt die Prosobranchier in zwei Gruppen: in die Diotocardier und die Monotocardier. Die Diotocardier sind primitive Formen und besitzen durchweg zwei Vorhöfe und meistens auch zwei Nieren, zwei Kiemen und zwei Spengel'sche Organe. Die Monotocardier dagegen besitzen nur einen Vorhof, und die übrigen oben angeführten Organe sind bei denselben nur in der Einzahl vorhanden.

Wie den Diotocardiern sind die Kommissuren und Konnektive der Paludina sehr lang, die Ganglien diffus, während das Nervensystem der Bythynia im Gegenteil wie das der höchst differenzierten Monotocardier sich durch große Konzentration auszeichnet. Dem entsprechend liegen bei Paludina die Anlagen der Pedal-, der Intestinal- und der Visceralganglien weit voneinander entfernt und gehen keineswegs aus einer gemeinsamen Anlage hervor. Ich neige daher zu der Ansicht, daß, wenn erwähnte Ganglien der Bythynia wirklich aus einer gemeinen Ektodermwucherung hervorgehen, es eine cänogenetische Erscheinung ist, hervorgerufen durch die große Konzentration des Nervensystems.

Da SARAsin sämtliche Entwicklungsstadien bei einer und derselben zu schwachen Vergrößerung gezeichnet hat, so läßt sich in Bezug auf diese Entwicklung des Nervensystems und dessen feineren Bau nicht viel aus seinen Abbildungen entnehmen.

Verschiedene Autoren legen auf das Vorkommen zweier Paare von Exkretionsorganen bei den Mollusken insofern großes Gewicht, da sie in demselben einen Grund sehen, dem Molluskenkörper eine Zusammensetzung aus zwei Segmenten zuzuschreiben, was sie in einen näheren Zusammenhang mit den Anneliden bringen soll. Zu ähnlichen Schlüssen ist auch SARAsIs, besonders in Bezug auf das Nervensystem, gelangt.

Obgleich mir die Hypothese der Zusammensetzung des Molluskenkörpers aus zwei Segmenten berechtigt erscheint, sprechen wichtige, auf die vergleichende Anatomie gegründete Thatsachen eher für eine Verwandtschaft der Mollusken mit den Plattwürmern, bei welchen übrigens schon die Andeutung einer Segmentierung vorkommt. Auf diese Verwandtschaft der Mollusken mit den Plattwürmern hat Bütschli in seinem Aufsatze: „Zur Herleitung des Nervensystems 
der Nematoden " zuerst klar hingewiesen ${ }^{1}$, nachdem v. Ihering einen Teil der Mollusken, seine Ichnopoden, von den Turbellarien abgeleitet hatte.

So bietet das Nervensystem der Amphineuren zahlreiche Anklänge an die Verhältnisse der Plattwürmer, und diese lassen sich bei den niederen Prosobranchiern, den Diotocardiern, in den zahlreichen Anastomosen zwischen den Pedalsträngen wiederfinden, eine Erscheinung, welche sich noch bei Paludina, einem in vielen Hinsichten niedrig stehenden Monotocardier, erhalten hat.

Was die Entwicklung des Nervensystems anbelangt, so bietet dieselbe mindestens ebensoviele Anknüpfungspunkte an diejenige der Plattwürmer als an die der Anneliden.

Ungleich wichtigere Finwände gegen die Verwandtschaft der Mollusken zu den Plattwürmern wären das Vorhandensein bei den Mollusken: erstens eines Afters, zweitens einer echten sekundären Leibeshöhle.

In betreff des ersten Punktes wäre zu bemerken, daß der After hier kein Proktodäum, wie bei den Anneliden, ist, sondern als ein Rest des Blastoporus aufgefaßt werden kann, geht doch bei Paludina der After direkt aus dem Urmund hervor, und spricht nicht in den meisten Fällen die längliche Gestalt desselben dafür, daß der Mund an einem Ende des Spaltes, der After am anderen Ende gebildet wird. In Bezug auf den zweiten Punkt scheint mir die Frage, ob eine Leibeshöhle bei den Plattwürmern existiert oder nicht, eingehender Untersuchung bedürftig zu sein. Brock ${ }^{2}$ glaubt in den beiden Stämmen des Wassergefäßsystems des von ihm entdeckten Trematoden Eurycoelum Sluiteri ${ }^{2}$ den Anfang einer Leibeshöhle zu sehen, da dieselben außerordentlich weit sind (sie nehmen stellenweise mehr als die Hälfte des Querschnittes durch das ganze Tier ein) und keine regelmäßige Begrenzung haben. Ich glaube dagegen, daß bei Eurycoelum die bei den Plattwürmern im allgemeinen stark zurückgebildete Leibeshöhle in ausgiebiger Weise erhalten geblieben ist. Jedenfalls müßte die Frage auf vergleichend-anatomischen sowie auf embryologischem Wege genauer geprüft werden, da die bis jetzt über die Anatomie und Entwicklung der Plattwürmer erschienenen Arbeiten über Existenz und Beschaffenheit der Leibeshöhle keinen genügenden Aufschluß geben.

1 Morph. Jahrb. X. 1885.

2 J. Brock, Eurycoelum Sluiteri n. g. n. sp. Nachrichten von der kgl. Gesellschaft der Wiss. zu Göttingen. Nr. 18. 1886. 
Im Anschluß an die eben berührte Frage von der Abstammung der Mollusken will ich zwei Abhandlungen erwähnen, welche dasselbe Thema eingehend behandeln.

v. InERING ${ }^{1}$ hat neuerdings seine bekannte Theorie von der Phylogenie der Mollusken mit einigen Veränderungen von neuem erörtert. Ich glaube, daß das Stadium der neueren, die Anatomie und Ontogenie der Mollusken behandelnden Litteratur zur Genüge zeigt, daß nur die wenigsten die Ansicht r. IHerings teilen, nach welcher die von Cuvier als Mollusken zusammengefaßten Tiere aus zwei heterogenen Gruppen bestehen, von denen die eine von den Plattwürmern, die andere von den Anneliden abstammen soll. ThIELE $^{2}$ leitet die Mollusken von turbellarienartigen Formen ab, kommt also zu denselben Resultaten wie Bürschli. Es wäre hier nicht am Platze, auf seine Spekulationen über die Phylogenie der übrigen Metazoen einzugehen. THIele beansprucht zwar für die Mollusken eine sekundäre Leibeshöhle oder Cölom, bestreitet aber entschieden, daß dieselbe ein Enterocöl und der Leibeshöhle der Vertebraten homolog sei. Ich brauche nicht hervorzuheben, daß diese Ansicht meinen an Paludina gemachten Erfahrungen vollständig widerspricht.

v. Ihering und Thiele schlagen beide den Wert der Embryologie für die Ermittelung der Abstammung der Tiere sehr gering an. Von anderer Seite ist die Embryologie in dieser Hinsicht gewiß überschätzt worden; doch wird man im allgemeinen zugeben müssen, daß beide Disciplinen sich gegenseitig ergänzen und daß man nur durch Kritik der von der vergleichenden Anatomie, der Embryologie und der Paläontologie gelieferten Thatsachen in der Abstammungslehre weiterzukommen hoffen darf.

\section{Cirkulationssystem.}

Paludina besitzt die für die Mollusken typische Ausbildung des Gefäßsystems, dessen Beschreibung ich nach der Darstellung LEydigs (1) in Kürze folgen lasse und sein Schema beifüge.

Aus der Kieme, welche, wie schon erwähnt wurde, von rechts vorn nach links und hinten in einem Bogen zum Herzen zieht, das am inneren Ende des Bodens cler Mantelhöhle gelegen ist und ron

1 1. c.

2 J. Thiele, Die Stammesverwandtschaft der Mollusken. Ein Beitrag zur Phylogenie der Tiere. Jenaische Zeitschrift für Naturwissenschaft. Bd. XXV. N. F. XVIII. 1891. 
diesem durch ein Septum getrennt wird (vgl. Fig. 9 Taf. I), kommt das Blut als arterielles durch die Kiemenvene $(K v)$ in den Vorhof (Vo). Die Kiemenvene folgt dem Verlauf der Kieme, an deren

Fig. 2.

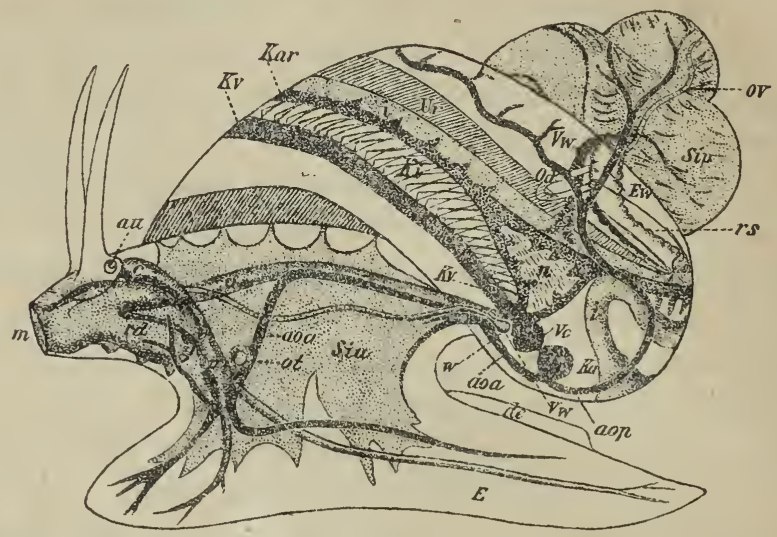

Vorderrand sie hinzieht. Vom Vorhof gelangt das Blut in die Kammer $(K a)$, welche es in die Aorta treibt. Die Wurzel derselben ist außerordentlich kurz, indem sich das Gefäß sofort in zwei Äste teilt, in einen vorderen, die Aorta anterior (aoa), und in einen hinteren, die Aorta posterior (aop).

Die vordere Aorta versorgt den Rumpf, den Fuß und den Kopf. Sie entspringt links vom Schlund, wendet sich aber bald nach rechts und verläuft eine Strecke weit rechts von demselben. Etwa in der Mitte des Rumpfes angelangt, richtet sie sich nach abwärts und begiebt sich, dicht unter der Pedalkommissur verlaufend, in den Fuß, den sie sodann von vorn nach hinten in der Medianlinie durchzieht. Gleich vor der Pedalkommissur schickt sie einen starken Ast in den Kopf und etwas später einen anderen noch bedeutenderen in das Vorderende des Fußes.

Die Aorta posterior (aop) zieht in der der Aorta anterior entgegengesetzten Richtung nach hinten und versorgt die Geschlechtsorgane und die Eingeweide.

Nachdem das Blut die verschiedenen Organe bespült hat, sammelt es sich in den sogenannten Sinusen, nämlich das Blut des Kopfes, Rumpfes und Fußes in dem venösen Sinus (Sia), welcher den Ösophagus umgiebt, oder Rumpfsinus, das Blut des beschalten Hinterendes in dem venösen Sinus, welcher Leber, Magen und Darm umgiebt (Sip). Aus den venösen Räumen entstehen die Venenwurzeln (vw), 
welche schließlich die Kiemenarterie (Kar) bilden, nachdem ein großer Teil des venösen Blutes die Niere $(n)$ durchströmt hat.

Die erste Anlage des Gefäßsystems zeigt sich auf sehr frühen Stadien, und zwar ganz unabhängig von dem Herzen, welches viel später auftritt. Sie zeigt sich in der Gestalt eines Sinus, welcher bereits von Leydig beobachtet wurde, da dessen Pulsationen seine Aufmerksamkeit erregten. Der Sinus liegt am Vorderende des Embryo in der Gegend des Fußes unter dem Darm, ich will denselben als Ursinus (Us) bezeichnen. Fig. 1 (Taf. I) ist ein Querschnitt durch die Schalendrüsengegend eines sehr jungen Embryo, bei welchem Fuß, Urniere und Herzbeutel sich eben anlegen. Zwischen dem Urdarm $(U d)$ und dem verdickten Ektoderm der Fußanlage $(F u)$ bemerkt man auf der rechten Seite des Schnittes eine Anhäufung von Mesodermzellen, welche sich auf dem nächstfolgenden Schnitte auch links zeigt und die Anlage des Herzbeutels vorstellt (vgl. den ersten Teil dieser Untersuchung). Zwischen den paarigen Anlagen des Herzbeutels liegt nù ein Hohlraum, welcher dem sich anlegenden Ursinus entspricht. Da, wie schon früher auseinandergesetzt wurde, der Herzbeutel zum Cölum gehört, so entspricht der Ursinus einem Teil der primären Leibeshöhle oder der Furchungshöhle. In der That entsteht er auch zwischen dem Urdarm und dem anliegenden Mesoderm (splanchnisches Mesoblast), wird aber bald von dem Darm durch eine außerordentlich dünne Lage von Mesodermzellen getrennt.

Während auf dem eben beschriebenen Stadium die Grenzen des Ursinus schwer nachweisbar sind, ist er auf späteren Stadien (Fig 3 und 4 Taf. I) viel schärfer begrenzt, wird aber nach hinten immer enger und endigt vor dem Magen. Um Magen und Leber tritt ein neuer Sinus auf, welcher aber von dem eben erwähnten getrennt und lange nicht so scharf umgrenzt ist.

Der Ursinus, welcher ziemlich regelmäßige Pulsationen ausführt, entspricht einer Art von Larvenherz, ist aber kein vergängliches Gebilde, wie solche im allgemeinen zu sein scheinen, sondern verwandelt sich, indem er mit der Zeit enger und enger wird, in den vorderen Ast der Aorta um, und tritt mit dem Herzen, welches sich mittlerweile aus der Herzbeutelwand gebildet hat, in Verbindung ${ }^{1}$.

1 Bütschli (10) konnte keine Pulsationen im Fuße der Paludinenembryonen beobachten, ich habe mich aber in vielen Fällen von der Richtigkeit der LEYDIGschen Angaben überzeugt. Die Pulsationen zeigen sich nur beim unversehrten Embryo und hören bald, wenn dieser gedrückt oder sonst wie geschädigt wird, auf. 
Wie im ersten Teil dieser Arbeit genauer erörtert wurde, bildet sich das Herz als eine rinnenförmige Einstülpung der Herzbeutelwand und schnürt sich zu einer Röhre ab, deren offene Enden eine Kommunikation zwischen dem Herzbeutel (Cölom, sekundäre Leibeshöhle) und der Furchungshöhle, primäre Leibeshöhle, herstellen.

Fig. 3 (Taf. II) zeigt einen Querschnitt durch einen bedeutend älteren Embryo, bei welchem das Herz schon gut ausgebildet ist und deutlich Vorhof und Kammer erkennen läßt. In Us ist wieder der Ursinus $\mathrm{zu}$ sehen, welcher bereits viel enger geworden ist. Genau an derselben Stelle verläuft später der vordere Aortenast, welcher unter der Pedalkommissur nach vorn zieht. Uebrigens läßt sich der Übergang des Ursinus in die Aorta mit der größten Sicherheit nachweisen.

Auf Fig. 2 (Taf. II), welche einen Querschnitt durch die Herzgegend eines Embryo vorstellt, läßt sich die Entstehung desjenigen Teiles der Aorta $(A 0)$, welcher mit der Herzkammer in Verbindung tritt, verfolgen. Derselbe entsteht aus einem Teil des den Darm und die Leber umgebenden zweiten Ursinus. Die Aorta, deren Anfangsstück dorsal vom Ösophagus und links davon verläuft, richtet sich weiter oralwärts rechts und nach der Ventralseite, um unter dem Schlund den schon geschilderten Verlauf nach vorn zu nehmen. Der Querschnitt Fig. 14 auf Taf. I' zeigt diese Gegend eines Embryo. Ao und Ao sind Teile der Aorta, welche, wie die Durchmusterung der Serie lehrt, in Zusammenhang stehen. Derselbe Querschnitt zeigt ebenfalls die Kiemenvene $K v$ im Querschnitt, deren Ursprung ebenfalls in einem Lückenraum des Mesoderms liegt. Der Zusammenhang der Kiemenvene mit dem Vorhof ( $\left.V_{0}\right)$ ist auf Fig. 2 (Taf. II) $K v$ zu sehen.

Merkwürdigerweise erfolgt die Entstehung der venösen Sinuse erst viel später als diejenige der arteriellen Gefäße. Während auf mittleren Stadien das Mesoderm um den Darm herum (abgesehen von den beiden schon erwähnten Ursinusen) ziemlich kompakt erscheint (vgl. Taf. I Fig. 11, 13, 14 und Taf. II Fig. 3), zieht es sich auf beträchtlich älteren Stadien vom Ösophagus, Magen, Leber und Darm zurück und bildet einen Lückenraum um diese Organe, welche den venösen Teil des Cirkulationsapparates vorstellt (Taf. II Fig. 4 und 7 si). Fig. 7 zeigt den vorderen venösen Sinus, welcher hier dorsalwärts vom Ösophagus getroffen ist und den Plasmazellenstrang umgiebt. 
Die Entwicklung des Gefäßsystems ist bis jetzt nur wenig berücksichtigt worden. Nur die Enstehung des Herzens und der pulsierenden embryonalen Sinuse, welche unter dem Namen Larvenherz zusammengefaßt worden sind, waren Gegenstand eingehenderer Untersuchungen. Im übrigen begnügte man sich damit, anzugeben, daß die Gefäße im allgemeinen im Mesoderm durch Auseinanderweichen seiner Zellen entstehen.

Wie wir sahen, bildet sich bei Paludina der Ursinus zwischen Darm und splanchnischem Mesoblast; ebenso auch entstehen die anderen Teile der Aorta und auch die Sinuse des Cirkulationsapparates zwischen dem splanchnischen Mesoblast und dem Darm oder dem somatischen und dem Ektoderm. Mithin gehen die Gefäße aus der reduzierten primären Leibeshöhle, d. h. der Furchungshöhle hervor. Daher entspricht der Raum, welcher zwischen den beiden Blättern des Mesoderms liegt, nur dem Cölom oder_der sekundären Leibeshöhle, deren Bildung im ersten Teile dieser Arbeit genauer geschildert wurde. Ein sehr großer Teil des Cöloms wird aber von den Spindelzellen des Mesoderms, d. h. dem Blastem des Bindegewebes und der Muskeln ausgefüllt, zu einer Zeit sogar das ganze Cölom, bis sich der Herzbeutel in demselben anlegt. Das Perikard stellt unzweifelhaft den Rest des von Bindegewebe und Muskeln zum größten Teil in Anspruch genommenen Cöloms vor. Ich glaube diese Deutung des Herzbeutels durch zahlreiche vergleichend-anatomische und entwicklungsgeschichtliche Gründe hinreichend motiviert zu haben. Dieselbe wird aber nochmals durch das Studium der Entwicklungsgeschichte des Geschlechtsapparates gestïtzt.

\section{Geschlechtsapparat.}

Die Geschlechtsorgane von Paludina, welche wie weitaus die meisten Prosobranchiaten getrennten Geschlechts ist, sind von LEyDIG (1) und Baudelot (39) genauer untersucht worden. Ich habe die Beobachtungen dieser Forscher durch Zergliederungen und Schnitte kontrolliert und kann denselben in anatomischer Hinsicht nichts Neues hinzufügen. Für die Beschreibung der Geschlechtsorgane halte ich mich an BAUDELOT, dessen Abbildungen ich im beistehenden Holzschnitt wiedergebe, für die Lagerung derselben an LEyDIG $^{1}$, dessen Untersuchung das Übersichtsbild entnommen ist. 
Die männlichen Geschlechtsorgane bestehen aus dem Hoden, dem Vas deferens mit seinen verschiedenen Abschnitten, und dem Begattungsorgan, welches durch den umgebildeten rechten Tentakel gebildet wird.

Fig. 3.
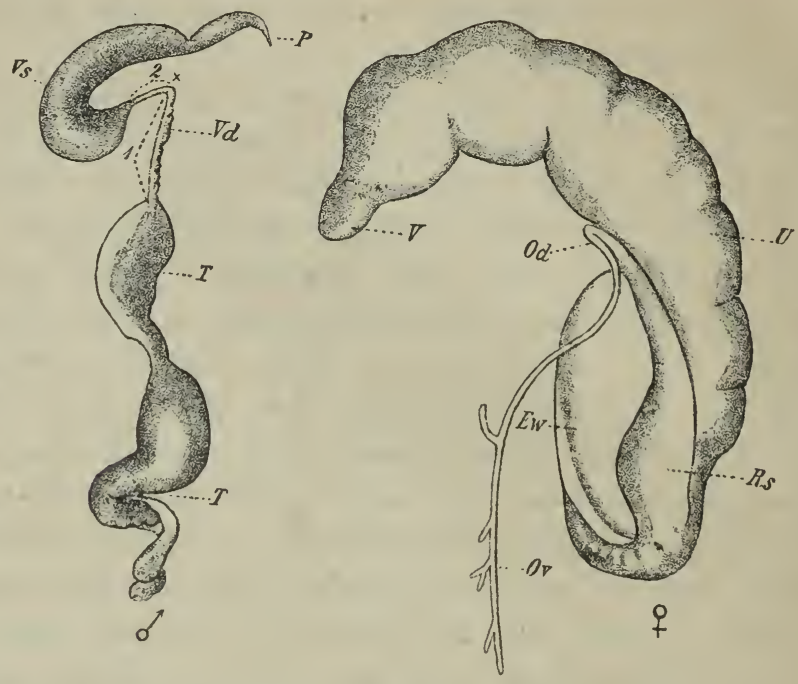

Der Hoden liegt im Eingeweidesack neben der Leber und verläuft der Schalenspindel entlang, deren Windungen er sich anbequemt. Er besteht aus zwei Abschnitten, von denen der kleinere dem vorderen Teile des Eingeweidesackes entspricht, der größere hintere sich bis zu dessen Ende erstreckt (vgl. den Holzschnitt TT). Beide Lappen sind miteinander durch einen verengten Abschnitt verbunden. Der Hoden hebt sich durch seine intensiv gelbe Farbe von der dunkelbraunen Leber ab und fällt, wenn man die Schale entfernt hat, sofort in die Augen.

Das Sperma wird durch das Vas deferens $(V d)$ aus dem Hoden herausgeführt. Dasselbe besteht zunächst aus einem, gleich auf den Hoden folgenden geraden Abschnitt, biegt dann aber ganz plötzlich in einem Winkel an dem inneren Ende des Bodens der Mantelhöhle um und erweitert sich bald zu dem stark muskulösen Abschnitt, welcher von einigen Autoren Samenblase, Vesicula seminalis (Vs), von anderen Prostata genannt wird und vielleicht passender als Ductus ejaculatorius aufgefaßt werden dürfte. Dieser Abschnitt erstreckt sich unter der Haut der Rückenseite, von links in der Nähe des Herzbeutels nach vorn rechts verlaufend, bis zur Basis des 
rechten Tentakels. Hier angelangt, verengt sich der Ausführgang wieder stark, um sich im Tentakel selbst wieder etwa auf die Hälfte des früheren Durchmessers zu erweitern und endigt auf einer freien Spitze $(P)$, welche in einer taschenförmigen Einstülpung der Tentakelhaut zurückgeschlagen und untergebracht werden kann. Während meistens der ganze Tentakel als Penis aufgefaßt wird, sieht BAUdelot nur in dieser freien Spitze das eigentliche Begattungsorgan.

Die weiblichen Geschlechtsorgane bestehen aus dem Ovar $(O v)$, dem Eileiter $(O d)$, in welchem eine Eiweißdrüse $(E w)$ zur Bereitung der Eiweißhülle, welche das Ei umgiebt, mündet, dem Uterus, dessen proximales Ende umgeschlagen ist und eine Samentasche (Receptaculum seminis [Rs]) bildet, während das distale Ende den Penis bei der Begattung aufnimmt und daher Vagina $(V)$ genannt wird. Das Ovar $(O v)$ nimmt eine entsprechende Lage im Eingerreidesack ẹin wie der Hoden, ist aber bedeutend dünner als derselbe, während es annähernd dieselbe Länge besitzt wie die männliche Keimdrüse. Die Feinheit des Ganges, denn das Ovar ist röhrenförmig gebaut, bewirkte, daß es längere Zeit der Untersuchung entging, bis es zuerst von JLEYDIG entdeckt wurde ${ }^{1}$. Die weibliche Keimdrüse zeigt dieselbe gelbe Farbe wie der Hoden, sie wird durch die Dotterkörnchen verursacht.

LEYDig fand den Eierstock mit zahlreichen Eiern angefüllt, während BAUDEI.от keine darin nachweisen konnte. Ich habe Querschnitte durch das Ovar ron Paludina geführt und kann die Angaben ILYDIGs bestätigen.

Das Ovar ist eine Röhre mit rundem Querschnitt, besitzt nach außen eine dünne Tunica propria, worauf ein niedriges, etwas kubisches Epithel folgt, aus deren Zellen die Eier sich bilden und stark in das Lumen vorspringen.

Vom Ovar aus gelangen die Eier in den Eileiter $(O d)$, welcher eine plötzliche Knickung erfährt und dessen Schenkel dadurch eng aneinandergepreßt verlaufen. Ich fand dasselbe mit Sperma angefüllt ${ }^{2}$. Die Eiweißdrüse $(E v)$, welche recht groß ist, mündet in

1 Baudelor, dessen Arbeit 13 Jahre nach der Lerdig'schen Abhandlung erschien, erwähnt dieselbe mit keinem Wort.

2 Die Spermatozoen im Eileiter und in der Samentasche gehörten alle zum fadenförmigen Typus, ehenso wie diejenigen, welche sich in der Eiweißhülle der Eier fanden. Ich kann hierin nur die diesbezüglichen Angaben von I. v. Bruxx (Über die doppelte Form der Spermatozoen von Paludina vivipara. Archir für mikr. Anatomie. Bd. XXYIII. 1883) bestätigen. 
den Anfangsteil des Eileiters, an der Stelle, wo er in das Ovar übergeht. Der zweite Schenkel des Eileiters geht allmählich in die geräumige Samentasche über, welche durch eine enge Òffinung in den Uterus führt, der gewöhnlich mit Eiern verschiedensten Alters vollgepfropft ist. Die Öffnung liegt aber nicht am hinteren Ende des Uterus, sondern seitlich, so daß das hintere Ende des Uterus einen Blindsack bildet.

Auf die morphologische Bedeutung der einzelnen Abschnitte des männlichen und weiblichen Geschlechtsapparates, wie auf die Homologien derselben soll erst nach der Schilderung ihrer Entwicklung eingegangen werden, da dieselbe darüber die besten Aufschlüsse gewährt.

Die erste Anlage der Geschlechtsorgane tritt schon verhältnismäßig früh auf, und zwar auf einem Stadium, welches einen noch ganz larvalen Charakter besitzt, d. h. ein noch deutliches Velum und die Urnieren im Naximum ihrer Entwicklung zeigt.

Die Anlage ist von vornherein keine einheitliche, sondern besteht einerseits aus der Anlage der Keimdrüse, andererseits aus derjenigen des Ausführganges. Sie ist aber für beide Geschlechter ganz gleich, denn ein erkennbarer Unterschied zeigt sich erst viel später, wie das Folgende lehren wird.

Die Anlage des Ausführganges ist eine Einstülpung der Mantelhöhle, welche sich am rechten hinteren Ende derselben ventral vom Ureter bildet. Dieselbe $(P a)$ ist in Fig. 5 Taf. II auf einem Querschnitt, in Fig. 8 Taf. II auf einem horizontalen Schnitt, in Fig. 9 Taf. II auf einem sagittalen Schnitt dargestellt ( $g g)$. Gleichzeitig bildet die Wand des Herzbeutels an der der eben besprochenen Einstülpung gegenüberliegenden Stelle der Mantelhöhle eine Ausstülpung (Fig. 5, 8 und 9 auf Taf. II g), welche nichts anderes wie die Anlage der Geschlechtsclrüse ist.

Ich konnte auf Grund einer Schnittserie durch einen Embryo, bei welchem das Septum des Herzbeutels ungewöhnlich lang erhalten geblieben war, feststellen, daß die Anlage der Genitaldrüse in der ursprünglich linken Hälfte des Perikards entsteht, und zwar ungefähr da, wo sich die rudimentäre linke Niere zurückgebildet hat. Ebenso entsteht auch die Anlage des Ausführungsganges an dei Stelle, wo der rudimentäre Ausführgang der linken Niere sich befand, und scheint einfach aus diesem hervorzugehen.

Der Querschnitt (Fig. 5 Taf. II) veranschaulicht die Topographie der Anlagen der Geschlechtsorgane. Der Abschnitt der Mantelhöhle ( $\boldsymbol{M} h$ ), 
weIcher zum primären Geschlechtsgang wird, liegt ventralwärts vom Ureter $(U r)$ zwischen Niere $(N)$, Herzbeutel $(P e)$, dem Endabschnitt des Darmes ( $i)$ und dem Eingeweidesack $(E)$. Auf demselben Schnitt ist die Verbindungsstelle zwischen Herzbeutel und Niere getroffen $(x)$.

Sehr bald schnürt sich die Anlage der Geschlechtsdrüse von der Herzbeutelwand ab (Fig. 9 Taf. II) und bildet dann ein rundes Bläschen $(g)$, dessen Lumen sehr eng ist; gleichzeitig rückt sie dem Geschlechtsgang immer näher. Sie streckt sich dann allmählich in die Jänge (Fig. 10 Taf. II), während der Geschlechts. gang mittlerweile etwa bis zur dreifachen Länge ausgewachsen ist.

Letzterem Stadium entspricht der auf Taf. I Figur 9 in toto abgebildete Embryo, welcher bei Betrachtung von der linken Seite die Anlage des Geschlechtsapparates mit großer Klarheit zeigt $(G g . G)$ : Der Geschlechtsgang $(G g)$ liegt am hinteren ventralen Ende der geräumigen Mantelhöhle $(M h)$, hinter der Kieme $(K i)$, ventralwärts vom Endabschnitt des Darmes und dem Harnleiter (Ur). Er liegt auf der Figur unter dem Herzbeutel $(P e)$, ventralwärts von der Scheidewand, welche denselben von der Mantelhöhle trennt, vor der Urinkammer $(U k)$ und der Niere $(N)$. Er ist im stumpfen Winkel nach hinten und ventralwärts gerichtet. Dicht an sein blindes Ende schlieft sich die Geschlechtsdrüse $(g)$ an, welche etwas nach vorn und stark ventralwärts gerichtet ist und in der Figur unmittelbar über der Leber $(L)$ liegt.

Aus diesen Lagebeziehungen zur Leber erklärt es sich sofort, warum man die Anlage des Geschlechtsapparates nur von der linken Seite am ganzen Embryo sehen kann, sie wird bei Betrachtung von der rechten Seite von der Leber, welche mit ihren Drüsenschläuchen einen großen Teil des Eingerveidesackes einnimmt, vollkommen überdeckt.

Übrigens zeigen Geschlechtsdrüse und Geschlechtsgang genau dieselbe histologische Beschaffenheit, ein Zustand, welcher sich bis zur Geburt der jungen Schnecke und noch längere Zeit darauf erhält.

Von dem eben besprochenen Stadium ab können die Geschlechtsorgane wegen der rasch zunehmenden Größe des Embryo nicht mehr am ganzen Objekt verfolgt werden, und da dieselben zu klein und zerbrechlich sind, als daß sie präpariert werden könnten, so ist man auf die Schnittmethode angewiesen. 
Die Geschlechtsdrüse und der primäre Geschlechtsgang wachwen immer stärker aus und fangen an, sich der Körperform anpassend, $\mathrm{zu}$ winden. Bei Embryonen von 2,5-3 $\mathrm{mm}$ Länge zeigt sich der erste Unterschied in Bezug auf das Geschlecht, insofern sich beim Männchen jetzt das eigentliche Vas deferens anlegt. Nur der gerade auf den Hoden folgende Teil des männlichen Ausführganges entspricht dem primären Geschlechtsgang, der ganze übrige Teil entsteht unabhängig davon durch Einstülpung einer auf dem Boden der Mantelhöhle gebildeten Rinne, welche sich nach der Einstülpung abtrennt und ein unter der Rückenhaut im Bindegewebe liegendes Rohr bildet.

Auf dem in Fig. 6 und 7 der Taf. II algebildeten Stadium verläuft diese Rinne, welche also die Anlage des sekundären männlichen Geschlechtsganges ist, von dem hinteren Ende des Rückenwulstes bis etwa in die Gegend der Otolithenblase nach vorn. Fig. 7 , welche die Rinne bei stärkerer Vergrößerung darstellt, während Fig. 6 nur die Topographie derselben erläutern soll (7 ist ein Stück des in 6 abgebildeten Schnittes bei stärkerer Vergrößerung), zeigt, daß die Rinne durch zwei Falten des Rückenepithels gebildet wird.

Diese Falten dürfen nicht mit den später bei beirlen Geschlechtern auftretenden Falten des. Bodens der Mantelhöhle verwechselt werden, welche eine Art Sipho bilden, welcher das Wasser zu der Kieme leitet. Diese, beim reifen Embryo schon mächtig entwickelten Falten existieren auf dem eben besprochenen Stadium noch nicht.

Bald schnürt sich die Samenrinne zu einer Röhre ab, welche sich in das Innere herabsenkt und als feines Rohr auf der rechten Seite des Embryo von hinten nach vorn wächst (Fig. 4 Taf. II $v d)^{1}$. Das Rohr scheint dann selbständig nach vorn auszuwachsen und gelangt so am Kopfende in den rechten Tentakel hinein, welchen es bald in seiner ganzen Länge durchsetzt, während schon die Rinne nach hinten und links bis zu der Stelle verläuft, wo der primäre Geschlechtsgang in die Mantelhöhle mündet (Taf. II Fig. $11 \mathrm{Gg}$ und $V d$ ). Auf Grund dieser Befunde läßt sich feststellen, daß der ganze vordere Abschnitt der männlichen Ausführ-

1) Die auf der rechten Seite in Fig. 4 sichtbare Falte ist die sogenannte Krause oder Epipodium. Bouvıkr hält dasselbe für ein falsches Epipodium, auf Grund der Innervierung, während Petseneer es für ein echtes Epipodium erklärt. 
gänge bis zu der Knickung (Holzschnitt) auf Kosten des sekundären männlichen Geschlechtsganges entsteht, während der gerade auf den Hoden folgende Abschnitt (mit 1 bezeichnet) dem primären männlichen Geschlechtsgang zum größten Teil entspricht. Auf dem Stadium, wo der Embryo als reif bezeichnet werden kann, d. h. unniittelbar vor der Geburt, steht bereits die Keimdrüse beim Männchen in Zusammenhang mit dem hinteren Ende des primären Geschlechtsganges. Nicht so beim Weibchen, wo der Zusammenhang noch nicht ganz hergestellt ist.

Stadien, welche etwas jünger als das eben erwähnte sind, zeigen, daß bei beiden Geschlechtern ein wenn auch kurzes Stück der Leitungswege der Geschlechtsprodukte aus der Keimdrüsenanlage selbst hervorgeht.

Beim reifen Embryo befindet sich die Keimdrüse beider Geschlechter in einem noch völlig indifferenten Zustand und läßt sich kaum von den Leitungswegen unterscheiden, welche aber noch auf Schnitten einen Flimmerbesatz ihres Epithels zeigen (Fig. 12 Taf. II $G g$ ).

Fig. 12 (Taf. II) stellt einen Querschnitt durch den Spindelteil eines reifen weiblichen Embryo vor. Das Ovar fängt bereits ań, die Ausstülpungen oder kurzen Blindschläuche zu bilden, welche sich am röhrenförmigen Eierstock des geschlechtsreifen Tieres nachweisen lassen.

Bis jetzt ist nur von Entwicklungsvorgängen die Rede gervesen, welche sich innerhalb des Muttertieres am Embryo abspielen. Wie schon erwähnt, wird die junge Schnecke geboren, ehe der Geschlechtsapparat seine definitive Ausbildung erlangt hat.

Für das Männchen ist es möglich, den Ursprung der verschiedenen Teile des Geschlechtsapparates vor der Geburt festzustellen, nicht so für das Weibchen. Hier ermöglicht erst das Auftreten der Eiweißdrüse zu entscheiden, welche Abschnitte dem Mesoderm, welche dem Ektoderm ihre Entstehung verdanken.

Die ersten Spuren der Eiweißdrüse fand ich an jungen Schnecken, welche zwischen 7-9 Wochen alt waren. Sie zeigen sich als Drüsenschläuche, welche als Ausstülpungen des weiblichen Ausführganges entstehen, und zwar dicht vor der Stelle, wo sich der Ausführgang mit der röhrenförmigen weiblichen Geschlechtsdrüse vereinigt hat.

Somit ist die Eirveißdrüse eine ektodermale Bildung. Daß dieselbe wirklich aus dem Geschlechtsgang, welcher jetzt schon mit 
dem Ovar in Zusammenhang getreten ist, hervorgeht, läßt sich leicht aus dem Vergleich mit jüngeren Stadien entnehmen. Die Vereinigung vom weiblichen Ausführgang und dem Ovar findet in der Gegend statt, wo der Verbindungskanal zwischen Herzbeutel und Niere sich befindet. Der weibliche Ausführgang zeigt schon an dieser Stelle die Knickung, welche für den eigentlichen Eileiter (vgl. Holzschnitt 3) charakteristisch ist. Die Drüsenschläuche der Eiweißdrüsen treten gleich in Mehrzahl, 8-12, auf. Das Ovar selbst unterscheidet sich noch gar nicht von dem des Stadiums, von welchem Fig. 12 Taf. II entnommen ist. Das Keimdrüsenepithel ist noch vollkommen undifferenziert.

Es ergiebt sich aus dem Verlaufe der Entwicklung der Geschlechtsorgane, daß die Keimdrüsen beider Geschlechter einander homolog sind, weiter entspricht der gerade auf den Hoden folgende Abschnitt der männlichen Jeitungswege mit Ausnahme eines kurzen unmittelbar auf den Hoden folgenden mesodermalen Stückes der Totalität der weiblichen Ausführgänge, d. h. dem Eileiter, welcher an der Einmündungsstelle der Eiweißdrüse beginnt, dem Uterus und der Vagina. Dem kurzen mesodermalen Teile des männlichen Ausführganges entspricht derjenige Teil des Ovars, welcher sich von der Eiweißdrüse bis etwa zu der Stelle erstreckt, wo der Eierstock Ausstülpungen treibt. Das eigentliche Vas deferens, von der Knickung bis zum rechten Tentakel, ist beim Weibchen gar nicht mit einem homologen Teil vertreten, es ist eine dem Männchen allein zukommende Bildung.

Ich glaube somit einen Überblick über die wichtigsten Punkte in der Entwicklung des Geschlechtsapparates gegeben zu haben und habe die weiteren Veränderungen, welche derselbe bis zu seiner völligen Ausbildung noch durchzumachen hat, die vorwiegend histologischer Natur sein dürften, nicht untersucht.

Ich habe bereits hervorgehoben, daß die Bildung der Geschlechtsdrüse aus dem Epithel des Herzbeutels die Deutung desselben als sekundäre Leibeshöhle oder Cölom bestätigt. Diese Thatsache ist schon durch vergleichend-anatomische Untersuchungen in allen Klassen der Mollusken festgestellt worden. Im ersten Teile dieser Arbeit führte ich schon die Durchbohrung des Herzens durch den Darm, welche sich bei den meisten Lamellibranchien und einigen Prosobranchiern findet, als Bewreis dafür an. Eine wichtige Stiitze für die Homologie des Cöloms und des Perikards wird durch das Verhältnis rer Geschlechtsorgane zum Herzbeutel geliefert. 
Die Untersuchungen Grobbexs ${ }^{1}$ an den Cephalopoden haben ergeben, daß die Geschlechtsprodukte in den Herzbeutel (Cölom) fallen und dort durch die Geschlechtsleiter nach außen geführt werden. Dasselbe Verhalten zeigen die Neomenien.

Bei den Lamellibranchiaten ist dies nur annähernd der Fall, wie ich später erklären will. Ich glaube gezeigt zu haben, daß die Prosobranchiaten prinzipiell dasselbe Verhalten zeigen, wenn man aus der Entwicklung von Paludina auf die übrigen Formen schließen darf.

Ich vermuthe, daß bei den Chitonen ebenfalls die Geschlechtsdrüse aus dem Epithel des Herzbeutels entsteht, da die Lagerungsbeziehungen derselben zum Perikard, mit welchem sie verwachsen ist, sehr dafür sprechen. Wahrscheinlich wird sich auch dasselbe für die Dentalien ${ }^{2}$ herausstellen, deren Herzbeutel erst neuerdings nachgewiesen worden ist.

Von großer Bedeutung sind auch die Beziehungen der Geschlechtsgänge zu den Harnleitern. HuвREснт giebt für Proneomenia Sluiteri und Dondersia festiva ${ }^{3}$ an, daß die Zwitterdrüse in den Herzbeutel führt, von dort gelangen die Geschlechtsprodukte durch die Harnleiter nach außen. Fast dasselbe Verhalten zeigen unter den Lamellibranchiaten die primitiveren Formen, wie die Nuculiden und Solenomya nach den neuesten Untersuchungen von Pelseneer ${ }^{4}$, mit dem Unterschied, daß die Geschlechtsprodukte nicht direkt in den Herzbeutel passieren, sondern in der Höhe des Herzbeutelnierenganges in den Anfangsteil der Niere gelangen. Pelseneer zieht daraus den Schluß, daß bei den Vorfahren der Lamellibranchiaten die Sexualprodukte in das Perikard gelangten. Auch bei den Dentalien soll nach LACAZE-Duthiers ${ }^{5}$ die Geschlechts-

1 C. Grobbex, Morphologische Studien über den Harn- und Geschlechtsapparat, sowie die Leibeshöhle der Cephalopoden. Arbeiten aus dem zoolog. Institut zu Wien. V. 1884.

2 L. Plate, Über das Helz der Dentalien. Zoolog. Anz. XIV. Jahrg. Nr. 357. 1891.

3 A. A. Hubrecht, Proneomenia sluiteri. Gen. IV. sp. n. with remarks on the anatomy and histologie of Amphineura. Niederl. Archiv für Zool. Suppl. 1881. Dondersia festiva. Gen. et spec. nov. Donders Fastbundel. Niederl. Tijdschr. Geneesk. T. 8-9. 1888.

4 P. Peisexeer, Contribution à l'étude des Lamellibranches. Archiv de biologie. XI. 1891. ilu Dentale.

H. De Lacaze-Dtтhers, Histoire de l'organisation et du développement 
drüse in die rechte Niere und gemeinschaftlich mit derselben aus. münden.

Plate ${ }^{1}$ verbesserte diese Angabe dahin, daß die Geschlechtsprodukte einfach durch Platzen der reifen Geschlechtsdrüse in die Niere ergossen werden, und zwar gewöhnlich in die rechte, ausnahmsweise auch in die linke.

v. Ihering (9) behauptet, daß die rechte Niere der Fissurella mit dem Geschlechtsgang gemeinschaftlich ausmündet, indem der Endteil der Niere den Geschlechtsgang aufnimmt.

Boutan (31) bestätigt dies.

Dasselbe gab Wegmann ${ }^{2}$ für Haliotis und DaLL ${ }^{3}$ für Patella zu.

Dagegen leugnet HalLer (30) aufs entschiedenste, daß bei den beiden erwähnten Prosobranchiern der Geschlechtsgang in näherer Beziehung zum Harnleiter stünde. R. PERrier bestätigt wieder die Angaben v. Iherings und Wegmanns, indem er auf Schnitten fand, daß bei Haliotis die Geschlechtsdrüse in den mittleren Teil der Niere ausmündet, bei Fissurella in der Nähe der Nierenmündung. Vergleicht man das Mitgeteilte mit der Entwicklung des Geschlechtsganges bei Paludina, wo derselbe aus dem Ausführgang der rudimentären (ursprünglich) linken Niere entsteht, so ist wohl der Schluß gerechtfertigt, daß bei den Monotocardiern der Geschlechtsgang sich aus dem Harnleiter hervorgebildet hat. Gleichzeitig wird dadurch die ron mir im ersten Teile dieser Arbeit aufgestellte Behauptung, daß die allein erhaltene Niere der ausgebildeten Paludina der linken Niere der Diotocardier und Heterocardier entspreche, bestätigt. Bei diesen Formen ist es ja stets die rechte Niere, in welche beim ausgewachsenen Tier die Geschlechtsdrüse mündet. Dem entsprechend hat die rudimentïre Nicre der Paludina, welche der rechten Niere der Diotocardier entspricht, sich zurückgebildet, und ihr Ausführgang ist zum Geschlechtsgang geworden. v. Ihering giebt in seiner Arbeit über die natürlichen Verwandtschaften der Cochliden und Ichnopoden ${ }^{4}$ eine Übersicht über die allmähliche Entwicklung der Geschlechtsleiter bei den Gasteropoden,

1 L. Plate, Bemerkungen zur Organisation der Dentalien. Zool Anz. 1888. pag. $509-416$.

2 H. Wegrasx, Contribution à l'histoire naturelle des Haliotides. Arch, de Zoologie experimentale. 1. Serie. T. II. 1884.

3 W. H. Dall, Recent advances in our knowledge of the limpets (Patella). Bull. Phil. Soc. Washington. Vol. VII. pag. 4.

4 1. c. 
und zwar bei seinen Cochliden, welche mit der eben vorgetragenen Ansicht harmoniert. -

Demnach stimmen meine Beobachtungen mit den Resultaten der vergleichenden Anatomie überein. Ich will nun versuchen zu zeigen, daß sie ferner mit den Beobachtungen anderer über die Entwicklung der Geschlechtsorgane der Mollusken übereinstimmen, falls man dieselben kritisch prüft und richtig deutet.

Wenn auch die Molluskenentwicklung der Gegenstand zahlreicher Untersuchungen gervesen ist, so haben sehr wenige die Entwicklung des Geschlechtsapparates berücksichtigt und nur EIsig (38), RouzaUd (42), Brock (43) und KLotz (48) haben speziell dieses Thema behandelt. Diese Arbeiten beziehen sich sämtlich auf Pulmonaten, meines Wissens giebt es gar keine Untersuchung, in welcher die Bildung der Genitalorgane bei Prosobranchiern beschrieben ist.

Wenn man von einigen älteren Arbeiten absieht, so kommt zuerst die Untersuchung EIsigs (38) über Lymnaeus in Betracht. Er unterscheidet drei getrennte Anlagen des Geschlechtsapparates. ohne anzugeben, aus welchen Keimblättern dieselben sich anlegen, ein Mangel, welcher sich leicht aus der Zeit, in welcher Ersigs Arbeit verfaßt wurde, erklären läßt.

RouzAud (42) läßt bei mehreren Pulmonaten den ganzen Geschlechtsapparat aus einer ektodermalen Knospe entstehen, welche allmählich in das Innere des Embryo hineinwuchert und sich nach und nach differenziert.

BRock (43) dagegen findet bei Agriolimax agrestis die sämtlichen Leitungswege in einem mesodermalen Strang, welcher erst später mit den gleichfalls aus dem Mesoderm stammenden Geschlechtsdrüsen in Verbindung tritt.

Kцотz (48) nahm die Untersuchungen Eisigs an Lymnaeus wieder auf und fand, daß der Geschlechtsapparat in Ühereinstimmung mit den früheren Angaben sich aus drei getrennten Anlagen bildet. Der Penis entsteht als eine ektodermale hohle Einstülpung, der Uterus und die Prostata entstehen getrennt vom Penis und wahrscheinlich mesodermal, endlich entsteht die Zwitterdrüse wiederum für sich und ebenfalls mesodermal.

Die übrigen Autoren, welche sich mit der Bildung des Geschlechtsapparates befaßt haben, machen darüber nur ganz kurze Angaben.

So läßt Ganin (3) das Epithel der Genitalorgane aus dem Ektoderm entstehen, RABL (5) dagegen bestreitet dies, da er keine Ektodermeinstülpung beobachten konnte. Nach v. Ihering (6), 
welcher nur ältere Stadien berücksichtigte, gehen sämtliche Geschlechtsorgane aus dem Mesoderm hervor.

FoL (7) behandelt nur die Bildung der Keimdrüse bei den Pteropoden und behauptet, daß der männliche Teil derselben aus dem Ektoderm, der weibliche dagegen aus dem Entoderm des Lebersackes entsteht.

Joyeux Laffute (21) sieht bei Onchidium in einer kleinen Hervorragung des Ektoderms in das Innere des Embryo zwischen der Niere und dem After die Anlage der Geschlechtsdrüse. Diese soll sich schon ziemlich früh, etwa zu derselben Zeit wie die Niere anlegen. Er vermutet, daß der genannte Geschlechtsapparat vom äußeren Keimblatt abgeleitet werden dürfte.

Vor dem Erscheinen der KLotz'schen Arbeit gab Schiemenz einen Überblick über die sämtlichen Angaben, welche sich auf die Entwicklung der Genitalorgane bei den Gastropoden beziehen (42). Er kommt durch Vergleichung derselben zu folgenden Schlüssen, welche sehr gut mit den Resultaten meiner Untersuchung über die Entwicklung von Paludina harmonieren.

Es legt sich das Keimorgan nur aus dem Mesoderm an, dann stülpt sich der Penis aus dem Ektoderm ein, dann verbindet sich das Keimorgan mittels des Zwitterganges, der ein Teil von ihm ist, mit dem Ende des Genitalganges und dem Penis mit demselben durch das Vas deferens. Zum Schluß entwickeln sich die accessorischen Organe und Drüsen.

Die Schiemexz'schen Schlüsse beziehen sich sämtlich auf die Pulmonaten, da nur diese eingehender untersucht worden sind. Nun sind die Pulmonaten bekanntlich Zwitter, daher kann man auf Grund der vorliegenden, an einem Prosobranchier, welcher, wie alle zu dieser Gruppe gehörigen Tiere, mit der Ausnahme von Valvata, getrennten Geschlechtes ist, angestellten Beobachtungen nicht direkt auf die zwitterigen Formen schließen. Es scheinen mir aber folgende wichtige Punkte festzustehen.

Die Keimdrüse entsteht aus dem Mesoderm, wahrscheinlich durchgehend aus dem Epithel des Herzbeutels, d. h. der reduzierten sekundären Leibeshöhle; die Leitungswege, mit Ausnahme eines kurzen sich an die Geschlechtsdrüse anschließenden Stïckes, ektodermal, und zwar als eine Einstülpung der Mantelhöhle; das Begattungsorgan entsteht ektodermal, ebenso das Vas deferens, welches sich als eine Rinne anlegt und entweder als eine solche bestehen bleibt oder sich zu einer Röhre abschnürt. Die eben geschilderte 
Bildungsweise des Vas deferens wird durch die vergleichende Anatomie bestätigt, da bei den meisten Prosobranchiern der Samenleiter keine Röhre, sondern eine offene Rinne ist; was wohl als das primitivere Verhalten angesehen werden darf.

Auf Grund dieser Resultate glaube ich auch eine Erklärung der Angaben Fols liefern zu können. Ich vermute, daß die Zivitterdrüse ganz aus dem Mesoderm entsteht, die Leitungswege als eine Einstülpung des Ektoderms. Es ist nämlich sehr unwahrscheinlich, daß ein Teil der Zwitterdrüse aus dem Ektoderm, ein anderer aus dem Entoderm entstehen sollte. Die Lagerung derselben ganz in der Nähe der Leber und zwischen dieser und dem Herzbeutel gestatten den Schluß zu ziehen, daß die Entstehung eine ähnliche wie bei Paludina sein wird.

Diese jetzt abgeschlossene Untersuchung über die Entwicklung von Paludina sollte sich zuerst nur auf die Entwicklung des Herzbeutels und der Niere erstrecken. Es zeigte sich aber bald, daß Paludina ein besonders geeignetes Objekt für die Erforschung der Gasteropodenentwicklung ist, und ich hielt es für wünschenswert, gerade einen Prosobranchier eingehender zu studieren, da deren Embryologie nicht in dem Maße durchbearbeitet worden ist wie z. B. diejenige der Pulmonaten. Daher kommt es auch, daß diese Arbeit nicht so plangemäß eingeteilt ist, als es die meisten Arbeiten zu sein pflegen, welche die ganze Entwicklungsgeschichte eines Tieres behandeln sollen. So ist unter anderem die Furchung nicht beschrieben worden, da es mir nicht gelungen ist, alle nötigen Studien davon zu erhalten. Dasjenige, was ich selbst davon beobachtet habe, sowie die Angaben Bцосhмanns (24), zeigt, daß sie nicht wesentlich von dem für die Gasteropoden typischen Schema abweicht, nur ist der Größenunterschied zwischen den Makro- und den Mikromeren ein geringerer, als es sonst der Fall ist, weil bei Paludina die Dottermenge relativ klein ist. Auch die Entwicklung des Darmes ist nur nebenbei berücksichtigt worden. Jedoch hoffe ich über die meisten wichtigen Punkte genügende Auskunft gegeben zu haben.

Zum Schluß sei es mir gestattet, meinem verehrten Lehrer Prof. Bütschli für das Interesse zu danken, welches er auch dem zweiten Teil dieser unter seiner Leitung ausgeführten Untersuchung entgegengebracht hat.

Heirlelberg, den 1. Juli 1 \$\$1. 


\section{Litteratur-Verzeichnis.}

(Folge und Schluß.)

38) H. ElsıG, Beiträge zur Entwicklung der Geschlechtsorgane von Lymmaeus. Zeitschrift für wiss. Zoologie. Vol. XX. 1869.

39) M. Bavdelot, L'appareil générateur des Mollusques gastéropodes. Ann. sc. nat. zool. 4. Sér. XIX. 1863.

40) H. v. Iherixg, Vergleichende Anatomie des Nervensystems und die Phylogenie der Mollusken. W. Engelmann. Leipzig 1877.

41) J. Ввоск, Untersuchungen über die interstitielle Bindesubstanz bei den Mollusken. Zeitschrift für wiss. Zoologie. Bd. XXXIX. 1883.

42) H. Rouzaud, Recherches sur le développement des organes génitaux de quelques gastéropocles hermaphrodites. Thèse. Montpellier 1885.

43) J. Ввоск, Die Entwicklung des Geschlechtsapparates der stylommatophoren Pulmonaten. Zeitschrift für wiss. Zoologie. Bd. XLIV. 1886.

14) E. L. Bouvier, Système nerveux morphologie générale et classification des Gastéropodes prosobranches. Thèse. Paris 1887.

45) Н. Siмкотн, Über die Genitalentwicklıng der Pulmonaten etc. Zeitschrift für wiss. Zoologie. Bd. XLV. 1887.

46) P. und F. SArasix, Ergebnisse naturwissenschaftlicher Forschungen auf Ceylon. Aus der Entwicklungsgeschichte der Helix Waltonii. 1888.

47) P. Schiemexz, Die Entwicklung der Genitalorgane bei den Gasteropoden. Biologisches Centralblatt. Bd. VII. 1888.

48) J. KLotz, Beitrag zur Entwicklungsgeschichte u. Anatomie des Geschlechtsapparates von Lymnaeus. Jenaische Zeitschrift. Bd. XXIII. 1888.

49) P. Fischer et E. L. Bouvier, Sur l'organisation des Gastéropodes prosobranches sénèstres. Comptes rendus Acad. sc. Paris. T. CX. No. 8. 1890.

50) F. Schuid, Die Entwicklung des Centralnervensystems der Pulmonaten. Sitzber. der Dorpater naturf. Ges. 1890. 26. April.

51) F. Bennalid, Recherches sur les organes palléaux des Gastéropodes prosobranches. Thèse. Paris. Ann. sc. nat. zool. 1890.

52) Axvie P. Hexchun, The origin and development of the central nervous system in Limax Maximus. 


\section{Erklärung der Abbildungen.}

Folgende Bezeichnungen gelten durchweg für alle Figuren.

a After, au Auge, ao Aorta, aoc A. anterior, aop A. posterior.

b) Buccalganglien.

c Cerebralganglien, co Konnektiv.

$d$ Speicheldrïsen, de Deckel, $d r$ Drüsen des Mantelrandes.

err Eiweißdrüse, ect Ektoderm.

$f$ Fühler, $F$ Fuß, $f a$ Falte.

f) Geschlechtsdrüse, gl Glaskörper, gg Geschlechtsgang.

gr Gruben des SpexGel'schen Organs.

$h$ fingerförmige Ausstülpungen des rechten Mantelrandes.

$i$ Darm, $j$ Schalenknopf.

Ka Herzkammer, Kar Kiemenarterie.

$K i$ Kieme, $K v$ Kiemenvene.

7 Linse, $L$ Leber.

$m$. Mund, $M a$ Magen, $M n$ Mantelwulst, $M f$ Mantelfalz, $M h$ Mantelhönle.

$n$ Niere, $n c$ Nerv.

ov Ovar, Od Oviduct, Oe Ösophagus.

ot Gehörorgan.

$p$ Penis.

Pe Herzbeutel.

$q$ Plasmazellen $=$ Nuchalzellen.

$r s$ Receptaculum seminis, rd Radulasack.

sup $v$ Supraintestinalganglion, sul, Subintestinalganglion, Sp SPENGEL'sches Organ, Sch Schalendrüse, Si Sinus, Sia Rumpfsinus, Sip Fingeweidesinus.

$T$ Hoden.

$U$ Uterus, $U_{\text {. }}$ Ureter, $U_{s}$ Ursinus, $U n$ Unniere, $U d$ Urdarm, $I 7$ Urinkammer.

$v$ Velum, $\boldsymbol{V}$ Vagina, $\boldsymbol{V} s$ Vesicula seminalis, $V d$ Vas deferens, $V_{0}$ Vorhof, $V v$ Venenwurzel.

$W$ Visceralganglion.

Wu Wulst des Spengel'schen Organs.

$x$ Einmündung der Niere in den Herzbeutel.

Um das Alter der Embryonen, durch welche die abgebildeten Schnitte gelegt sind, zu bestimmen, wird jedesmal auf die im ersten Teile in toto abgebildeten Embryonen verwiesen.

Die Umrisse sämtlicher Figuren sind mit dem Aввs'schen Zeichenapparat entworfen. Die Vergrößerung ist bei jeder Figur angegeben. 
Sämtliche Schnitte sind so abgebildet, daß man auf die vordere Schnittfläche sieht, indem die Schnitte von der Mundgegend anfangend allmählich nach hinten fortschreitend geführt wurden. Was in der Figur rechts liegt, ist auch beim Embryo rechts, links, links. Benutzt wurden die ZeIss'schen Apochromate. Brennweite: $16-8-4$ und $2 \mathrm{~mm}$ mit den Kompensationsocularen $4-6-8-12$.

\section{Tafel I. $-x \times \times \ddot{i i}$}

Fig. 1. Querschnitt durch die Schalendrüsengegend eines noch sehr jungen Embryo (etwas älter als der auf Taf. XX Fig. ? I. Teil). Vergr. 200.

Fig. 2. Querschnitt durch die vordere Gegend eines etwas älteren Embryo (etwa wie Fig. 1 Taf. XXI I. Teil). Vergr.'100. Die Cerebralganglien sind getroffen.

Fig. 3. Querschnitt durch die vordere Gegend eines Embryo (etwa wie Fig. 2 Táf. XXI I. Teil). Vergr. 100. Die Pedalganglien sind getroffen.

Fig. 4. Querschnitt (obere Hälfte) durch das vordere Ende eines Embryo (etwas älter als der vorhergehende). Das linke Pallialganglion ist getroffen. Vergr. 100.

Fig. 5. Querschnitt durch den Rumpf (etwa wie Fig. 3 Taf. XXI I. Teil). Vergr. 100. Das Supra- und das Subintestinalganglion sind getroffen.

Fig. 6. Querschnitt durch das Auge eines Embryo (entspricht Fig. 9 auf Taf. XXII). Vergr. 200.

Fig. 7. Querschnitt durch die vordere Gegend eines Embryo (etwa gerade so alt wie Fig. 5). Vergr. 100. Die Buccalganglien sind getroffen.

Fig. 8. (Querschnitt durch die hintere Gegend eines Embryo (etwa wie Fig. 1 Taf. XXII I. Teil). Vergr. 100. Das Visceralganglion ist getroffen.

Fig. 9. Ein ganzer Embryo von der linken Seite gesehen. Vergr. 50. Übersichtsbild.

Fig. 10. Querschnitt durch das sich vom Ektoderm ablösende Pedalganglion. Homog. Immersion apochrom. $2 \mathrm{~mm}$ Brennweite. ZeIss.

Fig. 11. Querschnitt durch die Rumpfgegend eines Embryo (etwa wie Fig. 1 Taf. XXII I. Teil). Vergr. 100. Die Palliovisceralkonnektive sind getroffen.

Fig. 12. Querschnitt durch die Augenanlage. Vergr. 200 (etwa wie Fig. 1 Taf. XXI I. Teil).

Fig. 13. Querschnitt durch den Kopf eines Embryo (etwa wie Fig. 9 Taf. I). Vergr. 100. Das rechte Auge ist getroffen.

Fig. 14. Querischnitt durch die mittlere Gegend eines Embryo. Vergr. 100 (etwa wie Fig. 2 Taf. XXII I.' Teil). Das Spenger'sche Organ ist getroffen.

\section{Tafel II. $-Y(Y, 11$}

Fig. 1. Querschnitt durch das Spenger'sche Organ eines etwa $3 \mathrm{~mm}$ langen Embryo. Vergr. 200.

Fig. 2. Querschnitt durch die Herzgegend eines 2,5 $\mathrm{mm}$ langen Embryo. Vergr. 100.

Fig. 3. Querschnitt dicht hinter dem Kopf. Länge des Embryo etwa 2 mm. Vergr. 100. 
Fíg. 4. Querschnitt durch die vordere Rumpfgegend. Länge des Embryo $3 \mathrm{~mm}$. Vergr. 50.

Fig. $4 a$. Querschnitt durch das Vas deferens. Vergr. 400. Derselbe Embryo.

Fig. 5. Querschnitt durch das Hinterende eines Embryo (etwa Fig. 1 Taf. XXII I. Teil). Vergr. 100.

Fig. 6. Querschnitt durch den Vorderteil des beschalten Hinterendes eines Embryo von 2,8 mm Länge. Zur Bildung des Vas deferens. Vergr. 40.

Fig. 7. Das sich einstülpende Vas deferens. Vergr. 40. Aus derselben Serie wie Fig. 6.

Fig. 8. Teil eines horizontalen Schnittes durch Herzbeutel und Kiemenhöhle eines Embryo (etwa Fig. 1 Taf. XXII I. Teil). Vergr. 100.

Fig. 9. Teil eines sagittalen Schnittes durch Herzbeutel und Kiemenhöhle eines Embryo (wenig älter als der. vorhergehende). Vergr. 200.

Fig. 10. Teil eines sagittalen Schnittes durch einen Embryo, welcher etwas jünger als der in Fig. 9 auf 'Taf. I abgebildete ist. Die GeschlechtsIrïse und der primäre Geschlechtsgang sind getroffen.

Fig. 11. Querschnitt durch den vorderen Teil des beschalten Hinterendes. Länge des Embryo 3,4 mm. Vergr. 30.

Fig. 12. Querschnitt durch die Spindelgegend eines reifen weiblichen Embryo. Vergr. 200. 
C. F. Winter'sche Buchdruckerei. 

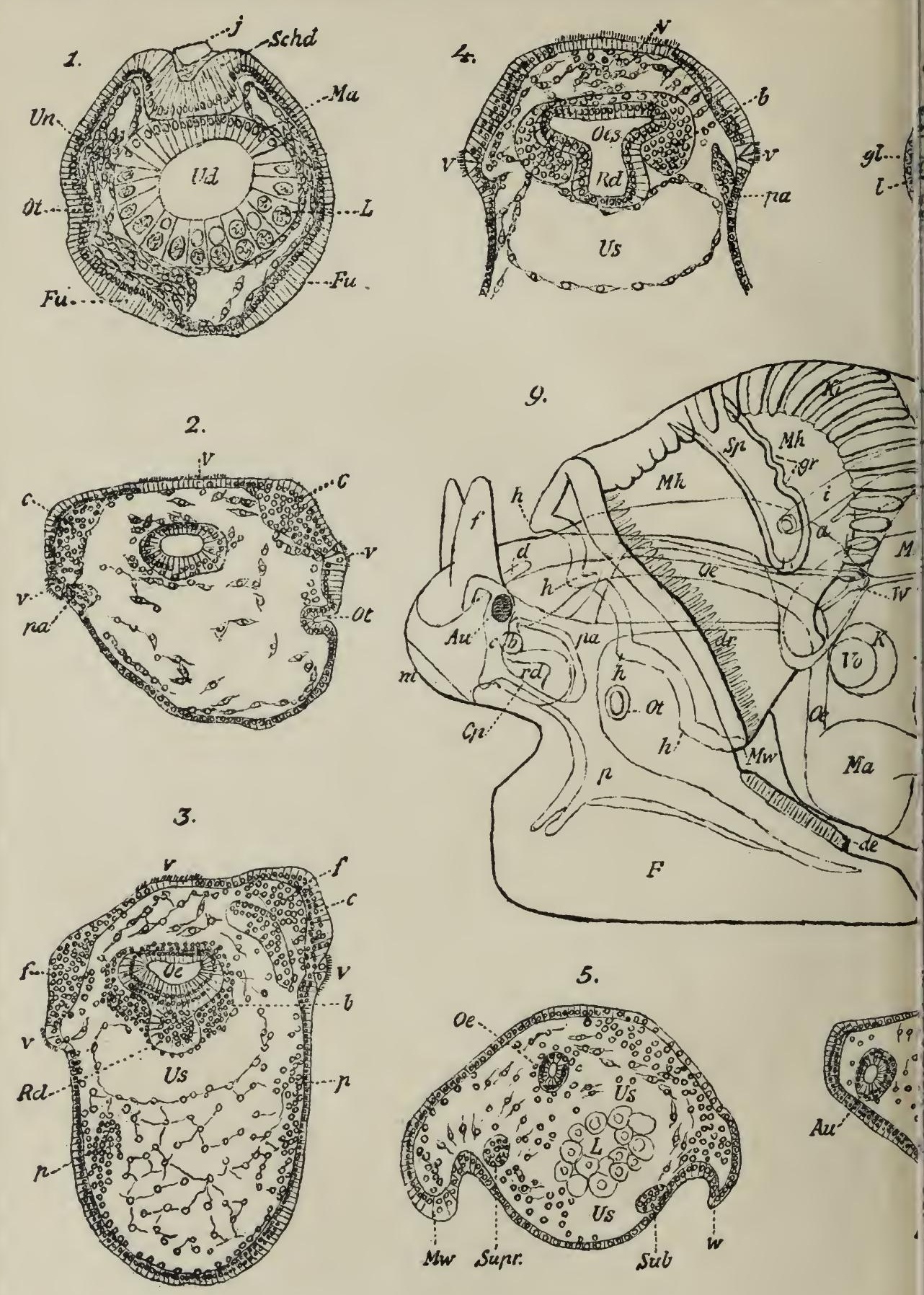

R.v.Erlanyer ad nab del. 


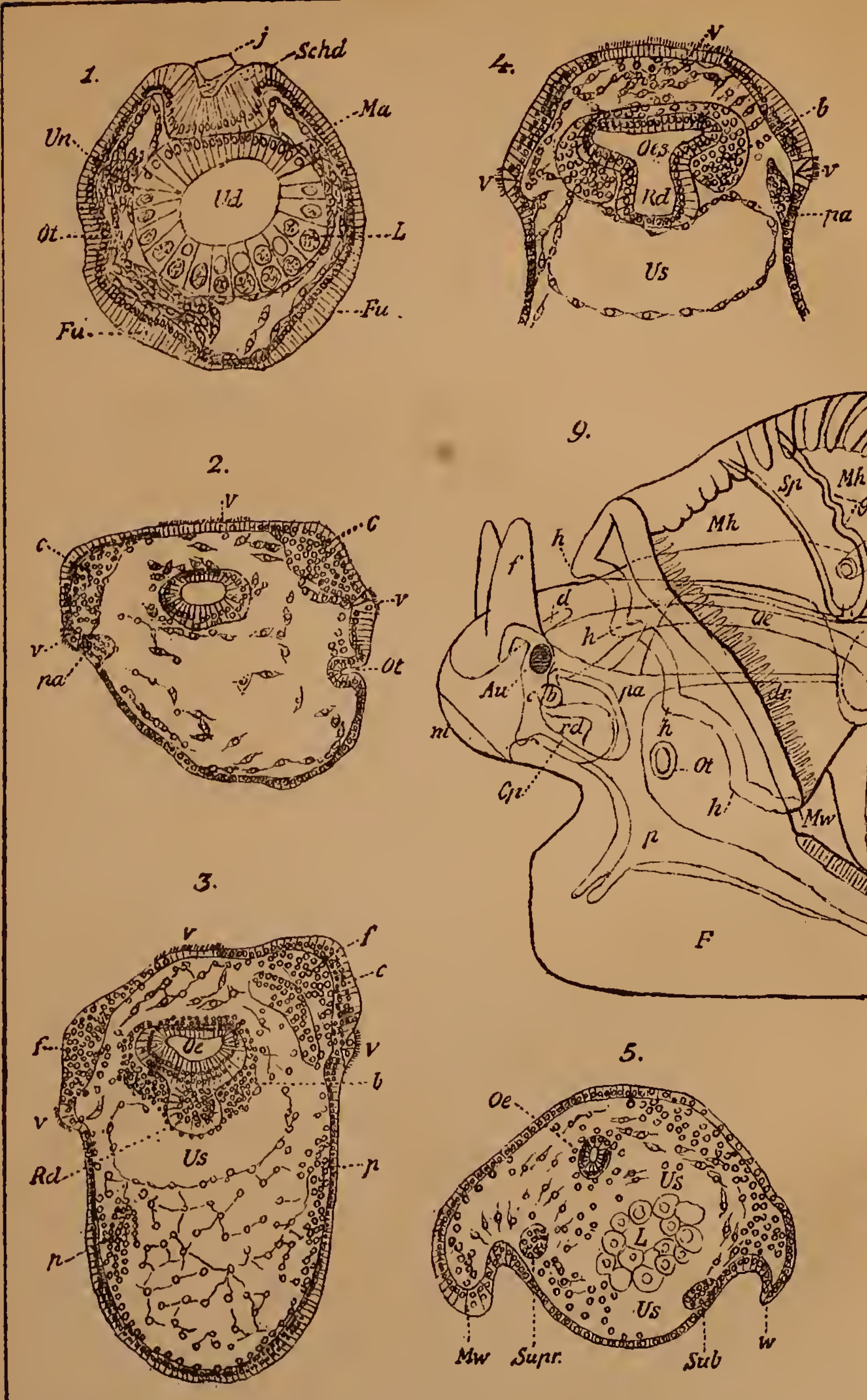
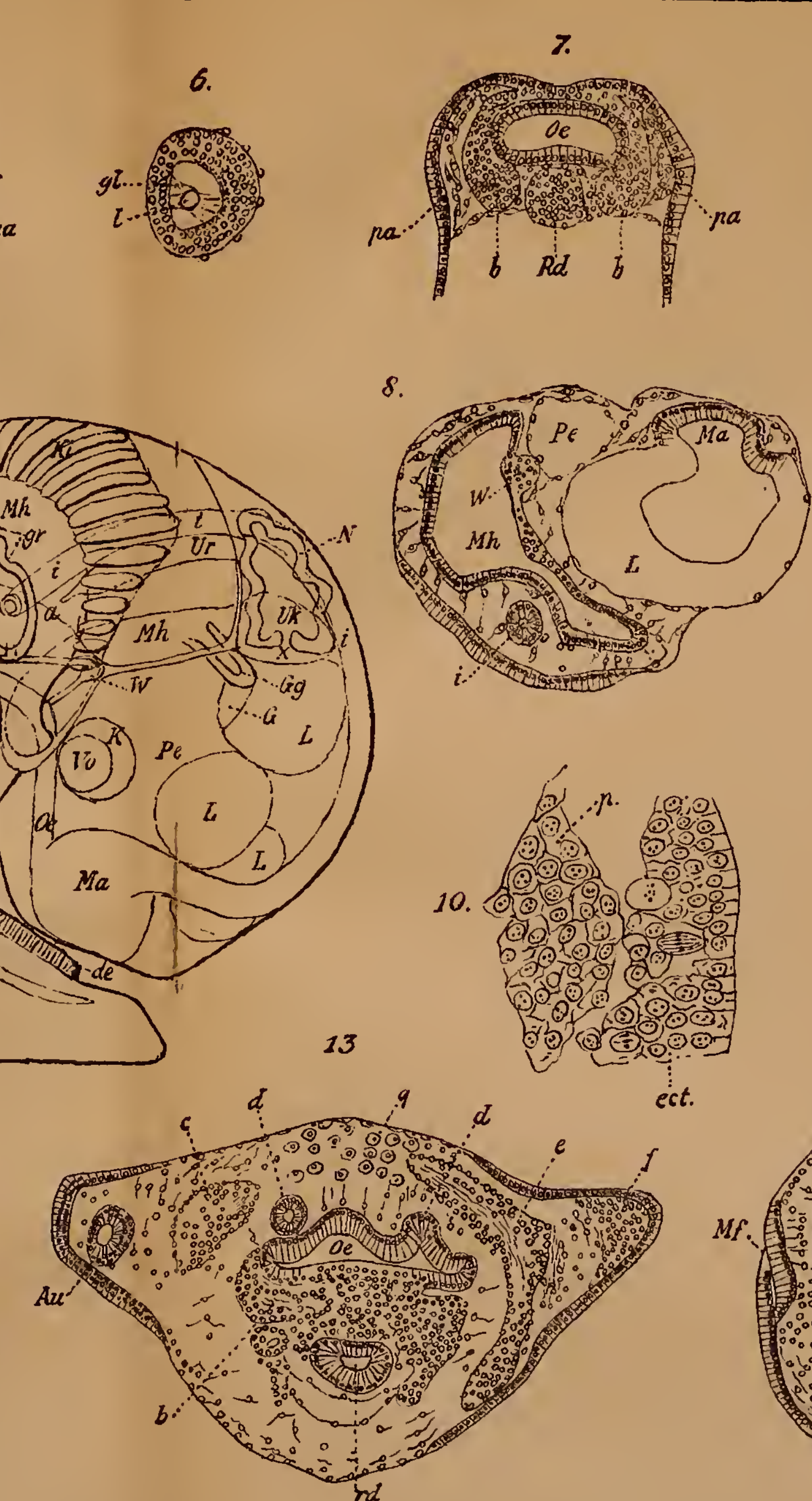
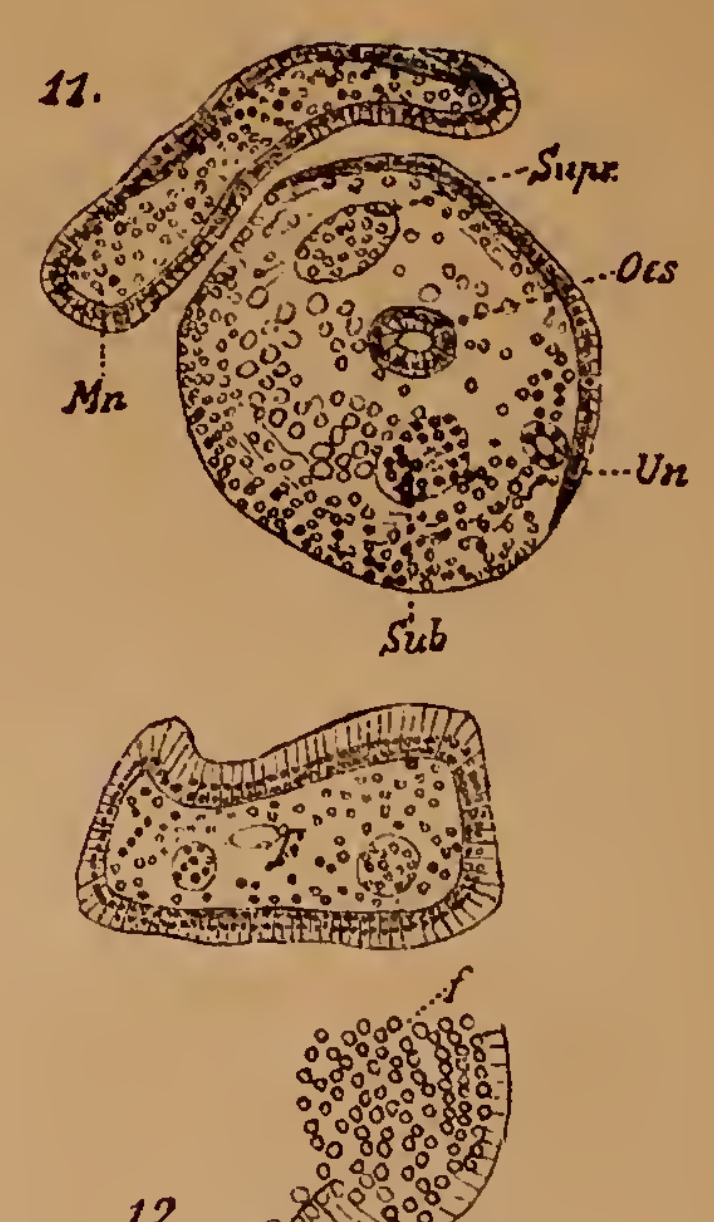

12.
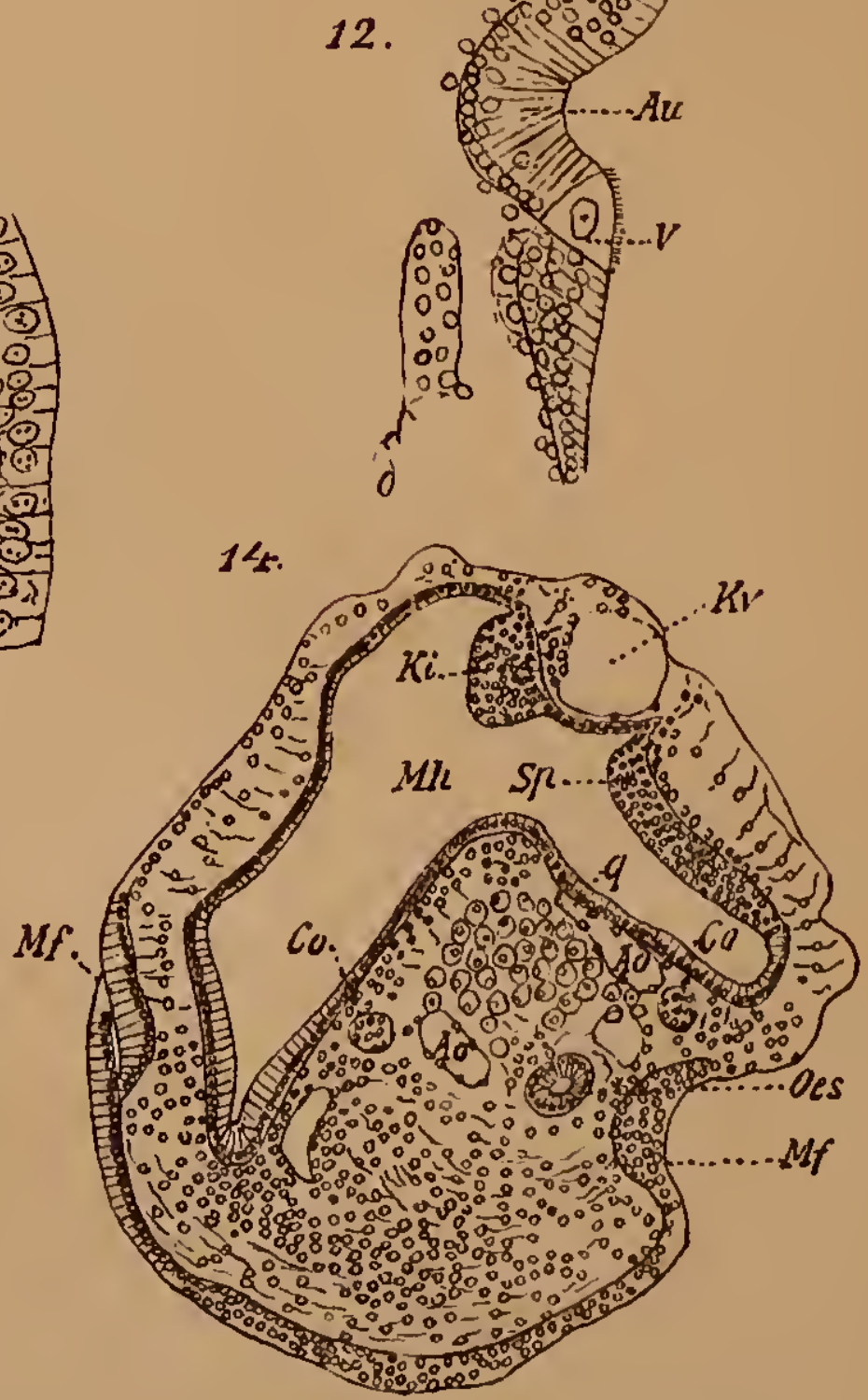



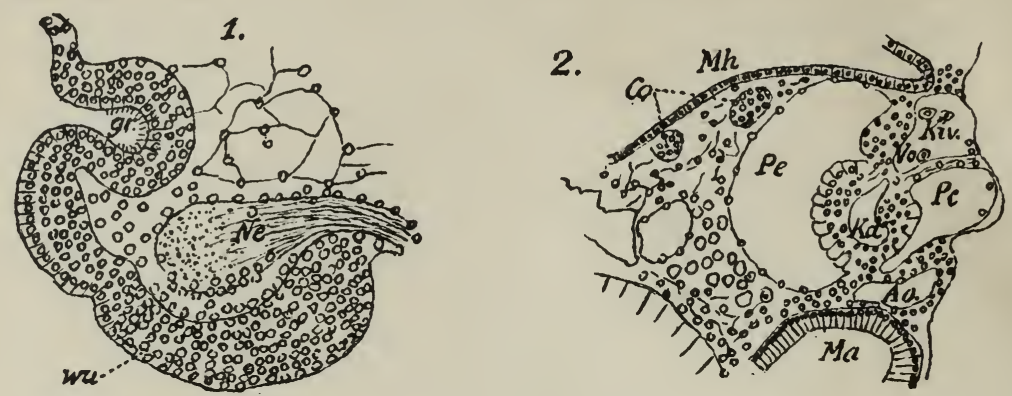

3.
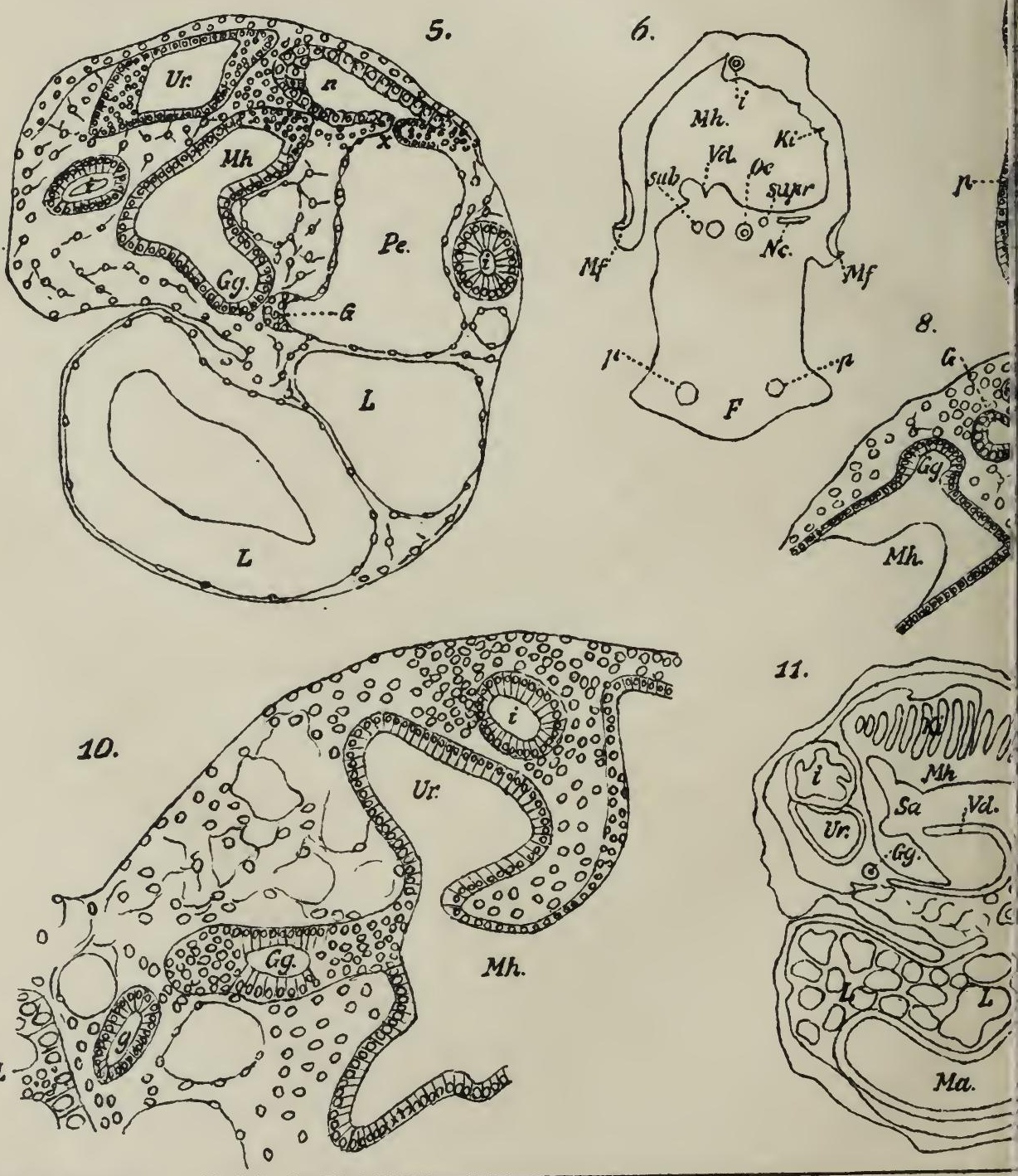
Taf. II.

\section{6\%}

O.

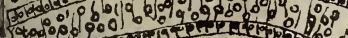
(1) .

$M w$.

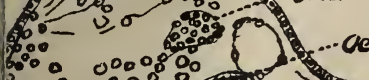

$600.0008 \%$

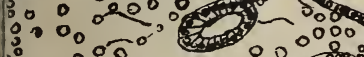

$\because: 00^{\circ} 0.00 \%$

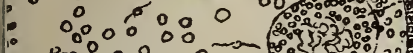

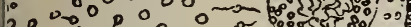

i 100 o 00

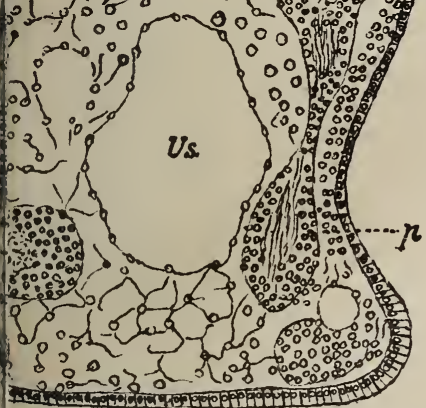

Pe

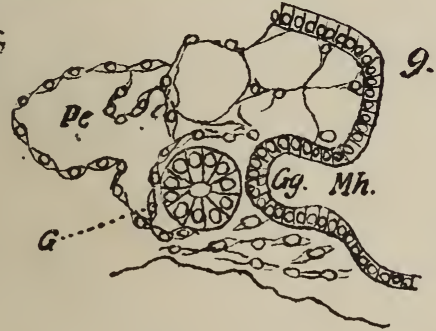

9.
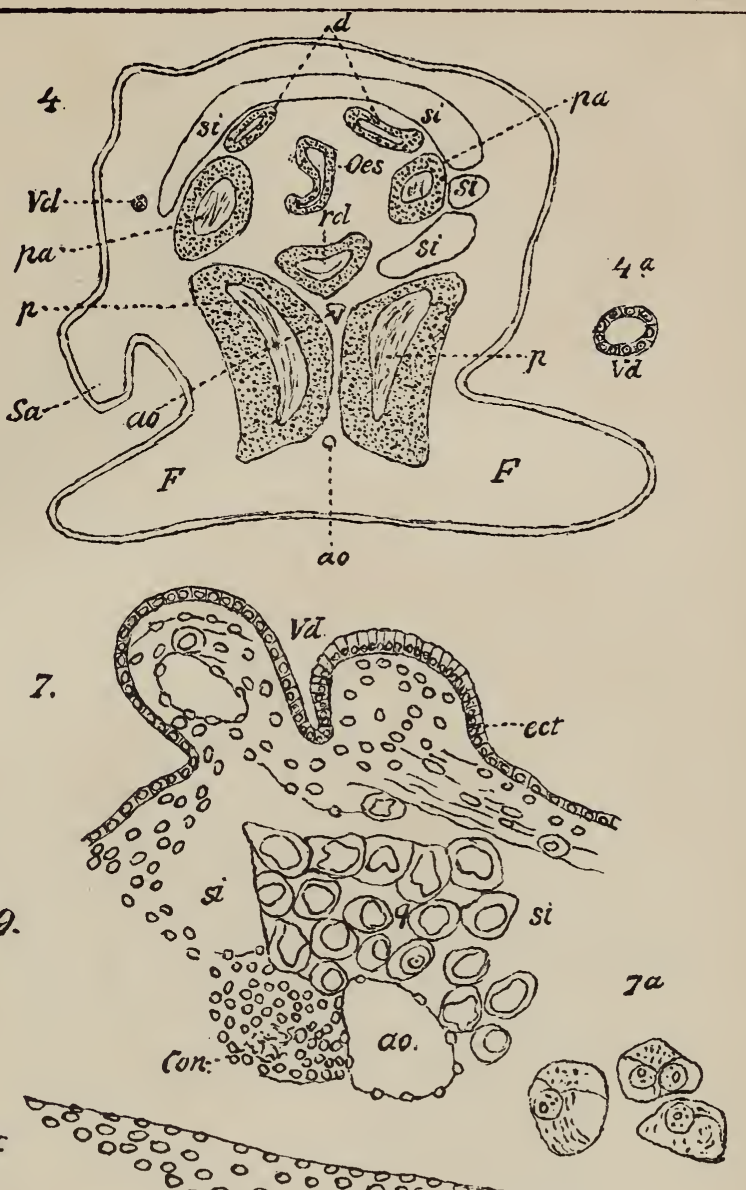

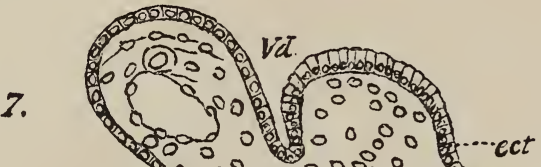

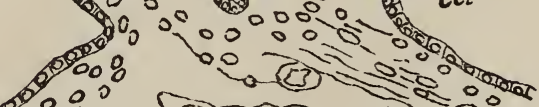

$880^{\circ}$ (5)

$\therefore$ si 0 O

-0íroloros si .00 a (Q) (C) $\because 000000$

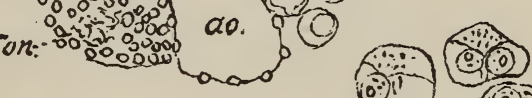

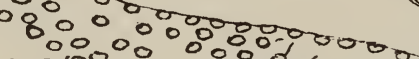

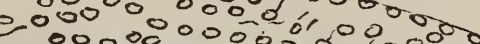

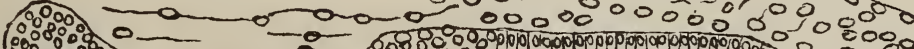

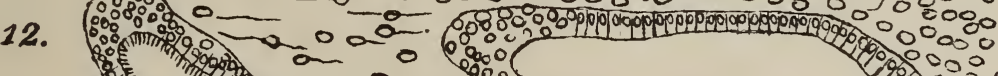

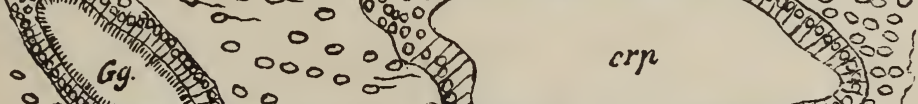

0 . 0000 on

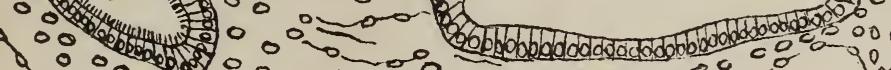

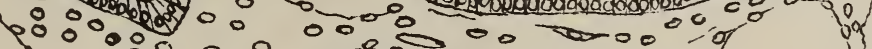

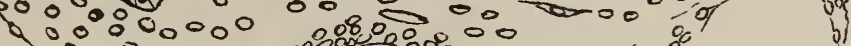

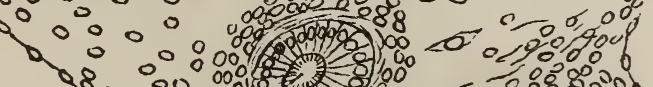

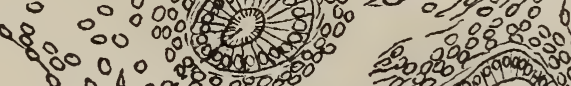

$20 \% 8 \%$

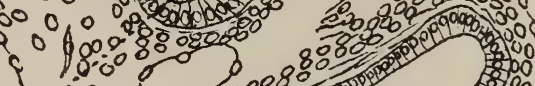

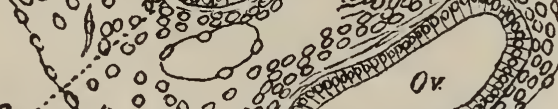

$\mathrm{Gg} . \mathrm{O}^{\circ} 0.000000$

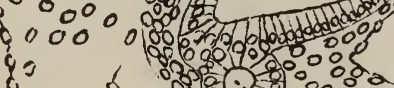

\&

$\rightarrow$ Or. 






等 (8) 2.

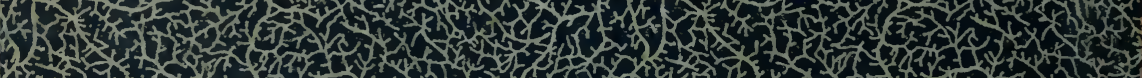

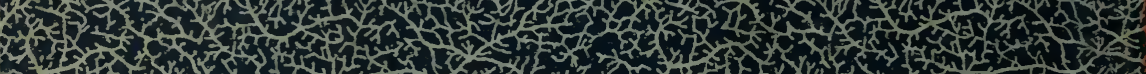

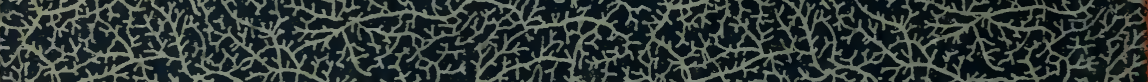

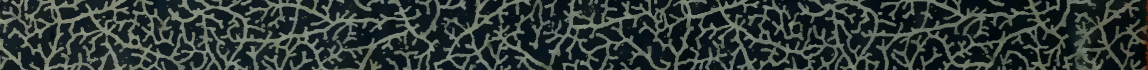

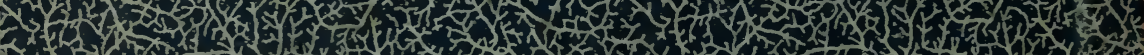

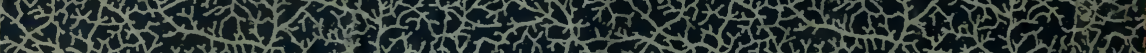

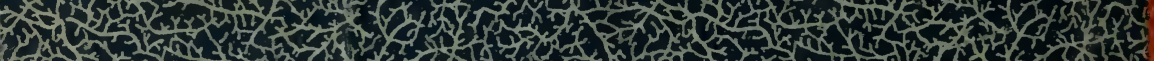

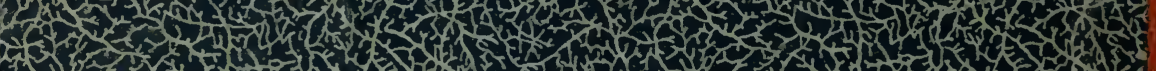

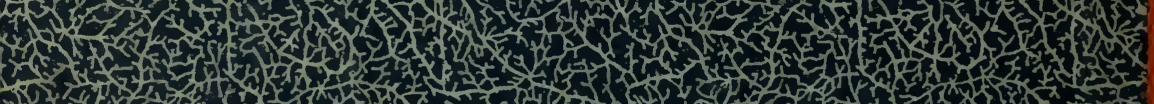

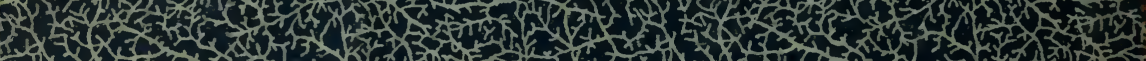

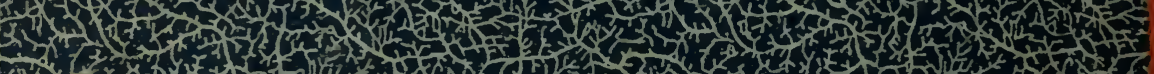

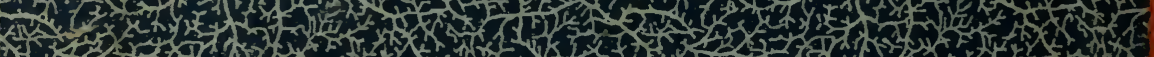

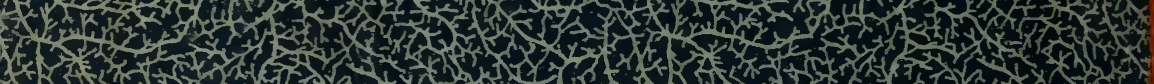

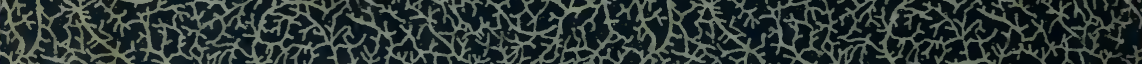

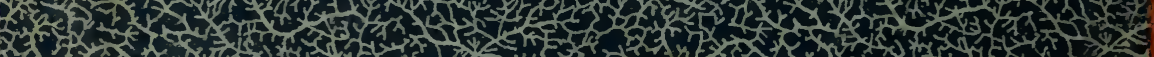

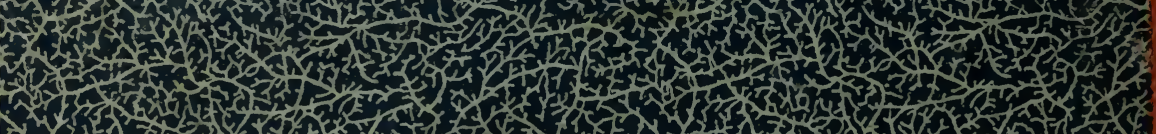

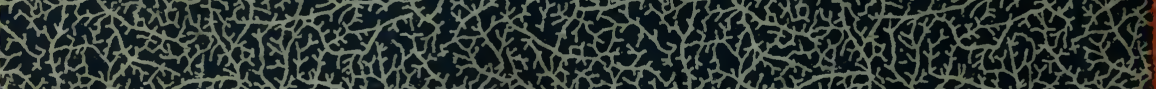

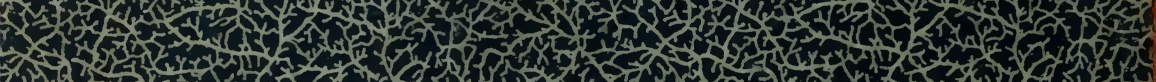

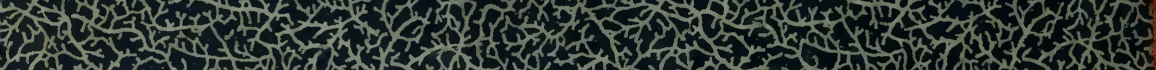

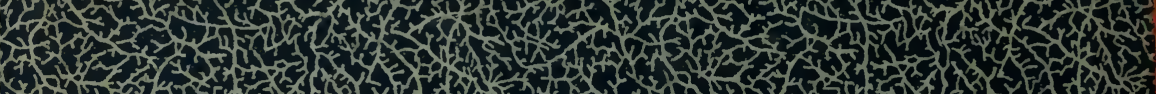

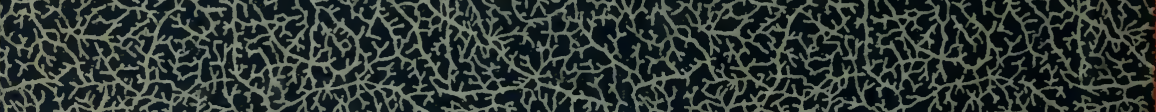

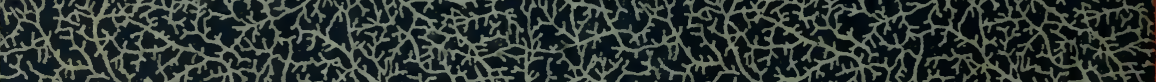

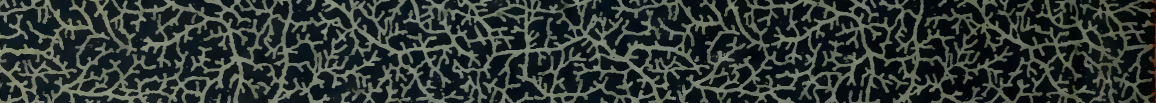

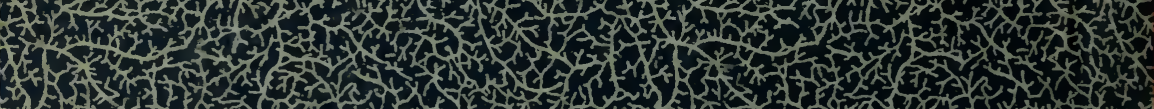

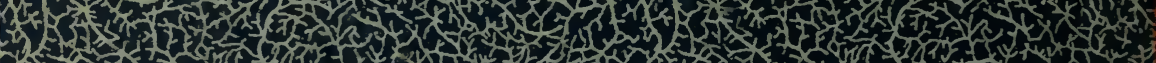

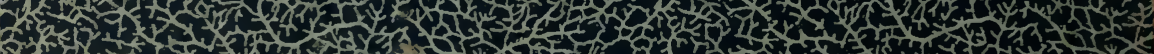

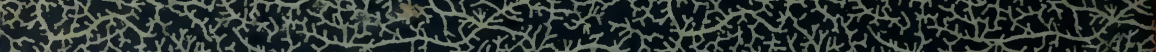

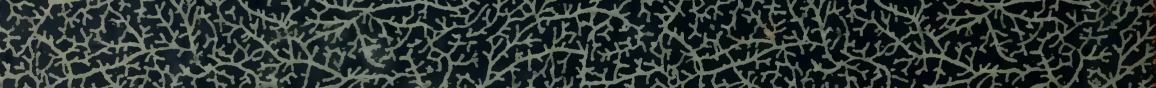

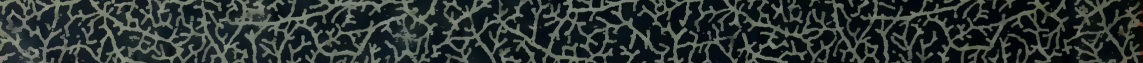

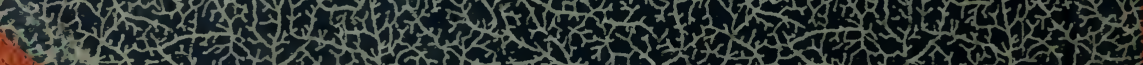

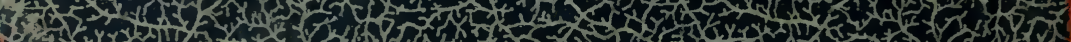

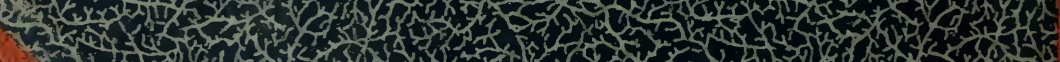

